\title{
EFEITO DA IDADE DE CORTE SOBRE A PRODUÇÃO, COMPOSIÇÃO QUÍMICO-BROMATOLÓGICA, DIGESTIBILIDADE IN VITRO E TEOR DE ÁCIDO CIANÍDRICO DE Cynodon dactylon (L.) Pers. cv. FLORAKIRK
}

\author{
ANDRÉA CAMPMANY VIEIRA \\ Engenheira Agrônoma
}

Orientador: Prof. Dr. CLÁUDIO MALUF HADDAD

Dissertação apresentada à Escola Superior de Agricultura "Luiz de Queiroz", Universidade de São Paulo, para obtenção do título de Mestre em Agronomia, Área de Concentração: Ciência Animal e Pastagens.

\footnotetext{
PIR A C I C A B A

Estado de São Paulo - Brasil

Dezembro - 1998
} 
Dados Internacionais de Catalogação na Publicação (CIP)

DIVISÃo DE BIBLIOTECA E DOCUMENTAÇÃO - Campus "Luiz de Queiroz"/USP

Vieira, Andréa Campmany

Efeito da idade de corte sobre a produção, composição químico-bromatológica, digestibilidade in vitro e teor de ácido cianídrico de Cynodon dactylon (L.) Pers. Cv. Florakirk / Andréa Campmany Vieira. - - Piracicaba, 1998.

$103 \mathrm{p}$.

Dissertação (mestrado) - - Escola Superior de Agricultura Luiz de Queiroz, 1998. Bibliografia.

1. Ácido cianidrico 2. Bromatologia 3. Digestibilidade in vitro 4. Grama bermuda 5. Gramínea forrageira 6. Produção vegetal 7. Variedade I. Título 
Ao meu esposo Alcides

e ao meus pais Edson e Carmen,

OFEREÇO

A todos que acreditam na ciência,

\section{DEDICO}




\section{AGRADECIMENTOS}

Ao Prof. Dr. Cláudio Maluf Haddad, pela orientação e amizade.

Ao Sr. Luiz Ermírio de Moraes, proprietário da Fazenda Guará do Pinhal, e seu administrador, Sr. Eurico, pelo apoio dado a este trabalho.

Ao Engenheiro Agrônomo Ricardo Mickenhagen, proprietário da Fazenda Progresso, pelas informações e materiais cedidos para a realização deste trabalho.

Aos Professores Umberto Irineu Packer, Carlos Guilherme Silveira Pedreira, Sila Carneiro da Silva, Francisco Monteiro e Hiroshi Kimati, pelas informações e esclarecimentos.

Ao Laboratórios de Bromatologia do Departamento de Zootecnia, de Análise de Solos do Departamento de Ciência do Solo e de Nutrição Mineral de Plantas do Departamento de Química da ESALQ, pelo auxílio na execução das análises laboratoriais.

Ao Laboratório de Nutrição Animal do Departamento de Zootecnia da Universidade Federal de Goiás e ao Centro de Estudos de Raízes Tropicais da Unesp de Botucatu, pelo auxilio na execução das análises laboratoriais.

Ao meus colegas Flávio, João Mauricio, Osvaldo e Vânia, pela amizade e ajuda na condução do experimento.

A todos os colegas do Curso de Pós-Graduação em Ciência Animal e Pastagem, pelos bons momentos passados juntos.

Aos professores do Curso de Pós-Graduação em Ciência Animal e Pastagens, pelos conhecimentos transmitidos.

Aos funcionários do Departamento de Zootecnia (Setores Ruminantes e Não Ruminantes), pela ajuda prestada.

Ao Conselho Nacional de Desenvolvimento Científico e Tecnológico, CNPq, pela concessão de boisa de estudos.

À ESALQ, por ter me recebido novamente. 


\section{SUMÁRIO}

Página

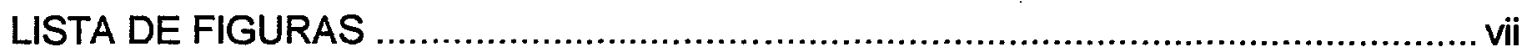

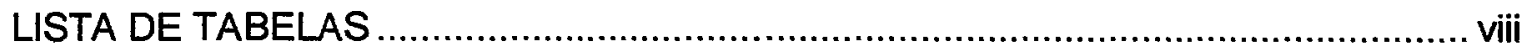

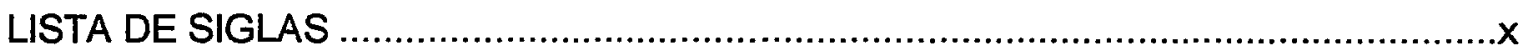

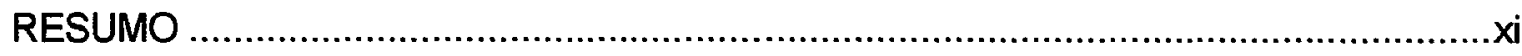

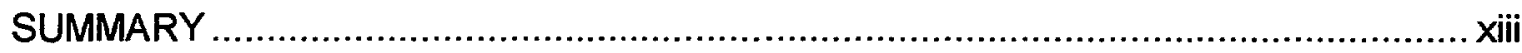

1 INTRODUÇĀO

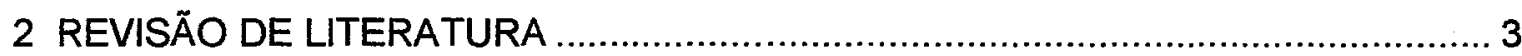

2.1 Gênero Cynodon: origem e caracterização ........................................................ 3

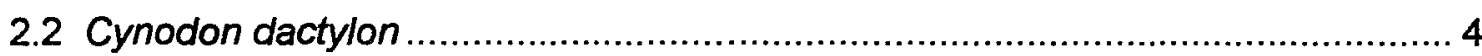

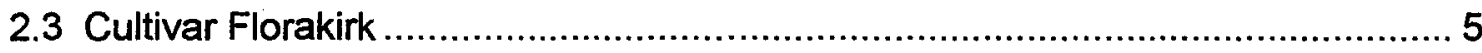

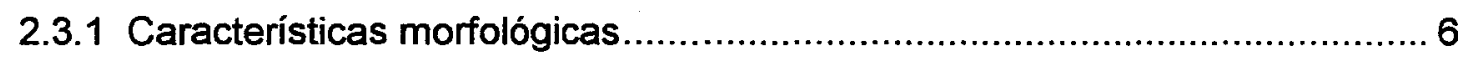

2.3.2 Características fisiológicas e manejo..................................................... 7

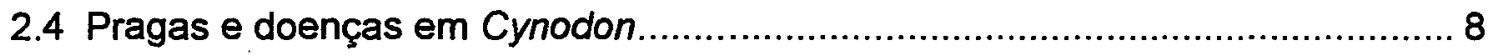

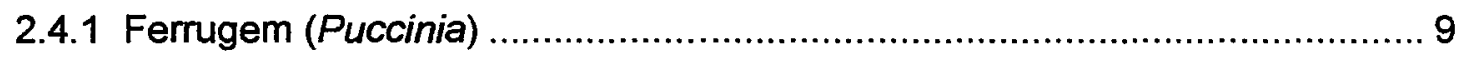

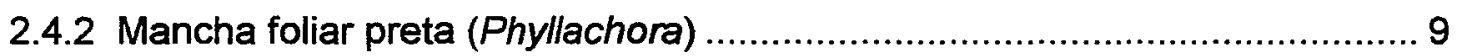

2.4.3 Mancha foliar (Helminthosporium) …................................................... 9

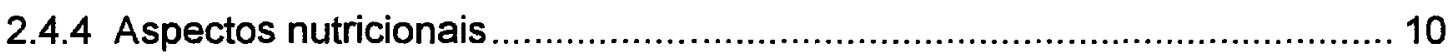

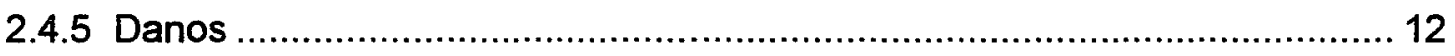

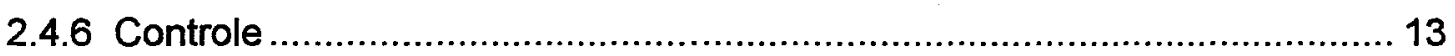

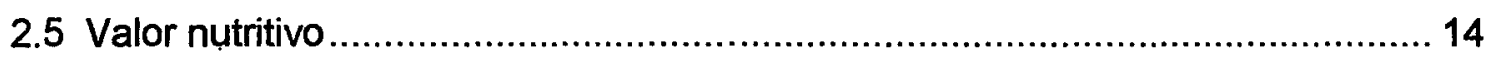

2.5.1 Composição bromatológica e digestibilidade ......................................... 17

2.5.2 Composição mineral da forrageira e exigência animal .............................. 23

2.5.2.1 Composição mineral de capins do gênero Cynodon ............................. 43

2.5.2.2 Acúmulo de minerais em forrageiras .................................................. 44

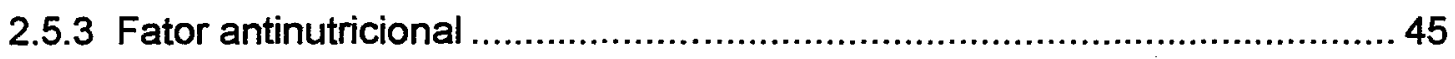

2.6 Produção de forragem em Cynodon ............................................................ 47

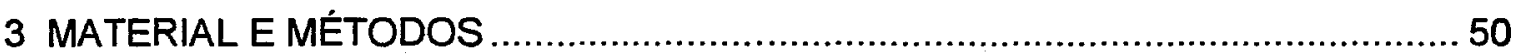

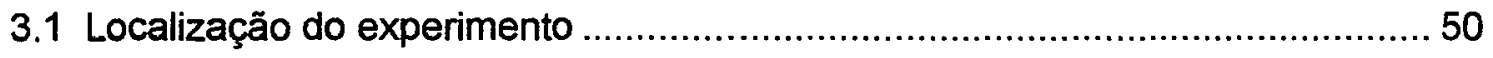




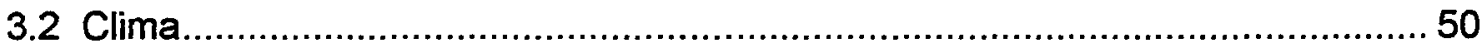

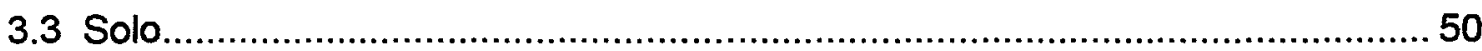

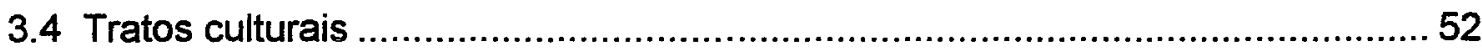

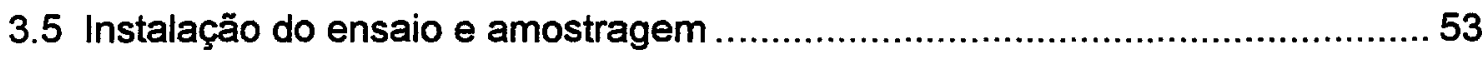

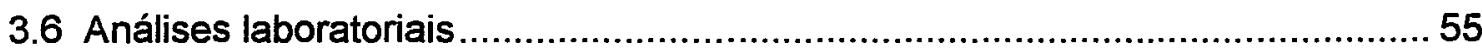

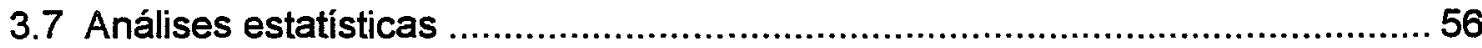

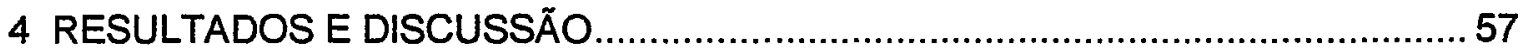

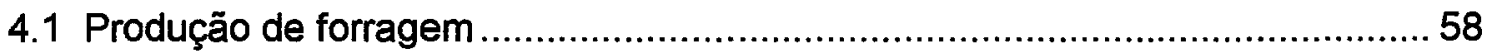

4.2 Composição bromatológica e digestibilidade verdadeira ...............................60

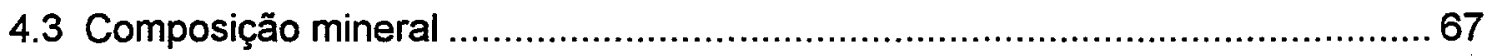

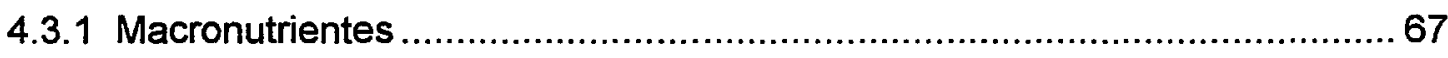

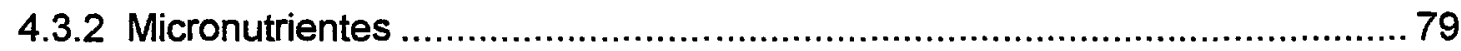

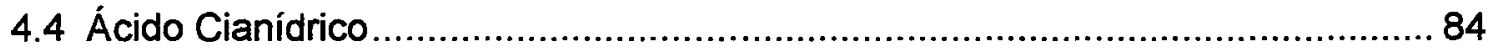

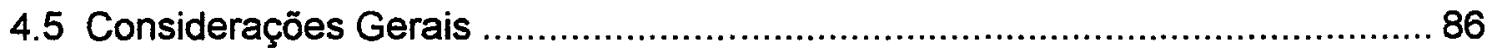

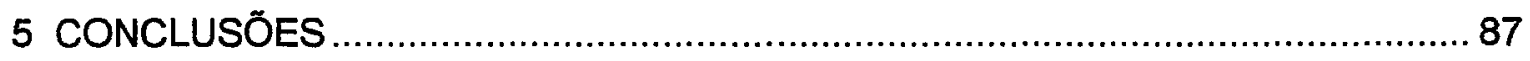

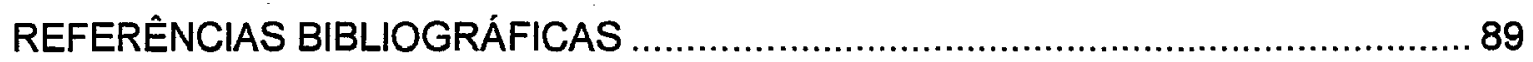




\section{LISTA DE FIGURAS}

Página

1 Produção de matéria verde e matéria seca $\left(\mathrm{g} \mathrm{m}^{-2}\right)$ e teor de matéria seca $\left(\mathrm{g} \mathrm{kg}^{-1}\right)$ da parte aérea de Cynodon dactylon (L.) Pers. cv. Florakirk, em função da idade de corte. 59

2 Teores $\left(\mathrm{g} \mathrm{kg}^{-1}\right)$ de cinza, proteína bruta, fibra em detergente neutro, fibra em detergente ácido, hemicelulose e digestibilidade verdadeira in vitro da MS e da MO da parte aérea de Cynodon dactylon (L.) Pers. cv. Florakirk, em função da idade de corte. 62

3 Digestibilidade de FDN $\left(\mathrm{g} \mathrm{kg}^{-1}\right)$ e produção de matéria seca digestivel e matéria orgânica digestivel $\left(\mathrm{g} \mathrm{m}^{-2}\right)$ da parte aérea de Cynodon dactylon (L.) Pers. cv. Florakirk, em função da idade de corte.

4 Teores de macronutrientes na matéria seca $\left(\mathrm{g} \mathrm{kg}^{-1}\right)$ da parte aérea de Cynodon dactylon (L.) Pers. cv. Florakirk, em função da idade de corte

5 Acúmulo de macronutrientes na matéria seca $\left(\mathrm{g} \mathrm{m}^{-2}\right)$ da parte aérea de Cynodon dactylon (L.) Pers. cv. Florakirk, em função da idade de corte

6 Teores de micronutrientes na matéria seca $\left(\mathrm{mg} \mathrm{kg}^{-1}\right)$ da parte aérea de Cynodon dactylon (L.) Pers. cv. Florakirk, em função da idade de corte.

7 Acúmulo de micronutrientes na matéria seca $\left(\mathrm{mg} \mathrm{m}^{-2}\right)$ da parte aérea de Cynodon dactylon (L.) Pers. cv. Florakirk, em função da idade de corte. 83

8 Teor de $\mathrm{HCN}$ na matéria verde $\left(\mathrm{mg} \mathrm{kg}^{-1}\right)$ da parte aérea de Cynodon dactylon (L.) Pers. cv. Florakirk, em função da idade de corte. 


\section{LISTA DE TABELAS}

Página

1 Efeito da freqüência de pastejo sobre a produção e composição de Florakirk (experimentos com dois anos de duração e realizados em Ona, Flórida, (EUA).

2 Concentração de minerais na matéria seca recomendada para algumas categorias de bovinos leiteiros.

3 Concentração de minerais na matéria seca recomendada para algumas categorias de bovinos de corte.

4 Concentração de minerais na matéria seca recomendada para algumas categorias de eqüinos.

5 Concentração mineral média em forrageiras tropicais sob diversas condições.

6 Porcentagem de amostras de gramíneas tropicais no Estado de São Paulo com teores adequados em relação à concentração normal de nutrientes na planta e à exigência de bovinos.

7 Amostras de forrageiras da América Latina com níveis deficientes ou marginais de minerais em relação à exigência animal.

8 Concentração crítica de micronutrientes nas plantas.

9 Experimentos para avaliação de cultivares de Cynodon (sob corte) realizados na Flórida (EUA)

10 Precipitação pluvial ocorrida no período experimental (20/01 a 26/03/1997). Fazenda Guará do Pinhal, Itapetininga, SP 
11 Resultados da análise química de terra da área experimental (profundidade: 0 a $25 \mathrm{~cm}$; amostragem: dezembro de 1996).

12 Resultados da análise química de terra da área experimental (profundidade: 0 a $25 \mathrm{~cm}$; amostragem: fevereiro e março de 1997)................. 52

13 Datas das amostragens realizadas na pastagem de Florakirk........................ 53

14 Produção de matéria verde e seca $\left(\mathrm{g} \mathrm{m}^{-2}\right)$ e teor de matéria seca $\left(\mathrm{g} \mathrm{kg}^{-1}\right)$ da parte aérea de Cynodon dactylon (L.) Pers. cv. Florakirk, em função da idade de corte. 58

15 Teores de cinza, proteína bruta (PB), fibra insolúvel em detergente neutro (FDN) e ácido (FDA) e hemicelulose na matéria seca, digestibilidade verdadeira in vitro, FDN digestível e produção de matéria digestível $\left(\mathrm{g} \mathrm{m}^{-2}\right)$ da parte aérea de Cynodon dactylon (L.) Pers. cv. Florakirk, em função da idade de corte. 61

16 Teores de macronutrientes da matéria seca $\left(\mathrm{g} \mathrm{kg}^{-1}\right)$ da parte aérea de Cynodon dactylon (L.) Pers. cv. Florakirk, em função da idade de corte.

17 Acúmulo de macronutrientes na matéria seca $\left(\mathrm{g} \mathrm{m}^{-2}\right)$ da parte aérea de Cynodon dactylon (L.) Pers. cv. Florakirk, em função da idade de corte. 68

18 Relação entre nutrientes na matéria seca da parte aérea de Cynodon dactylon (L.) Pers. Cv. Florakirk, em função da idade de corte 77

19 Teores de micronutrientes na matéria seca $\left(\mathrm{mg} \mathrm{kg}^{-1}\right)$ da parte aérea de Cynodon dactylon (L.) Pers. cv. Florakirk, em função da idade de corte 79

20 Acúmulo de micronutrientes na matéria seca $\left(\mathrm{mg} \mathrm{m}^{-2}\right)$ da parte aérea de Cynodon dactylon (L.) Pers. cv. Florakirk, em função da idade de corte. 79

21 Teor de $\mathrm{HCN}$ na matéria verde $\left(\mathrm{mg} \mathrm{kg}^{-1}\right)$ da parte aérea de Cynodon dactylon (L.) Pers. cv. Florakirk, em função da idade de corte. 85 


\section{LISTA DE SIGLAS}

DIVMO = digestibilidade in vitro da matéria orgânica

DIVMS = digestibilidade in vitro da matéria seca

DVIVMO = digestibilidade verdadeira in vitro da matéria orgânica

DVIVMS = digestibilidade verdadeira in vitro da matéria seca

FDA = fibra em detergente ácido

FDN = fibra em detergente neutro

$\mathrm{HCN}=$ ácido cianídrico

$M O=$ matéria orgânica

$M O D$ = matéria orgânica digestivel

MS = matéria seca

$M S D=$ matéria seca digestivel

$M V$ = matéria verde

$\mathrm{PB}=$ proteína bruta 


\title{
EFEITO DA IDADE DE CORTE SOBRE A PRODUÇÃO, COMPOSIÇÃO QUÍMICO- BROMATOLÓGICA, DIGESTIBILIDADE IN VITRO E TEOR DE ÁCIDO CIANÍDRICO DE Cynodon dactylon (L.) Pers. cv. FLORAKIRK
}

\author{
Autora: ANDRÉA CAMPMANY VIEIRA \\ Orientador: Prof. Dr. CLÁUDIO MALUF HADDAD
}

\section{RESUMO}

O objetivo deste experimento foi avaliar o efeito da idade de corte sobre a produção, composição químico-bromatológica, digestibilidade in vitro e teor de ácido cianídrico de Cynodon dactylon (L.) Pers. cv. Florakirk. O experimento foi instalado numa pastagem de Florakirk formada há um ano, situada no municipio de Itapetininga, SP. Antes do início do experimento a pastagem foi cortada e foram aplicados $5 \mathrm{Mg}$ de calcário dolomítico e $80-320-240 \mathrm{~kg}$ de $\mathrm{N}-\mathrm{P}_{2} \mathrm{O}_{5}-\mathrm{K}_{2} \mathrm{O}$ ha-1. O experimento iniciou-se em janeiro/1997, quando a pastagem foi submetida a um corte de rebaixamento e uniformização, a partir do qual foram realizadas amostragens da forragem a cada 10 dias, no periodo de 20 a 70 dias de crescimento (6 tratamentos). Utilizou-se o delineamento de blocos ao acaso, com 4 repetições. Foram analisadas as seguintes variáveis: produção de matéria seca, teor de matéria seca, digestibilidade verdadeira in vitro da matéria seca (DVIVMS) e orgânica (DVIVMO), teores de proteína bruta (PB), FDN, FDA, hemicelulose, FDN digestivel, macronutrientes e micronutrientes, acúmulo de minerais e teor de ácido cianídrico (HCN). Observou-se a ocorrência de cigarrinhas (Deois spp.) e doenças foliares (Phyllachora spp. e Bipolaris spp.). A produção de matéria seca da parte aérea aumentou de forma quadrática $(P<0,05)$, com valor máximo de $215 \mathrm{~g} \mathrm{~m}^{-2}$ aos 70 dias de idade. Os valores de DVIVMS foram superiores aos de DVIVMO, ambos decrescendo de forma quadrática $(P<0,05)$ com o avanço da idade de corte. $A$ 
DVIVMO decresceu de 710,9 $\mathrm{g}$ (aos 20 dias) para $549,1 \mathrm{~g} \mathrm{~kg}^{-1}$ (aos 70 dias). FDN e FDA aumentaram com a idade, com valores mínimos aos 20 dias $(714,3 \mathrm{~g}$ e $324,6 \mathrm{~g}$ $\left.\mathrm{kg}^{-1}\right)$ e máximos aos 55 e 70 dias de crescimento $\left(789,5 \mathrm{~g}\right.$ e $\left.389,9 \mathrm{~g} \mathrm{~kg}^{-1}\right)$, respectivamente, segundo equações quadráticas $(P<0,05)$. Não se observou efeito da idade de corte sobre a concentração de hemicelulose $(P>0,05)$. A digestibilidade de FDN decresceu linearmente $(P<0,05)$, sendo $622,2 \mathrm{~g} \mathrm{~kg}^{-1}$ aos 20 dias e $447,4 \mathrm{~g} \mathrm{~kg}^{-1}$ aos 70 dias. Os teores de $\mathrm{N}, \mathrm{P}, \mathrm{K}, \mathrm{Mg}$ e Ca decresceram com o aumento da idade de corte, sendo seus valores máximos de $28,2 \mathrm{~g} ; 5,8 \mathrm{~g} ; 31,5 \mathrm{~g} ; 3,0 \mathrm{~g}$ e $3,9 \mathrm{~g} \mathrm{~kg}^{-1}$, observados aos 20 dias, com exceção do $\mathrm{Ca}$ que foi aos 22 dias, e mínimos de $11,0 \mathrm{~g} ; 3,0 \mathrm{~g} ; 10,4 \mathrm{~g} ; 2,4 \mathrm{~g}$ e $2,1 \mathrm{~g} \mathrm{~kg}^{-1}$, aos 70 dias, respectivamente. Não houve diferença significativa $(P>0,05)$ na concentração de $S$ entre 20 e 60 dias (média de $2,4 \mathrm{~g} \mathrm{~kg}^{-1}$ ); aos 70 dias, a concentração reduziu para $1,6 \mathrm{~g} \mathrm{~kg}^{-1}$. Observou-se uma maior variação na concentração de macronutrientes com o aumento da idade de corte do que com relação aos micronutrientes. Não houve influência da idade de corte sobre a concentração de $B(P>0,05)$ e as concentrações de $\mathrm{Cu}, \mathrm{Mn}$ e $\mathrm{Zn}$ variaram de forma cúbica $(P<0,05)$ em relação à idade da planta. Ocorreu redução na concentração de Fe, porém não havendo diferença significativa entre 40 e 70 dias de crescimento. O teor de $\mathrm{HCN}$ decresceu com a idade e não atingiu valores considerados tóxicos para os animais. Associando-se informações relativas à produção, composição químico-bromatológica e exigência animal, conclui-se que a melhor utilização da pastagem, nas condições experimentais, ocorreria até os 40 dias de crescimento da planta, embora, em idades de corte mais avançadas, tenham sido observados parâmetro de valor nutritivo que permitiriam o aproveitamento da forragem na forma de pastejo diferido. Provavelmente devido à ocorrência de fatores ambientais limitantes, houve um atraso no desenvolvimento da pastagem e conseqüentemente da sua maturação, prolongando a manutenção do valor nutritivo em niveis adequados para a produção animal. 


\title{
EFFECT OF PLANT AGE ON PRODUCTION, CHEMICAL COMPOSITION, IN VITRO DIGESTIBILITY, AND HIDROCYANIC ACID CONTENT OF 'FLORAKIRK' \\ BERMUDAGRASS
}

\author{
Author: ANDRÉA CAMPMANY VIEIRA \\ Adviser: Prof. Dr. CLÁUDIO MALUF HADDAD
}

\section{SUMMARY}

The objective of this research was to evaluate the effect of plant age on yield, chemical and mineral composition, in vitro digestibility, and hidrocyanic acid content of Florakirk bermudagrass (Cynodon dactylon). The experiment was conducted on an one year-old pasture, in Itapetininga/SP. Before the evaluation, the pasture was cut and $5 \mathrm{Mg}$ of dolomitic lime and $80-320-240 \mathrm{~kg}$ of $\mathrm{N}-\mathrm{P}_{2} \mathrm{O}_{5}-\mathrm{K}_{2} \mathrm{O}$ ha ${ }^{-1}$ were applied. The evaluation started in January/1997, when the pasture was staged. The experimental design was a randomized complete block with six treatments replicated four times. Treatments consisted of six cutting ages (20-70 days) spaced ten days apart. Responses evaluated were: herbage dry matter production and concentration, in vitro dry matter (IVDMD) and organic matter (IVOMD) digestibility, crude protein (CP), neutral detergent fiber (NDF), acid detergent fiber (ADF), digestible neutral detergent fiber, and hidrocyanic acid ( $H C N)$ concentrations, macro and micro mineral concentration and accumulation. Occurrence of spittlebug (Deois spp.) and foliar diseases (Phyllachora spp. and Bipolaris spp.) were observed. Dry matter yield increased quadratically $(P<0,05)$ reaching a maximum at 70 days $\left(215 \mathrm{~g} \mathrm{~m}^{-2}\right)$. IVDMD was higher than IVOMD, both decreasing quadratically $(P<0,05)$ as age increased. IVOMD decreased (711 $\mathrm{g}$ to $549 \mathrm{~g} \mathrm{~kg}^{-1}$ ) between 20 to 70 days. NDF and ADF increased quadratically $(P<0,05)$ as age increased, with minimum values at 20 days ( $714 \mathrm{~g}$ and $325 \mathrm{~g} \mathrm{~kg}^{-1}$ ) and maximum values at 55 and 70 days $\left(790 \mathrm{~g}\right.$ and $\left.390 \mathrm{~g} \mathrm{~kg}^{-1}\right)$, 
respectively. Digestibility of NDF decreased linearly $(P<0,05)\left(622 \mathrm{~g}\right.$ to $\left.447 \mathrm{~g} \mathrm{~kg}^{-1}\right)$ between 20 to 70 days. $\mathrm{N}, \mathrm{P}, \mathrm{K}, \mathrm{Mg}$ and $\mathrm{Ca}$ concentrations decreased with the increase in age, with maximum values $\left(28,2 \mathrm{~g} ; 5,8 \mathrm{~g} ; 31,5 \mathrm{~g} ; 3,0 \mathrm{~g}\right.$ and $\left.3,9 \mathrm{~g} \mathrm{~kg}^{-1}\right)$ at 20 days, with exception of $\mathrm{Ca}$ (22 days), and minimum values $(11,0 \mathrm{~g} ; 3,0 \mathrm{~g} ; 10,4 \mathrm{~g}$; $2,4 \mathrm{~g}$ and $\left.2,1 \mathrm{~g} \mathrm{~kg}^{-1}\right)$ at 70 days. There were no significant differences $(P>0,05)$ in $S$ concentration between 20 and 60 days (mean value $=2,4 \mathrm{~g} \mathrm{~kg}^{-1}$ ); at 70 days, $\mathrm{S}$ concentration had decreased to $1,6 \mathrm{~g} \mathrm{~kg}^{-1}$. A higher variation in the macromineral concentration was observed than the micromineral concentration with the increase in plant age. There was no influence of age on $B$ concentration $(P>0,05)$ whereas $C u$, $\mathrm{Mn}$ and $\mathrm{Zn}$ concentration varied cubically $(P<0,05)$. Reduction in $\mathrm{Fe}$ concentration occurred, without significative difference between 40 to 70 days. $\mathrm{HCN}$ concentration decreased with plant age, but values considered to be toxic to animals were not found. By integrating these information about production, and chemical composition, with known animal requirements, it is possible to conclude that the best utilization of this forage, in the experimental conditions, should be around 40 days, whereas, at more advanced ages, the use as stockpiled forage could be viable. The fact that the nutritive value was relatively high even at advanced plant ages ( $>5$ weeks of growth) can probably related to environmental factors that prevailed over most of the experimental period, which probably slowed down the vegetation and maturation (aging) processes. 


\section{INTRODUÇÃO}

A escolha da espécie forrageira e a definição de um manejo racional deve ser baseada na finalidade do sistema de produção e em critérios técnico-econômicos como: destino da produção forrageira (produção de feno, silagem ou pastejo), valor nutritivo e alimentício, presença de fatores antinutricionais, potencial produtivo, exigências nutricionais da forrageira, resposta à adubação, adaptação às condições edafo-climáticas, persistência, custos de produção, entre outros.

A introdução de novas espécies forrageiras nos sistemas de produção animal só será válida quando esta trouxer benefícios relacionados ao aumento da eficiência econômica e/ou facilidade de manejo do sistema.

Infelizmente esta não é a realidade observada na maioria dos sistemas de produção animal brasileiros, onde a escolha das espécies forrageira está baseada na busca de um capim "milagroso" e influenciada por informações sem respaldo técnicocientífico ou por dados de pesquisas idôneas, que foram realizadas em condições ambientais diferentes.

Estão disponíveis no mercado brasileiro diversas cultivares e híbridos de Cynodon dactylon, conhecidos como grama bermuda, sendo a Coastcross-1 uma das mais utilizadas no país. No início da década de 90 foram introduzidas no Brasil outras cultivares, como a Tifton $85 \mathrm{e}$, mais recentemente, a Florakirk.

Os pastos de grama bermuda podem ser destinados para pastejo ou fenação, sendo que a cultivar mais adequada a ser utilizada dependerá das condições edafoclimáticas e da finalidade da pastagem.

Florakirk é um hibrido desenvolvido no Estado da Geórgia, EUA, destinado principalmente à produção de feno em regiões de inverno mais rigoroso, apresentando boa produção de matéria seca, boa relação folha:haste e elevado valor 
nutritivo (Mislevy et al., 1995).

As poucas informações existentes sobre a cultivar Florakirk são provenientes dos EUA, sendo escassos os trabalhos brasileiros envolvendo esta forrageira e os conhecimentos sobre seu comportamento em nosso meio. O seu potencial produtivo na regiāo centro-sul do país existe, porém só poderá ser explorado quando for devidamente avaliado em condições brasileiras.

O objetivo deste trabalho foi avaliar o efeito da idade de corte sobre a produção, composição químico-bromatológica (teores de matéria seca, proteína bruta, fibra insolúvel em detergente neutro e ácido, macronutrientes e micronutrientes), digestibilidade in vitro e teor de ácido cianídrico de Cynodon dactylon (L.) Pers. cv. Florakirk, obtendo-se assim informações que contribuam para a utilização eficiente desta forrageira. 


\section{REVISÃO DE LITERATURA}

\subsection{Gênero Cynodon: origem e caracterização}

As espécies vegetais do gênero Cynodon L. C. Rich são plantas monocotiledôneas que, segundo o Sistema de Classificação de Cronquist, pertencem à família Poaceae, subfamília Chloridoideae e tribo Chlorideae (Ellis, 1986).

O gênero possui oito espécies, sendo quatro destas (C. arcuatus, C. barberi, C. incompletus e $C$. transvaalensis) com pouca ou nenhuma importância como planta forrageira, pois são endêmicas e/ou pouco produtivas. C. aethiopicus, C. plectostachyus (grama estrela africana) e $C$. nlemfuensis são espécies robustas e não rizomatosas, oriundas do leste africano e conhecidas como 'gramas estrela'. A espécie $C$. dactylon é cosmopolita e recebe grande atenção em função de seu valor econômico como gramados (turfgrass), para pastejo, para produção de feno e devido à sua abundância e vasta distribuição como planta invasora. Esta espécie é muito variável e subdividida em seis variedades, das quais quatro $(C$. dactylon var. afghanicus, $C$. dactylon var. coursii, $C$. dactylon var. polevansii e $C$. dactylon var. elegans) são endêmicas e de valor relativamente menor quando comparadas às outras duas principais. Estas variedades, $C$. dactylon var. aridus e $C$. dactylon var. dactylon, apresentam grande valor para pastejo e produção de feno, sendo conhecidas como 'grama bermuda gigante' e 'grama bermuda', respectivamente (Harlan, 1970; Harlan et al., 1970). C. dactylon é uma das espécies mais dinâmicas, agressivas e cosmopolitas no mundo (Harlan \& de Wet, 1969).

Segundo Santos \& Boechat (1994), há discrepância em relação ao número de espécies do gênero Cynodon e isto se deve ao fato do gênero ser particularmente variável. A chave analítica para determinação das espécies apresentada por estes 
autores difere da apresentada por de Wet \& Harlan (1970), na qual estão baseados os trabalhos de Harlan (1970) e Harlan et al. (1970).

O termo 'grama estrela' tem sido utilizado para as espécies robustas e não rizomatosas e 'grama bermuda' para as formas rizomatosas, embora isto nem sempre seja consistente (Harlan, 1970). A cultivar Coastcross-1 é C. dactylon, conhecida como grama bermuda e não apresenta rizoma (Burton, 1972), enquanto a cultivar Tifton 68 é C. nlemfuensis e também não apresenta rizoma, mas é impropriamente denominada grama bermuda devido ao seu baixo potencial cianogênico (Burton \& Monson, 1984).

Dentre as gramas estrela, a espécie C. nlemfuensis apresenta o maior potencial produtivo (Harlan, 1970), sendo Florico (Mislevy et al., 1993a) e Florona (Mislevy et al., 1993b) as cultivares lançadas mais recentemente.

\subsection{Cynodon dactylon}

Segundo Harlan (1970), a introdução da grama bermuda nos EUA ocorreu provavelmente no século 18 ou anteriormente. No século 19 a grama bermuda já era encontrada de forma abundante nos estados sulinos, porém era considerada uma planta invasora até que, em 1943, Dr. G. W. Burton, de Tifton, Geórgia (EUA) produziu e lançou a cultivar Coastal, um híbrido derivado do cruzamento entre uma planta local ( $C$. dactylon var. dactylon) e uma introdução procedente da África do Sul. Ao contrário das gramas bermuda comuns, a Coastal não é uma invasora, produzindo de duas a quatro vezes mais e com qualidade superior à das espécies naturalizadas, além de ser mais eficiente no uso da água e responder à aplicação de nitrogênio. Nas décadas de 50 e 60 , outras gramas bermuda híbridas foram lançadas, entre elas Midland, Suwannee e Greenfield.

As gramas bermuda representaram um importante papel no desenvolvimento da pecuária no sul dos EUA e foram objeto de intensas pesquisas envolvendo programas de melhoramento genético. Estas forrageiras apresentaram alto potencial de produção por unidade de área, porém, mesmo com um adequado teor de proteína (120 a $180 \mathrm{~g} \mathrm{~kg}^{-1}$ ), o potencial de produção por animal era modesto. Provavelmente seu alto teor de matéria seca (MS), fibra e lignina estaria afetando a digestibilidade da 
matéria seca (Harlan, 1970).

A digestibilidade da matéria seca foi substancialmente melhorada com 0 desenvolvimento da cultivar Coastcross-1, em 1967 (Burton, 1972). Posteriormente, como resultado dos programas de melhoramento genético, foram desenvolvidas outras cultivares de grama bermuda destinadas à produção de forragem, entre elas: Tifton 44 (Burton \& Monson, 1978), Tifton 78 (Burton \& Monson, 1988), Tifton 85 (Burton et al., 1993) e mais recentemente a Florakirk (Mislevy et al., 1995).

Skerman \& Riveros (1992) descrevem a espécie C. dactylon e entre as características citadas estão:

- temperatura ótima para crescimento: $35^{\circ} \mathrm{C}$;

- crescimento lento a $15^{\circ} \mathrm{C}$; a temperatura durante o dia deve ser superior a $10^{\circ} \mathrm{C}$; a temperatura mínima para crescimento é $15^{\circ} \mathrm{C}$ para um dia de 8 horas e $5^{\circ} \mathrm{C}$ para noite de 16 horas;

- limite de latitude: $31,42 \pm 7,5^{\circ} \mathrm{N}$ e $\mathrm{S}$;

- limite de altitude: até $2300 \mathrm{~m}$ acima do mar;

- exigência hídrica: de 625 a 1750 mm por ano;

- resposta a fotoperiodo: a duração do dia é indiferente para o florescimento;

- toxicidade: a maioria das cultivares de C. dactylon não é tóxica, mas pode produzir ocasionalmente envenenamento com ácido cianídrico $(\mathrm{HCN})$;

- doenças: em algumas regiões C. dactylon é atacada por doenças foliares causadas por Helminthosporium spp.;

- principais atributos: adapta-se a muitos tipos de solo e clima; é palatável, nutritiva e protege o solo contra erosão; suporta pastejo intensivo, sendo útil para fenação e ensilagem;

- principais deficiências: pode se tornar planta daninha em cultivos e não cresce satisfatoriamente se não for bem fertilizada.

\subsection{Cultivar Florakirk}

A cultivar Florakirk é um híbrido desenvolvido em 1975 pelo Dr. G.W. Burton, da Estação Experimental de Coastal Plain, no municipio de Tifton, Geórgia (EUA). Foi 
obtida através do cruzamento de duas gramas bermuda, Callie ( $C$. dactylon var. aridus) e Tifton 44 (C. dactylon), buscando-se plantas com maior tolerância ao frio e mais resistentes à ferrugem (Puccinia spp.) que a cultivar Callie. Parte deste material vegetativo foi enviado à Flórida e submetido à avaliação em pastejo juntamente com outras introduções de Cynodon (Mislevy et al., 1995). Em 3 anos de avaliação, a Florakirk apresentou elevada produção de matéria seca quando pastejada numa freqüência de 4 a 5 semanas, boa qualidade de forragem, excelente persistência e boa tolerância à seca e ao frio (Mislevy et al., 1988).

Florakirk foi inicialmente denominada 'Tifton 35-5' e 'híbrido Callie 35-5', sendo lançada comercialmente pela Universidade da Flórida em 1994 e destinada principalmente à produção de feno no norte da Flórida e sul da Geórgia devido às suas características de caule fino, persistência, boa produção, boa qualidade e relativa resistência ao frio (Mislevy et al., 1995). Juntamente com as cultivares Alicia e Tifton 85, a Florakirk tem se destacado, entre as gramas bermuda, por apresentar adequada persistência em solos encharcados na região centro-sul da Flórida (Mislevy \& Pate, 1996).

Tifton 78 também é resultado de cruzamento entre Tifton 44 e Callie, porém, neste caso a Callie constituiu a linhagem materna, enquanto que no cruzamento que originou a Florakirk, constituiu a linhagem paterna (Burton \& Monson, 1988; Mislevy et al., 1995).

\subsubsection{Características morfológicas}

Florakirk é um grama bermuda perene, de estação quente, persistente, estolonífera e rizomatosa. Os colmos possuem diâmetro de 0,5 a $2,4 \mathrm{~mm}$, sendo folhosos e muito ramificados, podendo ter de 38 a $64 \mathrm{~cm}$ de altura. Os nós e entrenós são glabros; as bainhas são livres, sobrepostas e glabras. A ligula consiste numa membrana de 0,15 a $0,5 \mathrm{~mm}$ de comprimento, com pelos de 0,1 a $0,4 \mathrm{~mm}$ de comprimento. As junções do limbo e bainha são freqüentemente avermelhadas $e$ providas de rígidos pelos de 1,0 a $4,5 \mathrm{~mm}$ de comprimento. As lâminas foliares apresentam 2,5 a $25 \mathrm{~cm}$ de comprimento e 1,4 a $5,5 \mathrm{~mm}$ de largura, são lisas, flexiveis e suculentas; possuem pelos dispersos no dorso e geralmente são glabras 
ventralmente. A inflorescência é composta de 3 a 6 espigas púrpura-avermelhadas ou púrpura-esverdeadas. A produção de sementes é rara e sua propagação é inteiramente vegetativa, por meio de mudas. É difícil diferenciar Florakirk de outras gramas bermuda, especialmente Tifton 78 e Coastcross-1 (Mislevy et al., 1995).

\subsubsection{Características fisiológicas e manejo}

Ao contrário da Florico e Florona, cuja natureza tropical limita sua utilização a regiões tropicais mais quentes (Mislevy et al., 1993a, 1993b), a Florakirk tolera temperaturas de até $-13^{\circ} \mathrm{C}$, e com adequada fertilidade pode produzir mais forragem durante o inverno que a maioria das gramas bermuda, embora sua qualidade decresça após uma geada severa (Mislevy et al., 1995).

Assim como a maioria das gramas bermuda e estrela, a Florakirk é uma forrageira exigente em fertilidade e sua produção e utilização apenas será otimizada num sistema intensivo de pastejo ou corte com adubaçōes freqüentes. Numa situação de fertilidade adequada, é possivel obter boas produções no final da estação de crescimento e um início rápido da rebrota na primavera, mesmo sob condições de seca. A faixa ótima de $\mathrm{pH}$ (em água) varia de 5,5 a 6,5 e a disponibilidade de cálcio deve ser de 1100 a $1300 \mathrm{~kg} \mathrm{ha}^{-1}$ (2,75 a 3,25 $\mathrm{cmol}_{\mathrm{c}} \mathrm{dm}^{-3}$ ) (Mislevy et al., 1995).

Mislevy et al. (1995) recomendam, para sistemas intensivos de pastejo, a aplicação de $67-17-34 \mathrm{~kg} \mathrm{ha}{ }^{-1}$ de $\mathrm{N}-\mathrm{P}_{2} \mathrm{O}_{5}-\mathrm{K}_{2} \mathrm{O}$, no mínimo três vezes ao ano (a menos que, em função da análise de solo, sejam necessários diferentes níveis); no caso de produção de feno, deve-se aplicar 78-34-67 kg ha ${ }^{-1}$ de $\mathrm{N}-\mathrm{P}_{2} \mathrm{O}_{5}-\mathrm{K}_{2} \mathrm{O}$ e micronutrientes, de três a quatro semanas antes de cada corte, visando uma produção de feno de 3,4 a 4,5 Mg MS ha ${ }^{-1}$ após 4 a 5 semanas de crescimento, desde que ocorram condições ambientais favoráveis. O intervalo ideal entre cada ciclo de pastejo é de 4 semanas e entre cortes para produção de feno é de 4 a 5 semanas. Se este intervalo for menor, a qualidade da forragem aumenta, mas a persistência do estande pode ser afetada, e se for superior a 7 semanas, a produção e persistência podem melhorar, mas a qualidade e a palatabilidade da forragem são reduzidas. Ao contrário das gramas estrela, que não são rizomatosas, as gramas bermuda tendem a se desenvolver adequadamente sob uma altura residual da pastagem baixa. As gramas estrela 
requerem altura residual de 15 a $25 \mathrm{~cm}$, enquanto a Florakirk apresenta boa persistência e menor ocorrência de Helminthosporium spp. quanto pastejada até uma altura residual de 8 a $10 \mathrm{~cm}$.

Apesar da Florakirk possuir alto potencial cianogênico por aproximadamente 4 semanas após adubação nitrogenada, especialmente quando altos niveis de $\mathbf{N}$ são aplicados, nenhum efeito prejudicial tem sido atribuido ao teor de HCN desta forrageira (Mislevy et al., 1995).

\subsection{Pragas e doenças em Cynodon}

Segundo Mislevy et al. (1995), a Florakirk é suscetível ao ataque da lagarta-docartucho-do-milho (Spodoptera frugiperda) e do curuquerê-dos-capinzais (Mocis latipes); estando os problemas relacionados a pragas restritos a estes dois insetos, uma vez que a cultivar não sofre danos devido ao ataque de nematóide e aparentemente não é afetada por cigarrinhas. Entretanto, em condições brasileiras, tem-se observado uma alta suscetibilidade da Florakirk ao ataque de cigarrinhas (Deois spp. e Zulia spp.), podendo afetar sua produção e persistência, o mesmo ocorrendo com a cultivar Coastcross-1 (Haddad'1).

Florakirk é suscetível a doenças foliares como ferrugem (Puccinia sp.), mancha foliar (Helminthosporium = Bipolaris sp.) e mancha foliar preta (Phyllachora sp.). A ocorrência de ferrugem parece estar associada a estandes densos de pastagem alta, não submetidos a corte ou pastejo. A mancha foliar preta ocorre de modo mais severo quando a pastagem não é cortada após 5 semanas de crescimento; entretanto, a sua ocorrência não impede uma boa rebrota após corte, mesmo que tenha atingido de metade a dois terços das plantas. Estas doenças foliares não limitam a produção de forragem quando a pastagem é utilizada intensivamente para fenação, tendendo a ser mais freqüentes em condiçōes de pastejo (Mislevy et al., 1995).

\footnotetext{
1 HADDAD, C.M. Comunicação pessoal, 1996.
} 


\subsubsection{Ferrugem (Puccinia)}

Pastagens crescendo sob condições ambientais estressantes são mais facilmente parasitadas por fungos que causam ferrugem, ficando mais suscetiveis ao ataque de outros patógenos. A doença torna-se mais severa em situações de crescimento lento da forragem associado à seca, deficiência nutricional, altura de corte baixa, sombreamento e outros patógenos. Os sintomas iniciais são manchas de cor amarelo claro nas folhas e hastes; com a maturação da infecção, as áreas amareladas alargam-se e alongam-se paralelamente ao eixo das folhas ou hastes. Plantas severamente infectadas podem secar e morrer devido à perda excessiva de umidade através das folhas 'enferrujadas' (Smiley et al., 1992), embora, para Smith et al. (1989), a ocorrência de Puccinia cynodontis (ferrugem de Cynodon) raramente provoca a morte da grama bermuda, mas pode causar danos foliares severos, especialmente em conjunto com outros patógenos que causam manchas foliares.

A temperatura ótima para crescimento e esporulação de Puccinia varia, estando geralmente entre 20 e $30^{\circ} \mathrm{C}$. Condições ótimas para $P$. graminis incluem baixa intensidade luminosa, umidade na superficie da folha e temperatura próxima a $22^{\circ} \mathrm{C}$ (Smiley et al., 1992), sendo para $P$. cynodontis $20^{\circ} \mathrm{C}$ a temperatura ótima (Smith et al., 1989).

\subsubsection{Mancha foliar preta (Phyllachora)}

A mancha foliar preta é causada por muitas espécies de Phyllachora e caracteriza-se pelo aparecimento de manchas pretas pequenas, circulares a ovais, que ocorrem na superfície superior e/ou inferior das folhas. As áreas intensamente infectadas têm aparência mosqueada (verde-amarelo a amarelo brilhante) com manchas pretas (Smiley et al., 1992).

\subsubsection{Mancha foliar (Helminthosporium)}

A mancha foliar é uma doença comum em espécies forrageiras da família Poaceae, causada por diversas espécies de Helminthosporium que são favorecidas 
por temperaturas moderadas a quentes $\left(18\right.$ a $\left.32^{\circ} \mathrm{C}\right)$ e particularmente pelo tempo úmido (Smith et al., 1989). Entretanto, Smiley et al. (1992), referindo-se a Bipolaris cynodontis (Marig.) Schoemaker - (Helminthosporium cynodontis Marignoni), afirmam que a infecção da folhagem de pastagens tropicais ocorre durante periodos frios e úmidos, do outono até a primavera, causando lesões foliares com formato irregular e coloração verde bronzeada a preta.

Ricci Jr. et al. (1981) relataram a ocorrência de B. cynodontis em grama seda (C. dactylon), no Estado de São Paulo. Os sintomas surgiram inicialmente como pequenas manchas alongadas, de coloração castanho escuro; com o progresso da doença, as manchas tornaram-se necróticas e elipticas, com aproximadamente $3 \mathrm{~mm}$ de comprimento por $1 \mathrm{~mm}$ de largura. O centro da lesão era cinza claro, circundado por uma faixa de coloração preta, seguida por uma área de coloração castanho escuro, e por fim, um halo amarelo claro envolvendo toda a lesão.

\subsubsection{Aspectos nutricionais}

O fatores ambientais que afetam mais severamente 0 início $e \quad 0$ desenvolvimento de doenças infecciosas em plantas são: temperatura, umidade, luminosidade, $\mathrm{pH}$ e nutrientes no solo. Estes fatores atuam influenciando a) 0 crescimento e/ou suscetibilidade da planta hospedeira, b) a multiplicação e ativação do patógeno, c) a interação hospedeiro-patógeno e d) a severidade do desenvolvimento dos sintomas (Agrios, 1988).

A nutrição da planta afeta a taxa de crescimento e pode determinar sua resistência ou suscetibilidade a doenças. A severidade de muitas doenças é reduzida por formas ou niveis especificos de determinados nutrientes, embora raramente uma doença possa ser eliminada pela simples aplicação de um nutriente específico (Huber \& Arny, 1985; Agrios, 1988). Segundo Smith et al. (1989), os efeitos do potássio na suscetibilidade a doenças são geralmente mais aparentes que os do fósforo, mas o suprimento adequado e balanceado de NPK é importante para manter a sanidade da planta e reduzir os danos causados pela doença. Assim, segundo Huber \& Arny (1985), o balanço nutricional pode ser tão importante quanto o nível de algum nutriente específico. 
O nitrogênio afeta a taxa de crescimento da planta, influenciando sua suscetibilidade a determinados patógenos. $\mathrm{N}$ em abundância resulta em plantas mais suculentas, com período vegetativo mais prolongado e maturidade atrasada, tornando-as mais suscetíveis a patógenos que atacam tecidos mais jovens; ao contrário de plantas deficientes em $\mathrm{N}$, que crescem mais lentamente. O P aumentaria a resistência melhorando o balanço nutricional da planta elou acelerando a sua maturidade, tornando-a menos suscetível a patógenos que preferem tecidos mais jovens. $O$ cálcio aumenta a resistência à doenças provavelmente devido ao seu efeito na composição da parede celular, tornando-a mais resistente à penetração por patógenos (Agrios, 1988).

Segundo Huber \& Arny (1985), o K é um elemento com ampla oportunidade para modificar a resistência ou suscetibilidade da planta a doenças devido à intrinseca relação da nutrição potássica com funções metabólicas e crescimento, assim como sua interrelação com vários outros nutrientes na planta e no solo. O seu efeito é influenciado pela disponibilidade deste elemento no solo, suas interações com outros nutrientes, condições ambientais, suscetibilidade da planta e pelo patógeno envolvido.

Para Agrios (1988), além de afetar diretamente os vários estágios de estabelecimento e desenvolvimento do patógeno no hospedeiro, o $\mathrm{K}$ também afeta a infecção, favorecendo o restabelecimento das lesões, aumentando a resistência a injúrias causadas pelo frio e atrasando a maturidade e senescência da planta além do período no qual a infecção por certos parasitos facultativos pode ser severamente danosa. Entretanto, Huber \& Arny (1985) afirmam que o K está mais associado a taxa de desenvolvimento da doença que a incidência da mesma e citam exemplos de redução na severidade de doenças fúngicas devido à elevação do nivel de $K$ na planta, entre eles: Puccinia sp. em cereais, Helminthosporium sp. em arroz e gramados e $H$. cynodontis em grama bermuda.

Richardson \& Croughan (1989) observaram, em casa de vegetação, relação entre a suscetibilidade ao fungo causador de mancha foliar $(H$. cynodontis) e o nível de $\mathrm{K}$ no tecido dos híbridos de grama bermuda Grazer e Tifton 78 (C. dactylon). A severidade da doença aumentou quando os niveis de $\mathrm{K}$ no tecido decresceram a 
partir de $25 \mathrm{~g} \mathrm{~kg}^{-1}$, indicando que a análise de tecido e fertilização potássica adequada podem ser usadas como prevenção para reduzir problemas com doenças em grama bermuda. Matocha \& Smith (1980) também observaram, em condições de campo, relação entre a severidade de mancha foliar e o nivel de $K$ no tecido de grama bermuda Coastal (C. dactylon), porém o nível crítico de $\mathrm{K}$ no tecido foi $6 \mathrm{~g} \mathrm{~kg}^{-1}$, inferior ao observado por Richardson \& Croughan (1989).

\subsubsection{Danos}

Segundo Leath et al. (1996), as perdas com a ocorrência de doenças em pastagens incluem redução a) da produção de biomassa, b) no valor nutritivo, c) no consumo pelo animal e d) na longevidade da pastagem. Outros prejuizos indiretos são citados por Barbetti et al. (1996): a) mudanças indesejáveis na composição botânica da pastagem (decréscimo no valor competitivo da espécie forrageira), b) redução do $\mathrm{N}$ residual fixado, c) menor utilização de insumos (uso menos eficiente de fertilizantes e água), d) redução na produção animal e e) aumento dos custos de produção (menor longevidade e gastos com controle da doença).

Segundo Agrios (1988), a redução na produção de biomassa ocorre devido aos efeitos dos patógenos nas funções fisiológicas das plantas, sendo as principais:

- redução na fotossíntese devido ao decréscimo da superfície fotossintética (principalmente em doenças foliares), degeneração de cloroplastos (menor produção de clorofila) e presença de toxinas inibidoras de enzimas fotossintéticas;

- impedimento na translocação de água e nutrientes pela planta hospedeira;

- aumento de transpiração devido à destruição da camada externa de proteção das folhas (cutícula), decorrente da infecção pelo patógeno;

- aumento da respiração no início da infecção.

A longevidade da pastagem é prejudicada, pois as doenças afetam 0 estabelecimento e persistência de forrageiras perenes, reduzindo drasticamente a produtividade, principalmente quando a ressemeadura é necessária para garantir a perenidade (a ocorrência de doenças pode reduzir a produção e viabilidade das sementes). Além disso, as doenças afetam a capacidade da forrageira sobreviver a periodos climáticos adversos (Barbetti et al., 1996). E mesmo que a doença não seja 
ativa por longos períodos no campo, o potencial de produção de cortes subseqüentes pode ser menor devido à efeitos residuais da doença (Leath et al., 1996).

A qualidade da forragem é afetada pela redução de características desejáveis (carboidratos solúveis, carotenos, digestibilidade, valor nutritivo, palatabilidade, proteína e aminoácidos específicos) e aumento de características indesejáveis (parede celular, fibra bruta, lignina, metabólitos prejudiciais - fitoestrógenos, taninos, fenóis e micotoxinas). O decréscimo no valor nutritivo também é decorrente da alteração na composição botânica da pastagem. Quanto às perdas na produtividade animal, estas devem-se a: a) baixa qualidade alimentícia da pastagem, b) distúrbios digestivos devido ao consumo de plantas doentes, c) redução na reprodução devido à ingestão de compostos estrogênicos estimulados por patógenos e d) sub-utilização do alimento devido à rejeição da pastagem doente pelo animal em pastejo (Barbetti et al., 1996; Leath et al., 1996).

\subsubsection{Controle}

A melhor prática de controle de doenças é o uso de cultivares resistentes desenvolvidas especificamente para determinadas localizações geográficas (Leath et al., 1996), embora certas práticas culturais favoreçam o vigor da planta, aumentando sua resistência ao ataque de patógenos, sendo algumas delas: rotação de cultura, favorecimento de condições ótimas para o crescimento da planta (fertilização adequada, irrigação, drenagem e controle de plantas daninhas), erradicação de hospedeiros alternativos, remoção de resíduos culturais infectados e adoção de espaçamento entre plantas específico (Agrios, 1988; Leath et al., 1996).

Para o controle de ferrugem (Puccinia), Smiley et al. (1992) recomendam a) irrigação e fertilização adequada para evitar estresses nutricional e hídrico que impeçam o crescimento da planta, b) evitar o corte da pastagem abaixo da altura ideal, c) cortar a pastagem regularmente para remover as áreas infectadas e impedir a disseminação de esporos, d) evitar sombreamento e formação de pastagem em área onde acumula umidade e com pouca movimentação do ar e e) uso de fungicidas, pois há vários que são efetivos no controle da ferrugem. Na ocorrência de mancha foliar preta (Phyllachora), estes autores não sugerem nenhum método de controle. 
Segundo Agrios (1988), o controle de mancha foliar (Helminthosporium) depende do uso de variedades resistentes, rotação de culturas, adubação adequada e do uso de fungicidas. Em pastagens, o controle é facilitado através de cortes na altura máxima recomendada, redução ou remoção da palhada densa acumulada e irrigação (rápida e suficiente, em intervalos espaçados de 7 a 10 dias). Smiley et al. (1992) recomendam a aplicação de fertilizante em quantidade necessária para estimular um crescimento moderado da planta, irrigação freqüente e moderada, o corte da pastagem para fenação, evitar acúmulo excessivo de palha, plantio menos denso ou aplicação de fungicida, uma vez que são efetivos no controle de mancha foliar.

Ao contrário das doenças, que reduzem a produção e a qualidade da planta forrageira, os insetos afetam principalmente a produção. Devido ao baixo valor associado à cultura forrageira, quando comparada à outras culturas, e ao alto custo relativo do controle de pragas, as perdas devido ao ataque de pragas nas culturas forrageiras geralmente não são monitoradas, podendo ser negligenciadas (Buxton \& Fales, 1994).

\subsection{Valor nutritivo}

O valor nutritivo de uma forragem é caracterizado pela sua composição química, digestibilidade e natureza dos produtos digestíveis, enquanto a qualidade (ou valor alimentício) da forragem envolve uma avaliação integrada de seu valor nutritivo e do nivel de consumo de matéria seca pelo animal (Mott, 1975; Crowder \& Chheda, 1982). A quantidade de forragem consumida pelo animal é influenciada pela sua disponibilidade, pela composição física e quimica da forragem e pelas exigências nutricionais do animal (Minson, 1992). Assim, a produtividade animal, expressa em termos de produção de carne, leite e lă, é em grande parte influenciada pelo valor nutritivo do alimento consumido (Vieira \& Gomide, 1970).

Segundo Van Soest (1994), o valor nutritivo das forragens é determinado por 2 fatores: a) proporção de parede celular na planta e seu grau de lignificação e b) quantidade de conteúdo celular na matéria seca, que determina a proporção de nutrientes completamente disponiveis para digestão pelos organismos, sendo 
compreendida por proteína, amido, açúcares, lipídios, ácidos orgânicos e cinza solúvel.

Normalmente a concentração energética da pastagem é o fator mais limitante para a produção animal. Porém, em determinadas condições, outros fatores, como conteúdo de proteina bruta (PB) ou de minerais, podem ser limitantes. Estas limitações precisam ser avaliadas em cada situação, pela análise de amostras de pastagens, para que possam ser corrigidas através de suplementação (Martz \& Gerrish, 1995). Outro fator a ser considerado é a diferença na composição química das espécies forrageiras com o avanço do crescimento que determinará o estágio ótimo de utilização das mesmas (Crowder \& Chheda, 1982), pois conforme a planta forrageira cresce, sua produção aumenta, mas seu valor nutritivo tende a decrescer. Portanto, a sua exploração envolve a combinação entre produção e valor nutritivo, requerendo, além da informação de valor nutritivo, dados de produção em diferentes estádios de maturidade, associados com dados de digestibilidade (Raymond, 1969).

O valor nutritivo das plantas é afetado por fatores fisiológicos, morfológicos (relação folha:haste), ambientais (temperatura, luminosidade, umidade, fertilização, solo, doenças e outros fatores de estresse) e por diferenças entre espécies (Van Soest, 1994). No caso das forragens, o declínio no valor nutritivo associado ao aumento da idade é geralmente explicado como resultado do desenvolvimento da maturidade da planta (Van Soest et al. 1978). Segundo Corsi (1990), à medida em que a planta torna-se mais velha, ocorre uma diminuição no conteúdo de carboidratos solúveis, proteínas e minerais e um aumento nas porções de baixa digestibilidade da planta, como os componentes da parede celular, e de outras frações indigestiveis, como cutícula. Entretanto, para Van Soest (1994), idade e maturidade não são necessariamente sinônimos, pois variações na composição de plantas na mesma idade e no mesmo estádio fisiológico de maturidade podem ocorrer como resultado de diferenças genotípicas entre plantas forrageiras ou espécies, assim como respostas fisiológicas a fatores ambientais que influenciam composição, mas não estádio fisiológico de desenvolvimento. Porém, no caso das gramas bermuda, onde a produção de inflorescência é irregular, Griffin \& Watson (1982) recomendam não usar - estádio de maturidade como índice de idade ou qualidade. Assim, a idade cronológica torna-se um importante fator de tomada de decisão na exploração da 
pastagem.

Segundo Buxton \& Fales (1994), Nelson \& Moser (1994) e Buxton \& Mertens (1995), a maturidade é o principal fator afetando a qualidade da pastagem dentro de uma espécie forrageira; embora Van Soest et al. (1978) considerem o efeito da maturidade (reduzindo o valor nutritivo) como um fator secundário, sendo a temperatura ambiental um fator dominante (influenciando a lignificação).

O declínio na qualidade da forragem com a idade resulta principalmente do decréscimo na relação folha:haste e na qualidade do componente haste (Nelson \& Moser, 1994). Entre as gramíneas, tanto folha como haste têm aumentado o seu conteúdo de parede celular e lignina com o avanço da maturidade, com conseqüente declínio do valor nutritivo; embora a taxa de declínio seja maior para hastes que folhas (Minson \& Wilson, 1994). Gomide (1996) observou um decréscimo na relação folha:haste com o aumento da idade de corte de Florakirk (de 0,93, aos 14 dias, para 0,29 , aos 70 dias) e uma redução no valor nutritivo de ambas as frações, sendo mais acentuada nas hastes.

Segundo Van Soest (1994), o valor nutritivo da forragem é muito afetado por fatores ambientais externos, como solo, clima e doenças. Há fatores ambientais (vento, doenças, entre outros) que promovem o desenvolvimento de estruturas de resistência com compostos de defesa (como lignina, cutina, fenóis, terpenos e alcalóides), que, quando presentes, reduzem o valor nutritivo da planta forrageira. Por outro lado, a ocorrência de doença retarda o processo de maturidade e lignificação da planta, favorecendo a manutenção da sua qualidade por mais tempo. Efeito semelhante também pode ser observado em caso de déficit hídrico. Entretanto, para Buxton \& Fales (1994), a ocorrência de doenças influencia negativamente a produção e a qualidade das forragens, dependendo do nivel de infecção, pois plantas doentes tipicamente têm menor digestibilidade e menor concentração de carboidratos não estruturais que plantas sadias, com variáveis diferenças na concentração de PB. Provavelmente ocorra aumento da resistência do tecido foliar à degradação ruminal por microrganismos e, geralmente, há perda foliar (senescência precoce). 


\subsubsection{Composição bromatológica e digestibilidade}

A digestibilidade é uma importante medida do valor nutritivo de forragens e pode ser definida como a diferença, em valor, entre o alimento consumido e o material evacuado pelo animal (Crowder \& Chheda, 1982). Embora a eficiência e o consumo alimentar determinem a resposta animal de forma mais direta que a digestibilidade do alimento, este último parâmetro é mais utilizado na avaliação dos alimentos, pois apresenta menor variação inter-animal, permitindo o estabelecimento de valores alimentares relativos (Van Soest, 1994).

A digestibilidade pode ser medida por métodos diretos (in vivo) ou por métodos químicos, como a digestibilidade in vitro (Crowder \& Chheda, 1982). Dos métodos laboratoriais disponiveis, a digestibilidade in vitro da matéria seca (DIVMS) é o de maior correlação com a digestibilidade in vivo e o melhor preditor de qualidade relativa da forragem, apresentando ainda como vantagem a pequena quantidade de forragem exigida, a possibilidade de análise de várias forragens simultaneamente e o baixo custo (Sollenberger \& Cherney, 1995).

Há vários procedimentos para medir DIVMS, mas a maioria deles constituemse em modificações da técnica de 2 estágios de Tilley \& Terry (1963). O primeiro estágio, no qual a forragem é incubada em fluído ruminal, simula a digestão ruminal dos conteúdos celulares e carboidratos estruturais. O segundo estágio envolve incubação com pepsina ácida (método original que simula digestão abomasal) ou extração com solução detergente neutra (modificação da metodologia original que simula digestão verdadeira) (Sollenberger \& Cherney, 1995). Nesta última, os valores são estimativas da digestibilidade verdadeira pois a extração com detergente neutro remove a matéria metabólica, que neste caso é essencialmente microbiana. Este método é tão preciso quanto o procedimento original de Tilley \& Terry (1963); requer metade do tempo para completá-lo e permite estimar a digestão da parede celular desde que o conteúdo de fibra em detergente neutro (FDN) da dieta seja conhecido (Van Soest, 1994).

$O$ coeficiente de digestibilidade verdadeira é sempre maior que $O$ de digestibilidade aparente pois não considera as perdas metabólicas nas fezes. A digestibilidade verdadeira representa a parte do alimento disponivel para digestão 
animal ou enzimas microbianas; assim, os métodos in vitro estão mais relacionados à digestibilidade verdadeira que à aparente, pois são incapazes de estimar material fecal endógeno, além do fato das perdas metabólicas também serem influenciadas pelo estado fisiológico e condição do animal (Van Soest, 1994).

Embora a digestibilidade verdadeira in vitro da matéria seca (DVIVMS) da planta toda seja um bom parâmetro para avaliar a qualidade de forrageiras tropicais, Moe \& Carr (1985) recomendam o uso da digestibilidade verdadeira in vitro da matéria orgânica (DVIVMO) em relação à DVIVMS, pois corrige as variações do conteúdo de cinza insolúvel. Com silagem de milho, os autores obtiveram elevada correlação entre DVIVMS e DVIVMO (r=0,94) sendo, em geral, a DVIVMO aproximadamente $80 \mathrm{~g} \mathrm{~kg}^{-1}$ menor que a DVIVMS. Nolte et al. (1987), Gutierrez-Ornelas \& Klopfenstein (1991) e Castro (1997) também obtiveram valores de DIVMS superiores aos de DIVMO em alimentos volumosos. Segundo Van Soest (1994), os resultados do método modificado de detergente neutro precisam ser expressos em base de matéria orgânica ou livre de sílica para corrigir a solubilidade da sílica a detergente neutro em forragens com elevada concentração de sílica.

A digestibilidade em capins tropicais declina continuamente durante o crescimento, havendo diferenças marcantes entre as espécies quanto à digestibilidade nos estádios iniciais e à taxa na qual esta declina com a maturidade. Espécies forrageiras que mantém alta digestibilidade por longos períodos durante a estação de crescimento são de maior valor para produção animal que aquelas que podem ter alta digestibilidade nos estádios iniciais de crescimento mas que decresce rapidamente (Norton, 1982). Além do estádio de crescimento, Crowder \& Chheda (1982) citam outros fatores que afetam a digestibilidade da forragem: genótipo, fração da planta, clima, conteúdo de PB e mineral.

Segundo Minson (1992), a redução na digestibilidade das gramíneas tropicais, à medida que amadurecem, deve-se principalmente à diminuição da digestibilidade tanto das folhas como das hastes e não ao aumento na proporção de haste, uma vez que a digestibilidade da matéria seca das frações haste e folha em gramíneas tropicais é similar. Entretanto, para Norton (1982), a concentração de lignina (componente não digerido pelos microrganismos ruminais ou pelas enzimas 
intestinais), é maior nas hastes que nas folhas.

Buxton \& Redfearn (1997) consideram a concentração de fibra como o principal fator afetando a digestibilidade da matéria seca, sendo a lignina um dos principais fatores que limitam a digestão da fibra. Para Van Soest (1994), a lignina é o componente fibroso isolado mais importante limitando a disponibilidade de nutrientes, embora seu efeito não seja uniforme. O conteúdo fibroso, por si só, não é um bom preditor de digestibilidade e a associação de qualquer fração fibrosa com a digestibilidade dependerá de sua associação com a lignina. Norton (1982) também cita a lignina como um fator de redução na digestibilidade da fração fibrosa, pois à medida que a planta amadurece, o conteúdo de lignina aumenta de forma mais acentuada que o conteúdo de parede celular e, assim, a parede celular com o avanço da maturidade torna-se mais lignificada e, portanto, menos digestível.

Embora outros componentes, como proteína e celulose, tenham pouca influência direta na digestibilidade e qualquer predição baseada no seu conteúdo nos alimentos precise refletir a associação secundária com lignificação (Van Soest, 1994), os seus efeitos indiretos devem ser considerados. Um exemplo é o conteúdo de PB na forragem, que pode ter um efeito significante na digestibilidade se for inferior a $70 \mathrm{~g} \mathrm{~kg}^{-1}$, pois a atividade microbiana ruminal é reduzida pela falta de nitrogênio, causando uma utilização incompleta dos carboidratos estruturais da forragem e um retardamento na taxa de passagem da digesta (Crowder \& Chheda, 1982).

Segundo Minson (1992), a digestibilidade da pastagem diminui geralmente numa taxa de 1 a $2 \mathrm{~g} \mathrm{~kg}^{-1} \mathrm{dia}^{-1}$ conforme avança a maturação da planta, embora Crowder \& Chheda (1982) citem diversos trabalhos com decréscimos diários de 5 a $6 \mathrm{~g} \mathrm{~kg}^{-1}$, em capins tropicais. Pedreira (1995) observou, entre ciclo de pastejo de $21 \mathrm{e}$ 35 dias, um decréscimo diário de $1,6 \mathrm{~g} \mathrm{~kg}^{-1}$ na DIVMO da cultivar Florakirk, estando de acordo com a afirmação de Minson (1992). Para Norton (1982), a taxa de decréscimo está relacionada à digestibilidade inicial; espécies com alta digestibilidade inicial tendem a decrescer em digestibilidade a taxas muito mais rápidas com a maturidade que aquelas com baixa digestibilidade inicial.

Forbes (1995) considera que, no caso das forragens, há, em geral, relação positiva entre digestibilidade da matéria seca e nível de consumo voluntário; embora Van Soest (1994) defina FDN da forragem como o componente alimentar mais 
consistentemente associado ao consumo, uma vez que este depende de volume estrutural e FDN representa a matriz fibrosa total insolúvel, enquanto lignina está fortemente associada a digestibilidade.

Segundo Moore \& Mott (1973), coeficientes de digestibilidade abaixo de $650 \mathrm{~g} \mathrm{~kg}^{-1}$ limitariam o consumo. Assim, para Hamilton et al. (1970), valores de digestibilidade próximos a este seriam indicativos de um bom valor nutritivo, permitindo um consumo adequado de energia digestível, exceto para animais em lactação.

Considerando-se que as forragens com alta digestibilidade contém maiores teores de fibra total digestivel, mais recentemente, a fração FDN indigestivel tem-se mostrado promissora como preditor de consumo de forragem (Martz \& Gerrish, 1995).

A concentração de PB na forragem é influenciada por diversos fatores ligados à planta (espécie, estádio de maturidade), ao ambiente (temperatura, disponibilidade hídrica, nível de nutrientes no solo) e ao manejo (Minson, 1990). A concentração de PB nas gramíneas geralmente diminui à medida que avança a maturidade. Esta queda deve-se ao aumento da proporção de hastes, cuja concentração protéica é inferior a das folhas, e devido à diminuição na concentração de PB nas frações folha e haste (Minson, 1992).

Na maioria das espécies, o declínio na concentração de PB com o avanço da idade ou maturidade é mais rápido em plantas mais imaturas, ficando mais lento conforme a planta torna-se mais madura (Buxton \& Mertens, 1995). O decréscimo médio na concentração de PB com o avanço da idade para várias espécies e experimentos sumarizados por Minson (1990) foi 2,2 $\mathrm{g} \mathrm{kg}^{-1} \mathrm{dia}^{-1}$; para C. dactylon, a redução diária foi $1,7 \mathrm{~g} \mathrm{~kg}^{-1}$ (média de 4 trabalhos).

Segundo Norton (1982), um mínimo de $150 \mathrm{~g} \mathrm{~PB} \mathrm{~kg}^{-1}$ é exigido para animais lactantes ou em crescimento, sendo observado em menos de $20 \%$ das gramíneas tropicais um conteúdo de PB acima deste mínimo. Ovinos e bovinos reduzem o consumo voluntário quando a concentração de PB é inferior a $80-100 \mathrm{~g} \mathrm{~kg}^{-1}$, embora vacas em lactação, onde a exigência protéica é maior, necessitem no minimo $120 \mathrm{~g} \mathrm{~kg}^{-1}$. A deficiência protéica em ruminantes reduz a atividade da microflora ruminal e portanto a taxa de digestão da celulose (Forbes, 1995). 
Outro fator associado ao consumo de forragem é o seu conteúdo de água, que varia com o estádio de crescimento da planta, nivel de $\mathrm{N}$ e condições hídricas. Em estudos com forragens cortadas observou-se que o consumo voluntário decresce quando o conteúdo de água excede $800 \mathrm{~g} \mathrm{~kg}^{-1}$ de matéria verde (MV) (Minson \& Wilson, 1994).

Espinosa et al. (1985) determinaram o teor de MS de Bermuda Cruzada-1 (C. dactylon x C. nlemfuensis) aos 28, 42, 56 e 70 dias de crescimento, sendo: $193 \mathrm{~g}$; $230 \mathrm{~g} ; 280 \mathrm{~g}$ e $323 \mathrm{~g} \mathrm{~kg}^{-1}$, respectivamente. Os cortes foram realizados no período seco, sendo utilizada irrigação, e a produção de MS variou de 1,2 a 4,2 $\mathrm{Mg} \mathrm{ha}^{-1}$.

Gomide et al. (1969a) avaliaram, em Minas Gerais, forrageiras tropicais (capim gordura, pangola, napier, quicuiu, bermuda Suwanee e capim sempre verde) submetidas a corte a cada 4 semanas no período de 4 a 36 semanas de idade. No periodo de 4 a 12 semanas, o teor de MS aumentou linearmente com a idade de corte (de $212 \mathrm{~g}$ para $266 \mathrm{~g} \mathrm{~kg}^{-1}$, respectivamente). $O$ teor de PB decresceu com a idade, sendo maior a queda entre 4 e 8 semanas (de $193 \mathrm{~g}$ para $126 \mathrm{~g} \mathrm{~kg}^{-1}$ ). A grama bermuda foi a que apresentou maior teor de MS em todo o experimento (de $314 \mathrm{~g} \mathrm{a}$ $371 \mathrm{~g} \mathrm{~kg}^{-1}$ ) e o seu conteúdo de PB reduziu de $175 \mathrm{~g}$ para $100 \mathrm{~g} \mathrm{~kg}^{-1}$ (no periodo de 4 a 12 semanas), estabilizando em $80 \mathrm{~g} \mathrm{~kg}^{-1} \mathrm{com} 16$ semanas de idade.

Arroyo-Aguilú \& Coward-Lord (1974) avaliaram 10 forrageiras tropicais, cortadas a cada 30 dias, até completarem 180 dias de crescimento. Observaram correlação positiva entre idade e produção de MS, concentração de extrativo não nitrogenado, FDN, FDA, lignina, sílica e celulose; correlação negativa entre idade e concentração de PB, cinza e extrato etéreo, sem correlação entre idade e concentração de hemicelulose e fibra bruta. A correlação foi maior entre FDA e idade que entre FDN e idade, provavelmente devido ao efeito mascarador do conteúdo de hemicelulose na fração FDN. Houve um declínio de 2,6 e 2,2 unidades de DVIVMS por unidade de FDN e FDA aumentada, respectivamente.

Griffin \& Watson (1982) avaliaram as cultivares Coastal, Alicia e Callie, cortadas a 2, 4, 6 e 8 semanas. A idade ideal para corte foi de 4 a 6 semanas e o aumento no intervalo entre cortes esteve associado à redução na qualidade da forragem. A concentração de PB decresceu e a de lignina aumentou com a idade, 
enquanto a digestibilidade e a concentração de FDN e FDA pouco variaram. Remy et al. (1979), analisando diversas gramas bermuda, também obtiveram melhor combinação de produção e valor nutritivo na idade de 4 a 6 semanas (entre estádio vegetativo e floração).

Mislevy et al. (1982) avaliaram diversas cultivares de grama estrela e bermuda sob pastejo e observaram redução na DIVMS e na concentração de PB com o aumento do intervalo de pastejo. Monson \& Burton (1982) avaliaram 8 cultivares de grama bermuda, cortadas com 1, 2, 4 e 8 semanas de idade, sendo que o decréscimo na DIVMS foi mínimo nas 4 primeiras semanas (DIVMS de $646 \mathrm{~g} \mathrm{~kg}^{-1}$ ) com um maior decréscimo entre 4 e 8 semanas (de $639 \mathrm{~g}$ para $570 \mathrm{~g} \mathrm{~kg}^{-1}$ ). A concentração média de

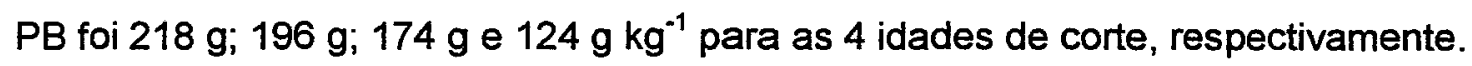

Holt \& Conrad (1986) avaliaram 5 cultivares de bermuda submetidas a cortes com 2, 4, 6 e 8 semanas de crescimento. Entre as semanas 2 e 8, observou-se redução na DIVMS com o avanço da idade (redução de $89 \mathrm{~g} \mathrm{~kg}^{-1}$ na DIVMS e declínio médio de $2 \mathrm{~g} \mathrm{~kg}^{-1}$ dia-1 no período) e na proporção de folhas.

Brown et al. (1988) avaliaram a cultivar Florakirk sob corte com 6 semanas de crescimento e obtiveram a seguinte composição química (em $\mathrm{g} \mathrm{kg}^{-1}$ ): $81 \mathrm{~g}^{\mathrm{g}} \mathrm{PB}$; $795 \mathrm{~g}$ de FDN; $412 \mathrm{~g}$ de FDA; $383 \mathrm{~g}$ de hemicelulose e $77 \mathrm{~g}$ de lignina. A DVIVMO e FDN digestível (após 96 horas de digestão in vitro) foi $439 \mathrm{~g} \mathrm{~kg}^{-1}$ e $499 \mathrm{~g} \mathrm{~kg}^{-1}$, respectivamente.

Palhano \& Haddad (1992), avaliando o efeito da idade de corte sobre o valor nutritivo de Coastcross-1, observaram decréscimo no teor de PB e na DVIVMS e aumento na concentração de FDN e FDA com o avanço da idade. Em função da associação entre produção de matéria seca $e$ valor nutritivo, os autores recomendaram a utilização da pastagem no período de 30 a 40 dias de crescimento. Gomide (1996) observou, em cinco cultivares de Cynodon (Florico, Florona, Tifton 68, Tifton 85 e Florakirk), comportamento semelhante ao apresentado por Palhano \& Haddad (1992) em relação à PB, FDN e FDA, sendo o intervalo de 28 a 42 dias de crescimento o recomendado pelo autor para utilização destas forrageiras.

O efeito da freqüência de pastejo sobre a produção e composição de Florakirk foi avaliado por Mislevy et al. (1988) e Adjei et al. (1989), cujos resultados obtidos são 
apresentados na Tabela 1. Em ambos os trabalhos, os teores de PB e a DIVMO decresceram com o aumento do intervalo entre pastejo. Adjei et al. (1989) observaram um grande acúmulo de folhas basais senescentes, o que poderia explicar a redução na produção de matéria seca que ocorreu entre 6 e 8 semanas de crescimento (período verão/outono). As freqüências de pastejo entre 4 e 6 semanas foram as que associaram as melhores produções de matéria seca, teor de PB e DIVMO.

Tabela 1. Efeito da freqüência de pastejo sobre a produção e composição de Florakirk (experimentos com dois anos de duração e realizados em Ona, Flórida, EUA) ${ }^{(1)}$.

\begin{tabular}{|c|c|c|c|c|c|c|c|c|c|}
\hline \multirow[t]{2}{*}{ Autor } & \multirow[t]{2}{*}{ Período } & \multirow[t]{2}{*}{ Item } & \multicolumn{6}{|c|}{ Freqüência de pastejo (semanas) } & \multirow[b]{2}{*}{ méd. } \\
\hline & & & 2 & 4 & 5 & 6 & 7 & 8 & \\
\hline \multirow{3}{*}{$\begin{array}{l}\text { Mislevy et } \\
\text { al. (1988) }\end{array}$} & Ano & produção( $\left.\mathrm{Mg} \mathrm{ha}^{-1}\right)$ & 12,3 & 16,8 & 16,8 & & 17,0 & & \\
\hline & Inteiro & $\left.\mathrm{PB}(\mathrm{g} \mathrm{kg})^{-1}\right)$ & 117 & 81 & 95 & & 77 & & \\
\hline & & DIVMO $\left(\mathrm{g} \mathrm{kg}^{-1}\right)$ & 585 & 550 & 548 & & 513 & & \\
\hline \multirow{8}{*}{$\begin{array}{l}\text { Adjei et } \\
\text { al. (1989) }\end{array}$} & $V / O^{(2)}$ & produção(Mg ha $\left.{ }^{-1}\right)$ & 3,4 & 6,7 & & 8,1 & & 7,4 & \\
\hline & Verão & PB $\left(g_{k g}{ }^{-1}\right)$ & 152 & 100 & & 91 & & 69 & \\
\hline & & DIVMO $\left(\mathrm{g} \mathrm{kg}^{-1}\right)$ & 630 & 560 & & 520 & & 440 & \\
\hline & Outono & $\mathrm{PB}\left(\mathrm{g} \mathrm{kg}^{-1}\right)$ & 182 & 126 & & 92 & & 80 & \\
\hline & & DIVMO $\left(\mathrm{g} \mathrm{kg}^{-1}\right)$ & 660 & 610 & & 530 & & 530 & \\
\hline & $I / P^{(3)}$ & produção(Mg ha $\left.{ }^{-1}\right)$ & & & & & & & 5,4 \\
\hline & & $\left.\mathrm{PB}(\mathrm{g} \mathrm{kg})^{-1}\right)$ & & & & & & & 51 \\
\hline & & DIVMO $\left(\mathrm{g} \mathrm{kg}^{-1}\right)$ & & & & & & & 440 \\
\hline
\end{tabular}

Adaptado de Mislevy et al. (1988) e Adjei et al. (1989).

${ }^{(1)}$ altura de corte $=7,5 \mathrm{~cm}$; adubação anual $=157-59-119 \mathrm{~kg} \mathrm{ha}^{-1}$ de $\mathrm{N}-\mathrm{P}_{2} \mathrm{O}_{5}-\mathrm{K}_{2} \mathrm{O}$; ${ }^{(2)} \mathrm{V}=$ verão, $\mathrm{O}=$ outono; $^{(3)} \mathrm{I}=$ inverno; $\mathrm{P}=$ primavera.

\subsubsection{Composição mineral da forrageira e exigência animal}

Os estudos sobre a composição mineral de plantas forrageiras são importantes para: 
a. estabelecer niveis críticos exigidos pelas plantas e orientar programas de manejo do solo e adubação, com o objetivo de garantir a perenidade e aumentar a produtividade de forragem de elevada qualidade (Crowder \& Chheda, 1982; Corsi \& Silva, 1985);

b. auxiliar na investigação de deficiência mineral em animais e verificar se os teores minerais nas forragens são baixos, adequados ou tóxicos para os animais que delas se alimentam, pois o material vegetal é a fonte primária de minerais para os animais em pastejo (Tokarnia \& Döbereiner, 1978; Malavoita et al., 1986);

c. auxiliar na determinação da suplementação mineral necessária para otimizar a produtividade animal (Crowder \& Chheda, 1982), uma vez que o consumo do suplemento é afetado pela composição mineral das forragens (Haddad \& Platzeck, 1985);

d. verificar se o solo, através do fornecimento de nutrientes, impõe limitações ao crescimento da forrageira (Malavolta et al., 1986).

Entretanto, segundo Tokarnia \& Döbereiner (1978), a interpretação dos resultados de análises de solo e pastagem pode ser dificultada por diversos fatores no solo e na planta capazes de influenciar a assimilação de elementos minerais pela planta e pelo animal.

Existe uma grande variabilidade na concentração dos minerais nas espécies vegetais (Little, 1982), sendo que os níveis de todos minerais na planta forrageira dependem basicamente de quatro fatores (Underwood, 1971):

a. espécie vegetal;

b. solo - composição química e disponibilidade dos minerais (influenciada por pH e umidade);

c. condição climática durante o crescimento - precipitação, temperatura e luminosidade;

d. estádio de maturidade da planta.

Segundo Fleming (1973), no campo não é possível isolar os efeitos do estádio de maturidade per se e das mudanças climáticas sazonais.

Há outros fatores complementares, como velocidade de crescimento, produção de matéria seca, partes da planta, relação folha:haste, época do ano, adubações e 
calagem, interações entre nutrientes e manejo da pastagem (Fleming, 1973; Corsi \& Silva, 1985).

O conceito clássico relacionado à influência da maturidade da planta sobre sua composição mineral prevê uma absorção relativamente rápida de minerais nos estádios iniciais de crescimento, quando a produção de MS é relativamente lenta. Conforme a área fotossintética aumenta, a produção de MS ultrapassa a absorção de mineral resultando, devido a um processo natural de diluição, no declínio do conteúdo mineral. Porém, exceções podem ocorrer com diferentes espécies e minerais, e, mais especialmente, com alguns micronutrientes, havendo grande variação no conteúdo de alguns nutrientes em diferentes espécies. Isto ocorre porque os diversos órgãos da planta variam muito em relação a composição mineral e, conforme a planta amadurece, a proporção destes diferentes órgãos pode mudar radicalmente. As variações na relação folha:haste contribuem para muitas das mudanças observadas (Fleming, 1973).

Além dos fatores citados por Fleming (1973), Malavolta et al. (1986) atribuem a variação na composição mineral das forrageiras ao longo do seu ciclo também à redistribuição dos nutrientes dentro da planta, perdas de nutrientes solúveis por lavagem, excreção via radicular e diversidade no padrão de absorção durante o ciclo. Para Little (1982), as mudanças no conteúdo mineral que ocorrem com o avanço da maturidade estão largamente associadas à alterações na relação folha:haste, no florescimento e liberação de sementes.

Dependendo do nutriente, o teor pode aumentar, diminuir ou permanecer constante à medida que a planta atinge a maturidade (Fleming, 1973). Diversos autores citam variados comportamentos nas concentrações dos minerais em relação à maturidade das forrageiras. Segundo Gomide (1978), há decréscimo nas concentrações de N, P e K. Little (1982) cita que, em geral, a concentração de Ca mantém-se relativamente constante, enquanto a de $\mathrm{N}, \mathrm{P}, \mathrm{S}$ e da maioria dos micronutrientes decresce com a maturidade da planta; para Norton (1982), a concentração de Ca geralmente decresce, embora não haja um padrão consistente em espécies tropicais. Minson (1990) concluiu que as concentrações de $\mathrm{Ca}, \mathrm{Mg}, \mathrm{Zn}$ e Mn podem ou não reduzir, enquanto as de $\mathrm{P}$ e $\mathrm{Cu}$ reduzem, sendo nesta última provavelmente devido ao decréscimo na relação folha:haste. Para Spears (1994), as 
concentrações de $\mathrm{P}$ e $\mathrm{K}$ decrescem acentuadamente, enquanto a de Ca não é muito afetada pela maturidade $\mathrm{e}$ as de $\mathrm{Cu}$, Fe e $\mathrm{Zn}$ podem reduzir.

Segundo Underwood (1971), o marcante declínio na concentração de macronutrientes na planta, como $\mathrm{P}$ e $\mathrm{K}$, com o avanço da maturidade, não é acompanhado por declínios consideráveis nos micronutrientes. A concentração destes minerais na planta pode aumentar, decrescer ou apresentar mudanças não consistentes com o estádio de crescimento. Observa-se normalmente redução na concentração de $\mathrm{Cu}$ e $\mathrm{Zn}$ e flutuação em Fe e Mn. As mudanças nas concentrações de micronutrientes em pastagens, em função do estádio de crescimento da planta, são mais significativas para animais em áreas marginais para determinados minerais.

Os bovinos de corte necessitam de 17 minerais essenciais: a) macrominerais: $\mathrm{Ca}, \mathrm{Mg}, \mathrm{P}, \mathrm{K}, \mathrm{Na}, \mathrm{Cl}$ e S; b) microminerais: $\mathrm{Cr}, \mathrm{Co}, \mathrm{Cu}, \mathrm{I}, \mathrm{Fe}, \mathrm{Mn}, \mathrm{Mo}, \mathrm{Ni}$, Se e Zn; sendo os mesmos, com exceção de $\mathrm{Cr}$ e $\mathrm{Ni}$, exigidos por bovinos de leite. Outros minerais são essenciais para uma ou mais espécies animais, sendo o nivel de exigência influenciado pela idade, peso, tipo, estado fisiológico, estágio de produção, raça do animal e biodisponibilidade do mineral na dieta (National Research Council NRC, 1989a e 1996).

Nos animais, os macrominerais $\mathrm{Ca}, \mathrm{P}$ e $\mathrm{S}$ estão presentes principalmente em compostos estruturais, enquanto $\mathrm{Na}, \mathrm{K}$ e $\mathrm{Cl}$ estão envolvidos na manutenção do balanço ácido-base; $\mathrm{K}, \mathrm{Ca}$ e Mg contribuem na transferência de energia, transmissão de impulsos nervoso e ativação de enzimas. Os microminerais $\mathrm{Mn}$ e $\mathrm{Cu}$ atuam como cofatores enzimáticos; $\mathrm{Zn}$, Mo e Se estão envolvidos em atividades estruturais ou funcionais de enzimas, enquanto I e Co são necessários em hormônios e vitaminas, respectivamente (Humphreys, 1991).

Recomendações de concentração de minerais na dieta, em função da espécie e da categoria animal, são apresentadas nas Tabelas 2, 3 e 4. 
Tabela 2. Concentração de minerais na matéria seca recomendada para algumas categorias de bovinos leiteiros.

\begin{tabular}{|c|c|c|c|c|c|c|c|}
\hline \multirow[t]{3}{*}{ Mineral } & \multicolumn{3}{|c|}{ Concentração na dieta } & \multirow{2}{*}{\multicolumn{3}{|c|}{$\begin{array}{l}\text { Vaca em lactação(1) }^{(1)} \\
\text { produção diária }(\mathrm{kg})\end{array}$}} & \multirow{3}{*}{$\begin{array}{l}\text { Concent } \\
\text { máxima } \\
\text { tolerada }\end{array}$} \\
\hline & \multirow{2}{*}{$\begin{array}{l}\text { Novilha em } \\
\text { crescimento }^{(2)}\end{array}$} & \multirow{2}{*}{$\begin{array}{c}\text { Vaca prenha } \\
\text { seca }\end{array}$} & \multirow{2}{*}{$\begin{array}{l}\text { Vaca no início } \\
\text { da lactação }\end{array}$} & & & & \\
\hline & & & & 10 & 20 & 30 & \\
\hline$\overline{C a}\left(\mathrm{~g} \mathrm{~kg}^{-1}\right)$ & 4,1 a 5,2 & 3,9 & 7,7 & 4,3 & 5,1 & 5,8 & 20 \\
\hline$P \quad\left(g^{~ k g}{ }^{-1}\right)$ & 3,0 & 2,4 & 4,8 & 2,8 & 3,3 & 3,7 & 10 \\
\hline $\operatorname{Mg}\left(g_{k g}{ }^{-1}\right)$ & 1,6 & 1,6 & 2,5 & 2,0 & 2,0 & 2,0 & 5 \\
\hline $\mathrm{K} \quad\left(\mathrm{g} \mathrm{kg}^{-1}\right)$ & 6,5 & 6,5 & 10,0 & 9,0 & 9,0 & 9,0 & 30 \\
\hline$S\left(g \mathrm{~kg}^{-1}\right)$ & 1,6 & 1,6 & 2,5 & 2,0 & 2,0 & 2,0 & 4 \\
\hline $\mathrm{Cu}\left(\mathrm{mg} \mathrm{kg}^{-1}\right)$ & 10 & 10 & 10 & 10 & 10 & 10 & 100 \\
\hline $\mathrm{Fe}\left(\mathrm{mg} \mathrm{kg}^{-1}\right)$ & 50 & 50 & 50 & 50 & 50 & 50 & 1000 \\
\hline $\operatorname{Mn}\left(\mathrm{mg} \mathrm{kg}^{-1}\right)$ & 40 & 40 & 40 & 40 & 40 & 40 & 1000 \\
\hline $\mathrm{Zn}\left(\mathrm{mg} \mathrm{kg}^{-1}\right)$ & 40 & 40 & 40 & 40 & 40 & 40 & 500 \\
\hline
\end{tabular}

Adaptado de NRC (1989a).

(1) vaca com $600 \mathrm{~kg}$ de peso vivo; ${ }^{(2)} 3$ a 12 meses de idade.

Tabela 3. Concentração de minerais na matéria seca recomendada para algumas categorias de bovinos de corte.

\begin{tabular}{|c|c|c|c|c|c|}
\hline \multirow[t]{3}{*}{ Mineral } & \multicolumn{4}{|c|}{ Concentração na dieta } & \multirow{3}{*}{$\begin{array}{l}\text { Concentração } \\
\text { máxima } \\
\text { tolerada }\end{array}$} \\
\hline & \multirow{2}{*}{$\begin{array}{c}\text { Bovino em } \\
\text { crescimento } \\
\text { e acabamento }\end{array}$} & \multicolumn{3}{|c|}{ Vaca } & \\
\hline & & $\begin{array}{l}\text { Final da } \\
\text { gestação }\end{array}$ & $\begin{array}{c}\text { Início da } \\
\text { (0 a } 3 \text { meses) }\end{array}$ & $\begin{array}{c}\text { Final de } \\
\text { lactaçãa }^{(1)}\end{array}$ & \\
\hline $\mathrm{Ca}\left(\mathrm{g} \mathrm{kg}^{-1}\right)$ & 1,9 a 7,3 & 2,4 & 2,4 & 1,5 & 20 \\
\hline$P\left(g k^{-1}\right)$ & 1,2 a 3,4 & 1,5 & 1,7 & 1,1 & 10 \\
\hline$M g\left(g ~ k g^{-1}\right)$ & 1,0 & 1,2 & 2,0 & 2,0 & 4 \\
\hline$K\left(\mathrm{~g} \mathrm{~kg}^{-1}\right)$ & 6,0 & 6,0 & 7,0 & 7,0 & 30 \\
\hline 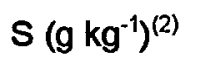 & 1,5 & 1,5 & 1,5 & 1,5 & 4 \\
\hline $\mathrm{Cu}\left(\mathrm{mg} \mathrm{kg}^{-1}\right)$ & 10 & 10 & 10 & 10 & 100 \\
\hline $\mathrm{Fe}\left(\mathrm{mg} \mathrm{kg}^{-1}\right)$ & 50 & 50 & 50 & 50 & 1000 \\
\hline $\mathrm{Mn}\left(\mathrm{mg} \mathrm{kg}^{-1}\right)$ & 20 & 40 & 40 & 40 & 1000 \\
\hline $\mathrm{Zn}\left(\mathrm{mg} \mathrm{kg}^{-1}\right)$ & 30 & 30 & 30 & 30 & 500 \\
\hline
\end{tabular}

Adaptado de NRC (1996).

${ }^{(1)}$ vaca com $454 \mathrm{~kg}$ PV produzindo 10 litros de leite; ${ }^{(2)}$ exigências ainda não bem definidas. 
Tabela 4. Concentração de minerais na matéria seca recomendada para algumas categorias de eqüinos.

\begin{tabular}{|c|c|c|c|c|c|c|}
\hline \multirow{3}{*}{\multicolumn{2}{|c|}{ Mineral }} & \multicolumn{4}{|c|}{ Concentração na dieta } & \multirow{3}{*}{$\begin{array}{c}\text { Concentração } \\
\text { máxima } \\
\text { tolerada }\end{array}$} \\
\hline & & \multicolumn{3}{|c|}{ Cavalo } & \multirow{2}{*}{$\begin{array}{l}\text { Égua prenha } \\
\text { e em lactação }\end{array}$} & \\
\hline & & Manutenção & Crescimento & Trabalho & & \\
\hline$\overline{\mathrm{Ca}}$ & $\left(\mathrm{g} \mathrm{kg}^{-1}\right)$ & 2,4 & 3,1 a 6,8 & 3,0 a 3,5 & 3,5 a 4,6 & \\
\hline $\mathbf{P}$ & $\left(g_{k g}{ }^{-1}\right)$ & 1,7 & 1,7 a 3,8 & 2,2 a 2,5 & 2,2 a 3,4 & \\
\hline $\mathrm{Mg}$ & $\left(\mathrm{g} \mathrm{kg}^{-1}\right)$ & 0,9 & 0,8 a 1,0 & 1,1 a 1,3 & 0,9 a 1,1 & \\
\hline $\mathrm{K}$ & $\left(\mathrm{g} \mathrm{kg}^{-1}\right)$ & 3,0 & 3,0 a 3,2 & 3,7 a 4,3 & 3,3 a 4,2 & \\
\hline $\mathrm{s}$ & $\left(\mathrm{g} \mathrm{kg}^{-1}\right)$ & 1,5 & 1,5 & 1,5 & 1,5 & 12,5 \\
\hline $\mathrm{Cu}$ & $\left(\mathrm{mg} \mathrm{kg}^{-1}\right)$ & 10 & 10 & 10 & 10 & 800 \\
\hline $\mathrm{Fe}$ & $\left(\mathrm{mg} \mathrm{kg}^{-1}\right)$ & 40 & 50 & 40 & 50 & 1000 \\
\hline $\mathrm{Mn}$ & $\left(\mathrm{mg} \mathrm{kg}^{-1}\right)$ & 40 & 40 & 40 & 40 & 1000 \\
\hline $\mathrm{Zn}$ & $\left.(\mathrm{mg} \mathrm{kg})^{-1}\right)$ & 40 & 40 & 40 & 40 & 500 \\
\hline
\end{tabular}

Adaptado de NRC (1989b).

Segundo Forbes (1995), a deficiência de qualquer dos minerais essenciais ou excesso de alguns minerais na dieta afeta o consumo voluntário, reduzindo-o principalmente nos casos de deficiência de $\mathrm{Ca}$, em bezerros, $\mathrm{K}, \mathrm{Cu}, \mathrm{Mn}$ e $\mathrm{Zn}$, em ruminantes adultos; o mesmo sendo observado com excessos de $\mathrm{Ca}$ e $\mathrm{Zn}$. A deficiência de Mg deprime a digestibilidade da celulose, mas não é suficiente para provocar um decréscimo significativo no consumo voluntário.

Na nutrição mineral de ruminantes, ao contrário dos outros seres vivos, as exigências microbianas e interações entre minerais precisam ser consideradas (Van Soest, 1994). Um exemplo é o S, citado por Minson (1982), que é exigido na formação de proteína microbiana no rúmen e a sua falta provavelmente causará deficiência de proteína e reduzirá o consumo; Humphreys (1991) define a concentração de $S$ de $1,7 \mathrm{~g} \mathrm{~kg}^{-1}$ como a mínima para que não haja limitação na taxa de consumo da forragem.

Para Humphreys (1991), a concentração crítica de $N$ na forragem na qual não há limitação no consumo é $11 \mathrm{~g} \mathrm{~kg}^{-1}$, podendo ser este valor estendido a $13 \mathrm{~g}$. Esta 
concentração está associada ao metabolismo do $\mathrm{N}$ dos microrganismos ruminais, os quais requerem um mínimo de $P B$ de 60 a $80 \mathrm{~g} \mathrm{~kg}^{-1}$ na dieta.

Para Durand \& Komisarczuk (1988), a depressão no consumo de forragem, induzida por deficiência mineral moderada ou proporções inadequadas dos minerais na dieta de ruminantes, pode ser devida, em parte, ao prejuizo da atividade microbiana ruminal. Como no caso do $\mathrm{N}$, as exigências minerais dos microrganismos ruminais devem ser avaliadas em termos de energia fermentável ao invés de conteúdo total do nutriente na matéria seca da dieta; assim, o fornecimento de $\mathrm{S}$ e $\mathrm{Mg}$ na dieta deve ser entre 2,5 a $3,1 \mathrm{~g} \mathrm{~kg}^{-1}$ de matéria orgânica digestível (MOD) e 1,5 a $2,5 \mathrm{~g} \mathrm{~kg}^{-1}$ de $\mathrm{MOD}$, respectivamente. Entretanto, o fornecimento de $\mathrm{S}$ não deve exceder as exigências, pois o consumo de $4,5 \mathrm{~g} \mathrm{~kg}^{-1}$ de MOD em dieta concentrada reduziu a solubilidade de $\mathrm{Cu}$ e os niveis sangüíneos de $\mathrm{Zn}$.

Segundo Norton (1982), a extensão na qual as proporções relativas dos minerais na forragem atendem às exigências microbianas e animal irá determinar a qualidade da forragem, sendo que a deficiência de um dos minerais essenciais limitará digestão, absorção e utilização de todos componentes dietéticos. Porém, a qualidade da forragem só será afetada quando o conteúdo mineral da forragem estiver fora do intervalo exigido para crescimento animal ótimo.

Georgievskii et al. (1982), com relação à nutrição animal, enfatizam a importância de se considerar as interações dos minerais entre si e com outros nutrientes, que podem ser sinergísticas ou antagônicas, interferindo na absorção e/ou metabolismo dos mesmos. Um exemplo sinergístico é a relação $\mathrm{Ca} \times \mathrm{P}$, onde o nível de absorção no trato gastrointestinal é determinado pela proporção entre os dois elementos. A relação $\mathrm{Ca} \times \mathrm{P} \times \mathrm{Zn}$ é um exemplo de antagonismo, com inibição da absorção de alguns elementos por outros no trato digestivo.

Há minerais exigidos pela planta em concentrações superiores àquelas exigidas pelos animais, como o $\mathrm{K}$, e dificilmente ocorrerá deficiência destes minerais para o animal, embora possam exercer efeito negativo sobre outros minerais; no outro extremo, a exigência animal pode exceder a da planta para crescimento normal e o mineral deverá ser fornecido para o animal como uma suplementação direta ou em fertilizante, embora não haja resposta da cultura à fertilização (exemplo do Mg, para animais em lactação no inicio da estação de pastejo, $\mathrm{Na}, \mathrm{Cl}, \mathrm{l}, \mathrm{Co}, \mathrm{e} \mathrm{Se}$ ). Há 
situações onde as exigências da planta e do animal para um dado mineral, como o $P$, são aproximadamente equivalentes e a deficiência pode deprimir a produtividade de ambos (Reid \& Jung, 1974).

Follett \& Wilkinson (1995) apresentam concentrações normais de minerais em plantas não sujeitas a limitação de crescimento, sendo: $25 \mathrm{~g} \mathrm{~N} ; 2,5 \mathrm{~g} \mathrm{P} ; 20 \mathrm{~g} \mathrm{~K} ; 4 \mathrm{~g}$ $\mathrm{Ca} ; 2,5 \mathrm{~g} \mathrm{Mg} ; 2 \mathrm{~g} \mathrm{~S} ; 20$ mg B; $15 \mathrm{mg} \mathrm{Cu} ; 100 \mathrm{mg} \mathrm{Fe;} 50 \mathrm{mg} \mathrm{Mn} \mathrm{e} 15$ mg Fe kg-1.

Assim como nos animais, as exigências minerais das plantas não são fixas, ocorrendo variações de acordo com a espécie, maturidade e nível de produção (Crowder \& Chheda, 1982). As plantas normalmente reagem à falta de um nutriente no solo limitando seu crescimento ou reduzindo a concentração do mesmo em seu tecido, ou ambos (Underwood, 1971). Assim, qualquer fator que limite o crescimento, seja luz, umidade, temperatura ou nutriente, pode ocasionar um acúmulo de determinados nutrientes na planta (Martin \& Matocha, 1973).

A concentração crítica (concentração do nutriente na planta associada a $90 \%$ da produção máxima) de P nas forragens varia de 1,4 a $3,0 \mathrm{~g} \mathrm{~kg}^{-1}$ (Follett \& Wilkinson, 1995), havendo consideráveis diferenças entre as espécies (Haag, 1984). Mesa et al. (1983) determinaram a concentração critica de $P$ em 4 cultivares de C. dactylon, cultivadas em solo de baixa fertilidade e cortadas na fase de florescimento, sendo:

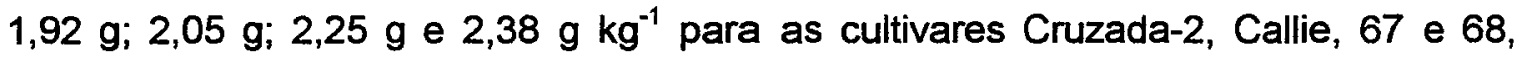
respectivamente. Kelling \& Matocha ${ }^{2}$ (citados por Robinson, 1996) apresentaram valores superiores para as cultivares Coastal $\left(2,4 \mathrm{~g} \mathrm{~kg}^{-1}\right)$, bermuda comum e Midland $\left(2,8 \mathrm{~g} \mathrm{~kg}^{-1}\right)$. A concentração crítica de outros nutrientes também foram apresentadas pelos autores, sendo para a cultivar Coastal: $22 \mathrm{~g} \mathrm{~N} ; 15 \mathrm{~g} \mathrm{~K} ; 1,5 \mathrm{~g} \mathrm{~S} \mathrm{e} 1 \mathrm{~g} \mathrm{Mg} \mathrm{kg}^{-1}$; e para a bermuda comum e Midland: $25 \mathrm{~g} \mathrm{~N} ; 18 \mathrm{~g} \mathrm{Ke} 1,8 \mathrm{~g} \mathrm{~S} \mathrm{~kg}^{-1}$.

De modo geral, as gramíneas tropicais contém baixo conteúdo de minerais (Norton, 1982). Na Tabela 5 são apresentadas concentrações médias de minerais em forrageiras tropicais amostradas em diversas condições.

${ }^{2}$ KELLING, K.A.; MATOCHA, J.E. Plant analysis as an aid in fertilizing forage crops. In: WESTERMAN, R.L., ed. Soil testing and plant analysis. Madison: SSSA, 1990. 
Tabela 5. Concentração mineral média em forrageiras tropicais sob diversas condições.

\begin{tabular}{|c|c|c|c|c|}
\hline & \multirow[t]{2}{*}{ Mineral } & \multicolumn{3}{|c|}{ Autor } \\
\hline & & $\begin{array}{l}\text { Norton (1982) } \\
\text { Minson }(1992)^{(1)}\end{array}$ & Camargo et al. $(1985)^{(2)}$ & $\begin{array}{c}\text { Malavolta et al. } \\
(1986)^{(3)}\end{array}$ \\
\hline $\bar{N}$ & $\left(\mathrm{~g} \mathrm{~kg}^{-1}\right)$ & & & 17,0 \\
\hline $\mathbf{P}$ & $\left(g \mathrm{~kg}^{-1}\right)$ & $2,2(0,2-5,8)^{(4)}$ & 1,1 & 2,1 \\
\hline $\mathrm{K}$ & $\left(g_{k g}^{-1}\right)$ & & & 21,0 \\
\hline $\mathrm{Ca}$ & $\left(\mathrm{g} \mathrm{kg}^{-1}\right)$ & $4,0(1,4-14,6)$ & 4,9 & 4,6 \\
\hline $\mathrm{Mg}$ & $\left(\mathrm{g} \mathrm{kg}^{-1}\right)$ & $3,6(0,4-9,0)$ & 1,9 & 2,7 \\
\hline$s$ & $\left(\mathrm{~g} \mathrm{~kg}^{-1}\right)$ & & & 1,0 \\
\hline B & $\left(\mathrm{mg} \mathrm{kg}^{-1}\right)$ & & & 17,0 \\
\hline $\mathrm{Cu}$ & $\left(m g k^{-1}\right)$ & 15 & $3-100$ & 6,0 \\
\hline $\mathrm{Fe}$ & $\left(\mathrm{mg} \mathrm{kg}^{-1}\right)$ & & & 154,0 \\
\hline$M n$ & $\left(\mathrm{mg} \mathrm{kg}^{-1}\right)$ & & & 142,0 \\
\hline $\mathrm{Zn}$ & $\left(\mathrm{mg} \mathrm{kg}^{-1}\right)$ & 36 & $15-120$ & 26,0 \\
\hline
\end{tabular}

Minson (1990) analisou diversos trabalhos da literatura mundial, observando, em gramineas tropicais, concentrações médias de $3,8 \mathrm{~g} \mathrm{Ca} ; 3,6 \mathrm{~g} \mathrm{Mg}$ e $36 \mathrm{mg} \mathrm{Zn} \mathrm{kg}{ }^{-1}$, com $6 \%$ das amostras com menos de $20 \mathrm{mg} \mathrm{Zn} \mathrm{kg}^{-1}$. Em gramineas tropicais e temperadas, a concentração média de $P$ observada foi $3,6 \mathrm{~g} \mathrm{~kg}^{-1}$, sendo que apenas $35 \%$ das amostras de gramíneas tropicais continham mais que $2,4 \mathrm{~g} \mathrm{~kg}^{-1}$. A concentração de $\mathrm{Mn}$ foi muito variada (de 1 a $2670 \mathrm{mg} \mathrm{kg}^{-1}$ ), sendo poucas as amostras com menos de $20 \mathrm{mg} \mathrm{kg}^{-1}$. Analisando separadamente os dados referentes a C. dactylon, os autores observaram concentração média de $5 \mathrm{~g} \mathrm{Ca} \mathrm{kg}^{-1}$ (variando de 3,4 a $7,4 \mathrm{~g}$ ), sendo que $C$. dactylon e Paspalum dilatatum foram as espécies com as maiores concentrações de $\mathrm{Ca}$ entre as gramíneas tropicais; $\mathrm{Cu}$ foi analisado em um único trabalho, com concentração média de $8 \mathrm{mg} \mathrm{kg}^{-1}$ (variando de 4,3 a $12,2 \mathrm{~g} \mathrm{~kg}^{-1}$ ).

Gallo et al. (1974) estudaram diversas espécies de gramineas tropicais no Estado de São Paulo, cortadas nos meses de fevereiro e março, comparando os 
teores observados com a concentração normal nas plantas e com a concentração adequada para bovinos. Os resultados são apresentados na Tabela 6.

Tabela 6. Porcentagem de amostras de gramineas tropicais no Estado de São Paulo com teores adequados em relação à concentração normal de nutrientes na planta e à exigência de bovinos ${ }^{(1)}$.

\begin{tabular}{|c|c|c|c|c|}
\hline \multirow[t]{2}{*}{ Mineral } & \multicolumn{2}{|c|}{ concentração normal na planta } & \multicolumn{2}{|c|}{ concentração adequada para bovinos } \\
\hline & $\mathrm{g} \mathrm{kg}^{-1}$ & $\%$ das amostras & $\mathrm{g} \mathrm{kg}^{-1}$ & $\%$ das amostras \\
\hline$N$ & $10-30^{(2)}$ & 91,0 & $>12,8$ & 77,9 \\
\hline $\mathbf{P}$ & $2-4$ & $40,2^{(3)}$ & $1,8-4,3$ & 59,0 \\
\hline K & $12-28$ & 72,1 & $6-8$ & $0^{(4)}$ \\
\hline $\mathrm{Ca}$ & $2-4$ & 63,9 & $1,8-6$ & 85,2 \\
\hline $\mathrm{Mg}$ & $1,2-2,6$ & 61,5 & $0,4-1$ & $0^{(4)}$ \\
\hline \multirow[t]{2}{*}{ S } & $1-3$ & $48,4^{(5)}$ & $>1$ & 48,4 \\
\hline & $\mathrm{mg} \mathrm{kg}^{-1}$ & $\%$ das amostras & $\mathrm{g} \mathrm{kg}^{-1}$ & $\%$ das amostras \\
\hline B & $10-100$ & $-(6)$ & - & - \\
\hline $\mathrm{Cu}$ & $4-8$ & 63,9 & $4-10$ & 77,1 \\
\hline $\mathrm{Fe}$ & $50-100$ & $29,5^{(7)}$ & $10-50$ & $3,3^{(4)}$ \\
\hline Mn & $40-200$ & 76,2 & $10-150$ & 68,8 \\
\hline $\mathrm{Zn}$ & $20-80$ & 68,9 & $10-30$ & 73,8 \\
\hline
\end{tabular}

Adaptado de Gallo et al. (1974).

(1) resultado de 22 amostras; ${ }^{(2)}$ faixa de maior freqüência; ${ }^{(3)} 57,4 \%$ das amostras abaixo da concentração normal e apenas $2,4 \%$ das amostras com mais de $4 \mathrm{~g} \mathrm{~kg}^{-1}$; ${ }^{(4)}$ demais amostras com concentração acima da adequada; ${ }^{(5)}$ demais amostras com concentração abaixo da normal; ${ }^{(6)} 80 \%$ das amostras na faixa de 10 a $20 \mathrm{mg} \mathrm{kg}^{-1} ;{ }^{(7)} 67,2 \%$ das amostras acima da concentração normal.

Segundo Fick et al. (1978), as concentraçōes de Mn, Zn, Fe, K e S nas forragens são, normalmente, adequadas para atender às exigências bovinas sob condições de pastejo, mas ocorrem deficiências em regiōes restritas, sendo que, no Brasil, há registros de deficiências de $\mathrm{Ca}, \mathrm{Mg}, \mathrm{P}, \mathrm{K}, \mathrm{Na}, \mathrm{S}, \mathrm{Co}, \mathrm{Cu}, \mathrm{I}, \mathrm{Fe}, \mathrm{Mn}, \mathrm{Se}$ e $\mathrm{Zn}$, havendo também toxicidade de $\mathrm{Cu}, \mathrm{Mo}, \mathrm{Mn}$ e Se. Tokarnia \& Döbereiner (1978) citam, em bovinos mantidos sob condições extensivas, a ocorrência de deficiências de $P$, 
$\mathrm{Mg}, \mathrm{Na}, \mathrm{Cl}, \mathrm{Cu}, \mathrm{Co}, \mathrm{I}$ e Se, havendo, em casos específicos, deficiência de $\mathrm{Zn}$ e Mn. Gallo et al. (1974), revisando diversos trabalhos realizados no Estado de São Paulo, encontraram teores de $\mathrm{P}$, Co e $\mathrm{Zn}$ considerados deficientes ou indicativos de possíveis deficiências estacionais para o gado mantido em condições de pastejo em gramineas forrageiras; os teores de $\mathrm{Ca}, \mathrm{Mg}, \mathrm{Cu}, \mathrm{Fe}, \mathrm{Mn}$ e $\mathrm{Cu}$ (desconsiderando os teores de Mo e S) foram considerados normais.

Fick et al. (1978) apresentam proporçōes de amostras de forrageiras da América Latina que apresentaram níveis deficientes ou marginais de minerais em relação à exigência animal (Tabela 7 ).

Tabela 7. Amostras de forrageiras da América Latina com niveis deficientes ou marginais de minerais em relação à exigência animal.

\begin{tabular}{|c|c|c|c|c|c|c|c|c|c|c|c|}
\hline & $P$ & $K$ & $\mathrm{Ca}$ & $\mathrm{Mg}$ & $\mathrm{Na}$ & Co & $\mathrm{Cu}$ & $\mathrm{Fe}$ & $\mathrm{Mn}$ & Mo & $\mathrm{Zn}$ \\
\hline & \multicolumn{5}{|c|}{$\mathrm{g} \mathrm{kg}^{-1}$} & \multicolumn{6}{|c|}{$\mathrm{mg} \mathrm{kg}^{-1}$} \\
\hline concentração $^{(1)}$ & 3 & 8 & 3 & 2 & 1 & 0,1 & 10 & 100 & 40 & 3 & 50 \\
\hline proporção (\%) & 72,8 & 15,1 & 31,1 & 35,2 & 59,5 & 43,1 & 46,6 & 24,1 & 21,0 & 86,4 & 74,6 \\
\hline
\end{tabular}

Adaptado de Fick et al. (1978).

(1) concentração mínima abaixo da qual a amostra foi considerada deficiente ou marginal;

(2) 2615 amostras analisadas.

Segundo Gallo et al. (1974), as variações nos teores fornecidos pela análise da forrageira nem sempre correspondem às variações na disponibilidade dos minerais, uma vez que existem diferenças entre forrageiras quanto à disponibilidade de minerais essenciais aos animais, devido às interrelações entre eles ou com outros constituintes da dieta. Entretanto, segundo Minson (1990), a deficiência ou a suficiência potencial de alguns minerais (como por exemplo $\mathrm{P}, \mathrm{Ca}$ e $\mathrm{Mn}$ ) pode ser diagnosticada através da análise da forragem, sendo o resultado comparado as exigências para as diferentes formas de produção animal. Para a análise de alguns minerais, como o $\mathrm{Zn}$, as amostras devem ser coletadas diretamente da pastagem, não podendo ser obtidas através de animais fistulados, pois há contaminação pela saliva. 


\section{Cálcio e fósforo}

A concentração de Ca na forragem é influenciada pela quantidade de $\mathrm{Ca}$ trocável no solo, pelo nivel de outros nutrientes, particularmente $\mathrm{N}$ e $\mathrm{K}$, e pelo ritmo de crescimento, sendo normalmente baixa durante periodos de crescimento ativo e alta quando a temperatura é baixa ou a umidade é insuficiente, atrasando o crescimento da planta (Minson, 1990). Segundo Haag (1984), altas concentrações de K e Mg na solução do solo diminuem a absorção de $\mathrm{Ca}$, sendo que a falta deste elemento reduz o desenvolvimento e a absorção radicular.

Norton (1982) observou que $65 \%$ das amostras de capim tropical foram deficientes em Ca $\left(<4,3 \mathrm{~g} \mathrm{~kg}^{-1}\right)$ para animais em crescimento, embora Minson (1990) afirme que, provavelmente, as exigências de $\mathrm{Ca}$ publicadas para ruminantes sejam superestimadas, sendo $4 \mathrm{~g} \mathrm{~kg}^{-1}$ suficientes para a maioria das formas de produção, com exceção de ovinos com altas taxas de crescimento.

Segundo Haddad \& Platzek (1985), o P é o mineral mais deficiente em condições tropicais. Norton (1982), compilando diversos trabalhos, observou que em $63 \%$ das amostras de capim tropical a concentração de $P$ foi deficiente em relação às exigências animais e que todas as espécies contém baixas concentrações de $P$ em estádios de maturação avançados, independentemente da aplicação de fertilizante fosfatado.

Para Minson (1992), não existe diferença na concentração de $P$ nas folhas $e$ hastes, sendo a concentração de $P$ na planta dependente da sua disponibilidade no solo, assim, forragens produzidas em solos com baixos niveis de $P$ apresentam baixas concentrações do nutriente.

A redução na concentração de $P$ na planta, observada conforme esta cresce $e$ amadurece, ocorre a taxas que variam com a espécie e com o comprimento do período de mensuração, onde as maiores taxas de queda estão associadas a um curto período de crescimento ativo, sendo observada em $C$. dactylon redução média de $0,05 \mathrm{~g} \mathrm{P} \mathrm{kg}^{-1} \mathrm{dia}^{-1}$ (Minson, 1990).

A nutrição adequada de Ca e $P$ não depende apenas do suprimento destes minerais, sendo a relação Ca:P na dieta também importante. Segundo Underwood (1981), assume-se que uma relação Ca:P entre 1:1 e 2:1 seja a ideal para o 
crescimento e formação dos ossos, por ser próxima à relação observada nos mesmos. Entretanto, os ruminantes podem tolerar uma ampla faixa de relação Ca:P, particularmente quando o fornecimento de vitamina D for elevado. Para NRC (1996), os efeitos da relação Ca:P foram muito enfatizados no passado e vários estudos mostraram que relações Ca:P dietéticas entre 1:1 e 7:1 resultam em desempenhos similares desde que o consumo de $P$ seja adequado para atender às exigências. Segundo Church (1993), os bovinos, com exceção das vacas imediatamente antes do parto, podem tolerar relação de até 6:1; acima disto há redução na absorção de $P$ e no consumo de alimento; entretanto, não toleram relações iguais ou inferiores a 1,1:1.

Para Vrzgula \& Bartko (1991), as relações Ca:P ideais seriam: 1,25:1 a 1,5:1 para vacas em lactação; $1,2: 1$ a 1,8:1 para novilhas em crescimento; $1,2: 1$ a 1,6:1 para ovelhas em lactação e 1:1 a 1,4:1 para ovelhas em engorda; nas 4 a 6 semanas antes do parto, a relação deve ser 1:1 ou, no máximo, 1,5:1 para evitar a ocorrência de febre do leite.

Segundo Gross \& Jung (1981), um suprimento insuficiente de Ca ou $P$, ou relação Ca:P inadequada, pode estar relacionado à ocorrência de vários problemas: febre do leite, falha de reprodução, redução na conversão alimentar e no ganho de peso, cetose, redução na produção de leite, menor aproveitamento dos microminerais e distúrbios funcionais, como perda da tonicidade muscular. Porém, para Boin (1985), quando as exigências de $\mathrm{P}$ são atendidas, a relação $\mathrm{Ca}: \mathrm{P}$ deixa de ser importante, sendo observadas diferentes respostas quanto a relação Ca:P. Wise et al. (1963) forneceram a bezerros dietas com relações Ca:P variando de $0,4: 1$ a 14,3:1 e observaram desempenho satisfatório e similar com relações entre 1:1 e 7:1. Com relações abaixo de $1: 1$ e acima de 7:1, o crescimento e a eficiência alimentar decresceram significativamente. Segundo Underwood (1981), uma relação de 0,3:1 acelerou o aparecimento de sinais de deficiência de $\mathrm{Ca}$ em ovinos; relação de 10:1 não afetou a absorção de $P$ em dietas relativamente ricas em $P\left(2,6 \mathrm{~g} \mathrm{~kg}^{-1}\right)$, mas ocorreram desordens ósseas quando a dieta continha apenas $0,8 \mathrm{~g} \mathrm{P} \mathrm{kg}^{-1}$.

As vacas em lactação são mais tolerantes ao consumo elevado de $P$, possivelmente devido às maiores necessidades dietéticas e maiores consumos de $\mathrm{Ca}$. Dietas com niveis de $5,5 \mathrm{~g} \mathrm{P} \mathrm{kg}^{-1}$ não prejudicam a produção de leite, ainda que possam reduzir as taxas de ganho de peso em novilhos confinados (Church, 1993). 
Entretanto, com altos níveis de $P$, especialmente na presença de níveis relativamente baixos de $\mathrm{Ca}$ (concentração de $\mathrm{P}$ excedendo a de $\mathrm{Ca}$ ), há elevada incidência de cálculos urinários em ovinos, chegando a $50 \%$ de mortalidade quando a relação $\mathrm{Ca:P}$ for 0,5 (Minson, 1990).

O excesso de Ca na dieta pode inibir a utilização de $\mathrm{Fe}, \mathrm{Cu}$ e Zn (Vrzgula \& Bartko, 1991), sendo que a inibição da absorção de $\mathrm{Zn}$ é observada em monogástricos mas não em ruminantes (Church, 1993).

\section{Potássio}

As forragens são excelentes fontes de $K$ para os animais, contendo normalmente de 10 a $40 \mathrm{~g} \mathrm{~kg}^{-1}$ (NRC, 1996); porém, mais interessante que conteúdo de K na planta forrageira é o efeito do K sobre a absorção e disponibilidade fisiológica de outros minerais, afetando o estado nutricional e a saúde do animal. Quando o fornecimento de $\mathrm{K}$ para a planta é abundante, ocorre um consumo de luxúria do nutriente e normalmente há redução nos níveis de $\mathrm{Na}, \mathrm{Ca}$ e $\mathrm{Mg}$ na planta, podendo constituir um problema em situações de pastejo onde os niveis desses elementos na forragem são marginais em relação às necessidades animal (Reid \& Jung, 1974; Marschner, 1986).

Segundo Church (1993), o consumo elevado de K está associado à ocorrência de tetania das pastagens em animais e pode contribuir para a presença de edema de úbere, uma vez que o elevado consumo de $\mathrm{K}$ reduz a absorção de $\mathrm{Mg}$. $\mathrm{E}$, de fato, para NRC (1996), o alto conteúdo de $K$ em pastagens suculentas de primavera parece ser o principal fator associado à ocorrência de tetania das pastagens em vacas de corte.

Também é conhecido o fato da rebrota das pastagens provocar diarréia no gado. Isto se daria, além dos efeitos dos alcalóides, pela maior concentração de $\mathrm{K}$ em relação a outros cátions ( $\mathrm{Ca}, \mathrm{Mg}$ e $\mathrm{Na}$ ), provocando distúrbios no equilibrio osmótico do organismo (Haddad \& Platzeck, 1985).

Teores adequados de $K$ nas forragens em relação à nutrição animal não devem ser tomados como indicação de que a adubação potássica seja desnecessária, pois estes teores são bem inferiores aos requeridos para adequado 
crescimento e produtividade das pastagens (Werner, 1986), podendo o K chegar a ser um fator limitante do crescimento das forrageiras, sobretudo quando existe abundância de $\mathrm{N}$ e uso intensivo da área, como no caso de capineiras e silagens em que não há retorno de K pelas fezes e urina (Haag, 1984). Gonzalez \& Oilda (1982), ao avaliarem a concentração crítica de $\mathrm{K}$ em Coastcross-1, classificaram a forrageira como muito exigente neste nutriente, com valores em torno de $26 \mathrm{~g} \mathrm{~kg}^{-1}$. Entretanto, Martin \& Matocha (1973) consideraram teores acima de $23 \mathrm{~g} \mathrm{~K} \mathrm{~kg}^{-1}$ excessivos para a cultivar Coastal e que as gramas bermuda, ao contrário de muitas gramineas, normalmente não acumulam $K$ devido ao efeito de diluição causado pelo rápido crescimento dessas cultivares.

\section{Magnésio}

A maioria das forragens contém níveis de $\mathrm{Mg}$ superiores às necessidades dos ruminantes e os animais em pastejo raramente necessitam de forragem com mais de $2 \mathrm{~g} \mathrm{Mg} \mathrm{kg}^{-1}$. Entretanto, a absorção de $\mathrm{Mg}$ é afetada pelo $\mathrm{K}$ e pela amônia no rúmen; se a concentração destes forem altas, o Mg será absorvido em quantidade insuficiente mesmo que a forragem contenha nivel de $\mathrm{Mg}$ aparentemente adequado. O Mg é relativamente atóxico para o animal, embora seu consumo excessivo possa provocar diarréia (Church, 1993; Minson, 1990). Para Vrzgula \& Bartko (1991), Ca e Mg são considerados elementos antagônicos no trato gastrointestinal; doses elevadas de Ca diminuem a utilização do $\mathrm{Mg}$ e excessos de $\mathrm{Mg}$ reduzem a absorção de Ca.

As interações que envolvem o Mg são as mais importantes em regiōes temperadas, principalmente na primavera, quando o conteúdo de $\mathrm{Mg}$ na forragem diminui e de $\mathrm{N}, \mathrm{K}$ e ácidos orgânicos aumentam, provocando tetania das pastagens (Boin, 1985). Este distúrbio ocorre apenas em animais ruminantes, devido a baixos níveis de Mg na dieta ou a partir da utilização limitada do Mg dietético, e normalmente está associado à pastagens em fase de crescimento luxuriante durante o início da primavera (Fontenot et al., 1989; Lucci, 1989). Vrzgula \& Bartko (1991) supõem que a causa seja a mudança repentina de um alimento usual para pastagem jovem com crescimento luxuriante de primavera ou outono ou a transição súbita para forragem verde, sendo a principal causa o alto conteúdo protéico (acima de $250 \mathrm{~g} \mathrm{~kg}^{-1}$ ), o baixo 
conteúdo de fibra e de MS da pastagem jovem. Com tais pastagens há produção excessiva de amônia no rúmen, o que prejudica a absorção de $\mathrm{Mg}$.

Segundo Fontenot et al. (1989), a utilização do Mg é afetada pelos níveis de certos componentes dietéticos, principalmente através de alterações na sua absorção. Alimentos com alto nível de $\mathrm{K}$ geralmente deprimem a concentração sérica de $\mathrm{Mg} \mathrm{em}$ ruminantes e a absorção aparente do elemento, sendo este efeito maior a partir de $22,5 \mathrm{~g} \mathrm{~K} \mathrm{~kg}^{-1}$. A concentração sérica de $\mathrm{Mg}$ também é reduzida com o aumento dietético de $P$ (de 4 para $14 \mathrm{~g} \mathrm{~kg}^{-1}$ ) associado à baixa concentração de Ca. Há outros fatores dietéticos que deprimem a absorção de $\mathrm{Mg}$, porém, a alta concentração de $\mathrm{K}$ dietético é o fator com efeito maior e mais consistente. NRC (1996) cita também as altas concentrações dietéticas de $\mathrm{N}$, ácidos orgânicos, ácidos graxos de cadeia longa, Ca e $P$ que podem reduzir a absorção e utilização de $\mathrm{Mg}$, sendo, em pastagens de início de primavera, mais um problema de disponibilidade insuficiente do que baixa concentração de Mg na forragem per se.

Mesmo a ocorrência de tetania das pastagens sendo maior na primavera, periodos de rápido crescimento durante qualquer estação do ano, resultando em forragens com baixo teor de $\mathrm{Mg}$ e elevados teores de água, $\mathrm{N}$ e $\mathrm{K}$, apresentam condições dietéticas que aumentam o potencial para desenvolvimento do distúrbio (Robinson et al., 1989) e embora este ocorra especialmente em paises de clima temperado (Vrzgula \& Bartko, 1991) e nas condições brasileiras este problema ainda não seja importante, a intensificação da produção de ruminantes, principalmente no setor leiteiro, com o uso intensificado de adubos nitrogenados e potássicos, poderá provocar o aparecimento do problema em alguns casos (Boin, 1985), pois, segundo NRC (1996), o uso de pastagens fertilizadas com muito $\mathrm{N}$ e $\mathrm{K}$ está associado ao aumento da incidência do distúrbio.

As fêmeas ruminantes são as mais afetadas, principalmente nos estágios iniciais da lactação, provavelmente em função da exigência relativamente alta de Mg. A incidência aumenta em fêmeas mais velhas, cuja capacidade de mobilização de $\mathrm{Mg}$ dos ossos é limitada (Fontenot et al., 1989; Lucci, 1989). Segundo Van Soest (1994), a ocorrência de tetania das pastagens em vacas lactantes pode estar relacionada à febre do leite com baixa concentração de Ca sangüineo ou cetose nervosa. 
Kemp \& 't Hart (1957) observaram que a relação $\mathrm{K}$ (Ca+Mg) na pastagem está significativamente relacionada à incidência de tetania das pastagens, sendo maior quando a relação supera o valor 2,2 (em base miliequivalente). Para Robinson et al. (1989), mesmo a concentração de $\mathrm{Mg}$ sendo superior em forragens jovens, a incidência do distúrbio é maior nesta fase devido à maior relação $\mathrm{K}:(\mathrm{Ca}+\mathrm{Mg})$.

Segundo Minson (1990), em forragens com relação $\mathrm{K}:(\mathrm{Ca}+\mathrm{Mg})$ superior a 3 , a incidência de tetania entre vacas pode exceder 15\%, porém, o autor critica o uso desta relação para avaliar a incidência de tetania por não considerar o efeito da PB na absorção de $\mathrm{Mg}$. Esta falha teria sido superada em trabalhos realizados na Nova Zelândia, onde a predição do $\mathrm{Mg}$ sérico é em função da concentração de $\mathrm{Mg}, \mathrm{K}$ e PB na forragem. Gross \& Jung (1978) recomendam, no caso de forrageiras com elevada concentração de $\mathrm{Ca}$, usar a relação $\mathrm{K}: \mathrm{Mg}$, pois a relação $\mathrm{K}:(\mathrm{Ca}+\mathrm{Mg})$ não se aplica nesta condição. Entretanto, não há um valor crítico definido para a relação $\mathrm{K}: \mathrm{Mg}$, servindo apenas para comparações entre cultivares.

Grunes \& Welch (1989) recomendam, como nivel seguro de $\mathrm{Mg}, 2 \mathrm{~g} \mathrm{~kg}^{-1}$ para vacas lactantes ou prenhas, e, se os níveis de $\mathrm{N}$ e $\mathrm{K}$ são altos, a concentração de $\mathrm{Mg}$ de ser no mínimo $2,5 \mathrm{~g} \mathrm{~kg}^{-1}$. Concentrações acima de $40 \mathrm{~g} \mathrm{~N}$ e $30 \mathrm{~g} \mathrm{~K} \mathrm{~kg}^{-1}$ são consideradas prejudiciais. Para Mayland \& Wilkinson (1989), $2,5 \mathrm{~g} \mathrm{Mg} \mathrm{kg}^{-1}$ seriam suficientes para evitar tetania das pastagens em gramíneas com $30 \mathrm{~g} \mathrm{~N}$ e $25 \mathrm{~g} \mathrm{~K} \mathrm{~kg}^{-1}$. Vrzgula \& Bartko (1991) consideram 2,5 a $3,0 \mathrm{~g} \mathrm{Mg} \mathrm{kg}^{-1}$ como nível ótimo na forrageira.

Na planta, a absorção de $\mathrm{Mg}$ depende do nivel de $\mathrm{K}$ no substrato e se a proporção $\mathrm{K}: \mathrm{Mg}$ for alta, há redução na absorção de $\mathrm{Mg}$, podendo a planta ficar deficiente nesse mineral (Haag, 1984). A concentração de Mg na planta também está relacionada a proporção do nutriente na CTC do solo, sendo que abaixo de $5 \%$ da CTC provavelmente estará ocorrendo deficiência de $\mathrm{Mg}$ na planta. Para uma disponibilidade adequada do $\mathrm{Mg}$ do solo para a planta, a proporção $\mathrm{K}: \mathrm{Mg}$ (base molar) deverá ser 2 (Mayland \& Wilkinson, 1989).

A deficiência de $\mathrm{Mg}$ nas gramíneas ocorre quando a concentração deste elemento decresce abaixo de $1,3 \mathrm{~g} \mathrm{~kg}^{-1}$ (Mayland \& Wilkinson, 1989). A concentração de $\mathrm{Mg}$ na parte aérea da planta pode ser reduzida através do suprimento de $\mathrm{K}$ e $\mathrm{Ca}$, que atuam negativamente na translocação líquida de $\mathrm{Mg}$ das raizes para a parte 
aérea (Grunes \& Welch, 1989).

\section{Enxofre}

Normalmente, a necessidade de $S$ para ruminantes é expressa na forma de relação N:S (Church, 1993), sendo também um dos parâmetros mais indicados para avaliar o estado nutricional da planta quanto ao enxofre, pois mantém-se relativamente constante nos diversos estádios de desenvolvimento, tendendo a estabilizar em 14:1 quando as gramíneas atingem a maturidade (Vitti \& Novaes, 1986; Follett \& Wilkinson, 1995). Para máxima produção vegetal é desejável relação N:S de 12:1 a 15:1 (Follett \& Wilkinson, 1995) e, segundo Reid \& Jung (1974), o valor desejável para ótimo crescimento da planta é, em geral, ligeiramente mais alto que o ideal para a nutrição de ruminantes. Assim, sendo a forragem o único alimento disponivel, pode ocorrer uma deficiência de S para o ruminante (Vitti \& Novaes, 1986).

Segundo Church (1993), a relação N:S ideal é, geralmente, 15:1 para bovinos e 10:1 a 12:1 para ovinos. Little (1982) recomenda N:S de 14:1 e, para Van Soest (1994), a relação N:S exigida pelos microrganismos ruminais é 12:1. Outros autores sugerem intervalos de relação N:S considerados ideais para ruminantes, como 10:1 a 15:1 (Reid \& Jung, 1974) e 13,5:1 a 15:1 (Vitti \& Novaes, 1986).

Follett \& Wilkinson (1995) citam valores críticos de alguns micronutrientes para as plantas em geral (Tabela 8).

Tabela 8. Concentração critica de micronutrientes nas plantas.

\begin{tabular}{lccc}
\hline & \multicolumn{3}{c}{ Concentração $\left(\mathrm{mg} \mathrm{kg}^{-1}\right)$} \\
\cline { 2 - 4 } & deficiente & normal & tóxica \\
\hline Boro & $<5$ & $5-30$ & $>75$ \\
Cobre & 4 & $4-15$ & $>20$ \\
Manganês & & $15-100$ & 500 \\
Zinco & $<15$ & $8-15$ & $>200$ \\
\hline
\end{tabular}

Adaptado de Follett \& Wilkinson (1995).

Entre os micronutrientes, o Mn é provavelmente o mais notadamente afetado 
pelas mudanças de $\mathrm{pH}$ do solo, reduzindo a sua disponibilidade com o aumento do $\mathrm{pH}$. Co, B, Cu e Zn também são afetados por mudanças no pH do solo, mas os efeitos com Cu e Zn são geralmente menores (Fleming, 1973). No solo, é muito estreita a faixa entre os niveis de deficiência e toxicidade de B para as plantas, sendo que sua disponibilidade decresce com o aumento do pH (Mattos \& Colozza, 1986).

O conteúdo de Fe das forragens é altamente variável, sendo a maioria entre 70 e $500 \mathrm{mg} \mathrm{kg}^{-1}$, e grande parte desta variação é causada por contaminação pelo solo (NRC, 1996).

Cobre

Após o $\mathrm{P}$, o $\mathrm{Cu}$ é provavelmente o mineral mais limitante para bovinos em pastejo na América Latina. A deficiência de $\mathrm{Cu}$ nos animais é induzida pela baixa concentração de $\mathrm{Cu}$ na forragem e também quando concentrações normais de $\mathrm{Cu}$ são inadequadas devido à interações com Mo, S e outros fatores (Fick et al., 1978). $O$ aumento da concentração de Mo e S na dieta reduz a absorção e retenção do $\mathrm{Cu}$ pelo animal, sendo a absorção de $\mathrm{Cu}$ também reduzida pelo $\mathrm{Cd}, \mathrm{Fe}$ e $\mathrm{Zn}$. $\mathrm{A}$ deficiência de $\mathrm{Cu}$ em bovinos normalmente é limitada ao seu primeiro ano, mas se a concentração de Mo na forragem for alta, os sintomas de deficiência de Cu podem ocorrer além dos 3 anos de idade. Bovinos pastejando forragem contendo menos de $3 \mathrm{mg} \mathrm{Cu} \mathrm{kg}{ }^{-1}$ apresentam sinais de deficiência de $\mathrm{Cu}$ e alta incidência de infertilidade (Minson, 1990).

As exigências animais de $\mathrm{Cu}$ podem variar de $4 \mathrm{mg}$ a mais de $15 \mathrm{mg} \mathrm{kg}^{-1}$, dependendo principalmente da concentração de Mo e $S$ na dieta. A concentração de Cu recomendada para a dieta de gado de corte é $10 \mathrm{mg} \mathrm{kg}^{-1}$, sendo esta quantidade suficiente para suprir o $\mathrm{Cu}$ adequadamente se a dieta não conter mais que $2,5 \mathrm{~g} \mathrm{~S}$ e $2 \mathrm{mg} \mathrm{Mo} \mathrm{kg}{ }^{-1}$ (NRC, 1996).

A concentração de Cu na forragem depende da disponibilidade do nutriente no solo (Minson, 1990), sendo de valor limitado para assegurar adequado fornecimento de $\mathrm{Cu}$ a menos que as concentrações de antagonistas, tais como Mo, S e Fe, também sejam consideradas (NRC, 1996).

A presença de ions de $\mathrm{Fe}, \mathrm{Mn}$ e Al em quantidades excessivas podem reduzir 
a disponibilidade de Cu para as plantas (Mattos \& Colozza, 1986).

\section{Manganês}

A ocorrência de deficiência de $\mathrm{Mn}$ em ruminantes é rara e o consumo em excesso pode ser tóxico, reduzindo o crescimento animal, o consumo voluntário e a eficiência alimentar. Concentrações de 75 a $200 \mathrm{mg} \mathrm{kg}^{-1}$ na dieta são consideradas ligeiramente excessivas, embora os bovinos e ovinos tolerem até $1000 \mathrm{mg} \mathrm{Mn} \mathrm{kg}{ }^{-1}$. Há interação entre $\mathrm{Mn}$ e outros elementos, sendo que o excesso de $\mathrm{Ca}$ ou $\mathrm{K}$ na dieta pode influenciar a utilização do Mn pelo animal (Church, 1993).

A concentração de Mn na planta está associada à disponibilidade do elemento no solo, que é influenciada diretamente pelo $\mathrm{pH}$ (aumento do $\mathrm{pH}$ do solo reduz disponibilidade de $\mathrm{Mn}$ ) (Minson, 1990); desbalanços em relação a $\mathrm{Ca}, \mathrm{Mg}$ e Fe podem causar deficiência de Mn na planta (Mattos \& Colozza, 1986).

Zinco

As forragens, especialmente as de baixa qualidade, geralmente contém concentrações de Zn abaixo dos niveis recomendados pelo NRC (1989a e 1996), mas as exigências de $\mathrm{Zn}$ têm sido estabelecidas principalmente em ruminantes consumindo forragens de alta qualidade ou dietas baseadas em concentrados, sendo superestimadas para ruminantes recebendo forragem devido às menores taxas de ganho (Spears, 1994). Segundo Minson (1990), dietas com 16 a 26 mg Zn kg${ }^{-1}$ seriam suficientes para ruminantes, raramente ocorrendo deficiência em ruminantes alimentados com forragem.

O teor de $\mathrm{Zn}$ na forragem está muito associado à disponibilidade do nutriente no solo, sendo mínima na faixa de $\mathrm{pH}$ entre 5,5 e 7,0 e aumenta quando a acidez é maior (Mattos \& Colozza, 1986). Segundo Haag (1984), o nivel crítico de Zn no solo é de $1,5 \mathrm{mg} \mathrm{dm}^{-3}$ e está associado a $14 \mathrm{mg} \mathrm{Zn} \mathrm{kg}^{-1}$ nos tecidos da planta, embora Minson (1990) afirme que não há valores críticos bem definidos para Zn.

Segundo Marschner (1986), altas concentrações de cátions bivalentes no solo, como $\mathrm{Ca}$, inibem parcialmente a absorção de $\mathrm{Zn}$. Excesso de $\mathrm{P}$ em solos com baixa disponibilidade de $\mathrm{Zn}$ pode induzir à deficiência de $\mathrm{Zn}$ e aumentar a exigência do 
nutriente pela planta, devido à sua diluição em função do crescimento favorecido pelo $\mathrm{P}$ e a adsorção de $\mathrm{Zn}$ do solo induzida pelo $\mathrm{P}$. Vários estudos indicam que há uma interação $\mathrm{P} \times \mathrm{Zn}$ adicional na planta, incluindo a inibição da translocação de $\mathrm{Zn}$ das raízes para as brotações e inativação biológica do elemento nas brotações.

\subsubsection{Composição mineral de capins do gênero Cynodon}

Sotomayor-Rios et al. (1974) avaliaram, em Porto Rico, o efeito da idade de corte sobre a composição química de 10 espécies forrageiras tropicais dos gêneros Brachiaria, Digitaria e Cynodon, submetidas a cortes aos 30, 45 e 60 dias de idade. Na média, o teor de MS aumentou de $220,7 \mathrm{~g}\left(30\right.$ dias) para $272,3 \mathrm{~g} \mathrm{~kg}^{-1}$ (60 dias), enquanto o teor de PB decresceu de $124,6 \mathrm{~g}$ para $81 \mathrm{~g} \mathrm{~kg}^{-1}$. O teor de Ca aumentou de $2,8 \mathrm{~g}$ para $4,4 \mathrm{~g} \mathrm{~kg}^{-1}$ e os de $\mathrm{P}$ e $\mathrm{K}$ reduziram de $2,7 \mathrm{~g}$ e $22,1 \mathrm{~g}$ para $1,7 \mathrm{~g} \mathrm{e}$ $15,5 \mathrm{~g} \mathrm{~kg}^{-1}$, respectivamente. O teor de $\mathrm{Mg}$ permaneceu constante $\left(2,6 \mathrm{~g} \mathrm{~kg}^{-1}\right)$. C. dactylon foi a espécie que apresentou maiores teores de MS (284 g e $328,7 \mathrm{~g} \mathrm{~kg}^{-1}$ aos 30 e 60 dias, respectivamente).

Ammerman et al. (1982) avaliaram a grama bermuda Suwanee (C. dactylon) cortada a 2, 4, 6, 8, 10 e 12 semanas. As concentrações de todos os minerais analisados (K, $\mathrm{Ca}, \mathrm{P}, \mathrm{Mg}, \mathrm{Na}, \mathrm{Fe}, \mathrm{Mn}$ e $\mathrm{Cu}$ ), com exceção a do $\mathrm{Zn}$ que não apresentou variação, decresceram com o avanço da idade. As concentrações de $K, P$, $\mathrm{Mg}$ e Fe decresceram aproximadamente $57 \%$ no periodo de 2 a 12 semanas; as de $\mathrm{Na}$ e Ca decresceram $38 \%$ no mesmo período.

Em Cuba, Oquendo et al. (1984) estudaram 4 variedades de C. dactylon (Bermuda Cruzada-1 e 2, Bermuda de Costa e Bermuda Alicia), cortadas a cada 4 a 5 semanas na época chuvosa e recebendo $40 \mathrm{~kg} \mathrm{~N} \mathrm{ha}^{-1}$ corte $^{-1}, 100 \mathrm{~kg} \mathrm{P}_{2} \mathrm{O}_{5}$ e $100 \mathrm{~kg}$ $\mathrm{K}_{2} \mathrm{O} \mathrm{ha}^{-1} \mathrm{ano}^{-1}$. A produção média de MS foi $2,94 \mathrm{Mg} \mathrm{ha}^{-1}$, com: $266,3 \mathrm{~g} \mathrm{MS} ; 133,5 \mathrm{~g}$ PB; $3,1 \mathrm{~g} \mathrm{P} ; 20,7 \mathrm{~g} \mathrm{~K} ; 3,9 \mathrm{~g} \mathrm{Ca} \mathrm{e} 1,6 \mathrm{~g} \mathrm{Mg} \mathrm{kg}^{-1}$. Os autores relataram a ocorrência de Helminthosporium.

Gomide et al. (1969b), avaliando a concentração de minerais, em Minas Gerais, de forrageiras tropicais (capim gordura, pangola, napier, quicuiu, bermuda Suwanee e capim sempre verde) cortadas a cada 4 semanas no período de 4 a 36 semanas de idade, observaram redução nos teores de $K, P, \mathrm{Cu}$ e $\mathrm{Fe}$ em função do 
avanço da idade, enquanto nos teores de $\mathrm{Ca}, \mathrm{Mg}, \mathrm{Mn}$ e $\mathrm{Zn}$ não houve tendência alguma em relação a idade de corte. Em C. dactylon (bermuda Suwanee), foram observadas as seguintes reduções na concentração de minerais, no intervalo de 4 a 12 semanas de idade da planta: de $11,7 \mathrm{~g}$ para $5 \mathrm{~g} \mathrm{~K} \mathrm{~kg}^{-1}$; de $2,2 \mathrm{~g}$ para $1,5 \mathrm{~g} \mathrm{P} \mathrm{kg}^{-1}$; de $25,8 \mathrm{mg}$ para $16,9 \mathrm{mg} \mathrm{Cu} \mathrm{kg}{ }^{-1}$ e de $167 \mathrm{mg}$ para $102 \mathrm{mg} \mathrm{Fe} \mathrm{kg}^{-1}$. Para os demais nutrientes, as concentrações médias no mesmo período foram: $3,3 \mathrm{~g} \mathrm{Ca} ; 2,7 \mathrm{~g} \mathrm{Mg}$, $61 \mathrm{mg} \mathrm{Mn} \mathrm{e} 33 \mathrm{mg} \mathrm{Zn} \mathrm{kg}{ }^{-1}$.

Mathews et al. (1994) compararam três sistemas de pastejo (contínuo, 2 dias e 13 dias de pastejo) e um sistema de corte para fenação quanto à concentração de nutrientes em grama bermuda Callie cultivada na Flórida (EUA). A produção média de MS ( 8 cortes durante 2 anos) no sistema de fenação foi $2,4 \mathrm{Mg} \mathrm{ha}^{-1}$, semelhante aos sistemas de pastejo, porém, nestes últimos, os teores de $\mathrm{N}, \mathrm{K}$ e $\mathrm{S}$ na forragem foram superiores aos do sistema de fenação devido à reciclagem destes nutrientes. Os teores médios dos nutrientes no sistema de fenação foram: $21,8 \mathrm{~g} \mathrm{~N} ; 3,2 \mathrm{~g} \mathrm{P} ; 20,9 \mathrm{~g}$ $\mathrm{K} ; 4,3 \mathrm{~g} \mathrm{Ca} ; 2,2 \mathrm{~g} \mathrm{Mg} ; 3,6 \mathrm{~g} \mathrm{~S} ; 50 \mathrm{mg} \mathrm{Fe} ; 62 \mathrm{mg} \mathrm{Mn} ; 33 \mathrm{mg} \mathrm{Zn} \mathrm{e} 9$ mg Cu kg-1.

Palhano \& Haddad (1992) avaliaram a composição mineral do capim Coastcross- 1 em relação a idade de corte $(20,30,40,50,60$ e 70 dias) e verificaram decréscimo linear com a idade para todos os macronutrientes estudados $(N, K, C a$, $\mathrm{Mg}$ e S), com exceção do $\mathrm{P}$, cuja concentração decresceu de forma quadrática. As máximas concentrações de macronutrientes foram observadas aos 20 dias de crescimento ( $\left.30,5 \mathrm{~g} \mathrm{~N} ; 2,7 \mathrm{~g} \mathrm{P} ; 17 \mathrm{~g} \mathrm{~K} ; 2,7 \mathrm{~g} \mathrm{Ca} ; 3,9 \mathrm{~g} \mathrm{Mg} \mathrm{e} 2 \mathrm{~g} \mathrm{~S} \mathrm{~kg}^{-1}\right)$, decrescendo com a idade $(14,1 \mathrm{~g} \mathrm{~N} ; 1,6 \mathrm{~g} \mathrm{P} ; 13,8 \mathrm{~g} \mathrm{~K} ; 1,6 \mathrm{~g} \mathrm{Ca} ; 2,8 \mathrm{~g} \mathrm{Mg} \mathrm{e} \mathrm{1,5} \mathrm{g} \mathrm{S} \mathrm{kg-1,} \mathrm{aos} 70$ dias). As concentrações de $\mathrm{B}, \mathrm{Fe}$ e $\mathrm{Mn}$ não diferenciaram significativamente em função da idade de corte (médias de $13,3 \mathrm{mg} \mathrm{B;} 227,8 \mathrm{mg} \mathrm{Fe}$ e $114,0 \mathrm{mg} \mathrm{Mn} \mathrm{kg}{ }^{-1}$, respectivamente). A concentração de $\mathrm{Cu}$ variou de forma cúbica (de 3,5 a $11,75 \mathrm{mg}$ $\mathrm{kg}^{-1}$, aos 60 e 70 dias, respectivamente) e a de $\mathrm{Zn}$ decresceu linearmente com a idade (de 35,3 para $11,5 \mathrm{mg} \mathrm{kg}^{-1}$ ).

\subsubsection{Acúmulo de minerais em forrageiras}

Segundo Robinson (1996), a remoção de nutrientes em forragens submetidas a corte é o resultado da produção da forragem e a concentração de nutrientes na 
cultura. Como a produção flutua mais que a concentração de nutrientes numa determinada faixa de condições, a produção é normalmente o principal determinante da remoção de nutrientes pela cultura. Em Palhano \& Haddad (1992), o acúmulo dos macronutrientes em Coastcross-1 deu-se de forma quadrática, com valores máximos aos 40 dias de crescimento (17 g N; $1,58 \mathrm{~g} \mathrm{P} ; 13,23 \mathrm{~g} \mathrm{~K} ; 1,81 \mathrm{~g} \mathrm{Ca} \mathrm{e} \mathrm{2,68} \mathrm{g} \mathrm{Mg} \mathrm{m}^{-2}$ ), com exceção do $S$, cujo acúmulo não variou com a idade (média de $1,2 \mathrm{~g} \mathrm{~S} \mathrm{~m}^{-2}$ ). $A$ produção de matéria seca deu-se também de forma quadrática, porém com valor máximo aos 60 dias.

\subsubsection{Fator antinutricional}

O ácido cianidrico ( $\mathrm{HCN}$ ) existe como um componente natural em muitas plantas e pode ser tóxico a animais em pastejo. Nas plantas, o cianeto só é encontrado na forma combinada, geralmente com um glicosídeo, sendo que, nas gramíneas, este composto é conhecido como 'Dhurrin'. O composto cianogênico pode ser acumulado em alguns tecidos sadios da planta em altas concentrações; quando o tecido é esmagado ou ingerido pelo animal ocorre hidrólise enzimática do composto, produzindo o HCN (Tapper \& Reay, 1973).

Com a introdução de novas espécies forrageiras, é importante conhecer quais podem ser potencialmente perigosas aos animais (Schroder, 1977; Harris et al., 1980). Segundo Mislevy \& Pate (1996), as gramas estrela (Florico, Florona, McCaleb e Ona) e Florakirk apresentam substancial quantidade de HCN. Porém, na Universidade da Flórida (EUA), o uso experimental e em larga escala destas pastagens, num período de 20 anos, não provocou nenhum efeito prejudicial nos animais que pudesse estar relacionado ao potencial cianogênico destas pastagens.

Os animais ruminantes são considerados muito suscetíveis ao envenenamento por HCN, pois a microflora ruminal é capaz de liberar as substâncias glicosídicas (Barnes \& Gustine, 1973). Os glicosideos cianogênicos são hidrolisados a HCN livre, que na corrente sangüínea provocam a paralisia respiratória à nível celular (Hegarty, 1982). Segundo Boyd et al. (1938), a dose letal mínima de HCN livre para intoxicação é da ordem de 2,0 a $2,3 \mathrm{mg} \mathrm{kg}^{-1}$ de peso vivo e concentraçöes a partir de $750 \mathrm{mg} \mathrm{kg}^{-1}$ (na matéria seca) são considerados perigosos para animais ruminantes. Harris \& 
Shearer (1994) classificaram os níveis de $\mathrm{HCN}$ em forragens verdes quanto à periculosidade mediante pastejo: 0 a $100 \mathrm{mg} \mathrm{kg}^{-1}$ - adequado para pastejo; 100 a $150 \mathrm{mg} \mathrm{kg}{ }^{-1}$ - possivelmente perigoso; 150 a $200 \mathrm{mg} \mathrm{kg}^{-1}$ - perigoso para pastejo; acima de $200 \mathrm{mg} \mathrm{kg}^{-1}$ - muito perigoso para pastejo.

Os níveis de HCN na planta variam conforme o genótipo, estado nutricional, estádio de crescimento, condições ambientais, o manuseio e armazenamento da amostra, a metodologia de extração do $\mathrm{HCN}$ e a parte da planta a ser analisada (Tapper \& Reay, 1973; Schroder, 1977). Em grama estrela Sumner foram detectados $396 \mathrm{mg} \mathrm{HCN} \mathrm{kg}^{-1}$ (na matéria verde) nas folhas e apenas $9 \mathrm{mg} \mathrm{kg}^{-1}$ no caule. Portanto, a menos que sejam tomados cuidados em relação a estes fatores, os valores encontrados podem não refletir corretamente a quantidade de HCN existente na planta e um simples valor de nivel de $\mathrm{HCN}$ pode não ser muito significativo (Schroder, 1977).

A idade da planta é um fator importante afetando o nível de $\mathrm{HCN}$, sendo este maior em tecidos jovens. Plantas mais velhas, com maiores proporções de hastes e bainhas, tecidos que contém baixo nivel de glicosídeos cianogênicos, são menos tóxicas (Tapper \& Reay, 1973). Aguilera ${ }^{3}$, citado por Herrera (1996), avaliou o potencial cianogênico de grama estrela e concluiu que este aumenta à medida que se coincide altas doses de nitrogênio, intensas precipitações e baixa luminosidade. 0 inverso é observado com a maturação da planta e com o aumento do tempo transcorrido depois do corte da pastagem. Castro (1997) não observou diferença significativa no teor de HCN em Florico em função da idade de corte, tendo analisado o capim a cada 10 dias, entre 20 e 70 dias de idade. A concentração de HCN na matéria verde variou entre 68,2 e $109,0 \mathrm{~g} \mathrm{~kg}^{-1}$.

Schroder (1977) avaliou o nível de HCN com base no peso verde após aplicação de $336 \mathrm{~kg} \mathrm{~N} \mathrm{ha}^{-1}$ em diversas gramas bermuda cortadas a intervalos de 1, 2, 3 e 4 semanas. Não foi detectada a presença de HCN na cultivar Coastal. Para as demais gramas bermuda, foram observados os seguintes niveis de HCN com 1, 2, 3 e 4 semanas de intervalo entre cortes, respectivamente: Coastcross-1: 193, 117, 56 e

\footnotetext{
${ }^{3}$ AGUILERA, J.M. Contribucion al estudio de la fertilización nitrogenada, la época y la edad de rebrote
} en el potencial cianogénico del pasto estrella. La Habana, 1983. Tese (Doutorado) - CENSA. 
26 mg kg ${ }^{-1}$; híbrido 74-68: 412, 141, 64 e $68 \mathrm{mg} \mathrm{kg}^{-1}$; Callie: 104, 52, 16 e 0 mg kg-1. Estas concentrações com base na matéria seca são aproximadamente 4 vezes maiores, pois os teores de MS destas forragens variaram de 220 a $260 \mathrm{~g} \mathrm{~kg}^{-1}$. A redução nos teores de $\mathrm{HCN}$ com o aumento da idade da planta também foi observada por Vélez-Santiago et al. (1979), ao avaliarem 10 cultivares de Cynodon.

Segundo Mislevy \& Pate (1996), o conteúdo de HCN pode ser mantido nos niveis normais através da adoção de práticas culturais como a) limitar os niveis de fertilização nitrogenada, b) atrasar o pastejo por 2 a 3 semanas após fertilização nitrogenada e c) não colocar animais excessivamente famintos em pastagens com alta fertilização nitrogenada e suculentas, especialmente se o gado não estiver acostumado com a pastagem. Estes procedimentos não têm significado para pastagens cortadas para feno ou silagem, pois o conteúdo de $\mathrm{HCN}$ em forragens desidratadas ou ensiladas é reduzido nos processos de secagem ou fermentação. $O$ enxofre também pode ser usado para detoxicar o $\mathrm{HCN}$, através da formação de tiocianeto, devendo para tal ser adicionado $1,2 \mathrm{~g} \mathrm{~S}$ por grama de HCN (Bird et al. ${ }^{4}$, citado por Durand \& Komisarczuk, 1988).

\subsection{Produção de forragem em Cynodon}

$\mathrm{Na}$ Tabela 9 são apresentados resultados de experimentos realizados na Flórida (EUA), onde cultivares de Cynodon foram submetidas a cortes freqüentes durante a estação quente (Mislevy et al., 1995). No experimento A, a Florakirk foi a cultivar mais produtiva no período (12,8 $\mathrm{Mg} \mathrm{MS} \mathrm{ha-1} \mathrm{ano}^{-1}$ ), embora a produção tenha decrescido ao longo dos 6 anos (19,5 $\mathrm{Mg} \mathrm{ha}^{-1}$ no primeiro ano e $7,2 \mathrm{Mg} \mathrm{ha}^{-1}$ no sexto ano). O crescimento de Tifton 78 e Tifton 44 foi severamente afetado pela ocorrência de geada no quarto ano de experimento, a partir da qual a produção foi praticamente nula. Nos experimentos B e C, a Florakirk também foi a mais produtiva $(15,5$ e 14,6 Mg MS ha ${ }^{-1}$ ano $^{-1}$, respectivamente) e apresentou DIVMO superior às demais, embora

\footnotetext{
${ }^{4}$ BIRD, P.R.; WATSON, M.J.; CAYLEY, J.W.D. The sulphur requirements of ruminants and de $S$ and $N$ status of perennial pastures in southern Australia. In: Sulphur in forages. Dublin: An Foras Taluntais, 1978. p.228-250.
} 
o teor de PB (116 g kg-1) tenha sido inferior aos teores da Coastcross-1, Tifton $44 \mathrm{e}$ Tifton 78 (experimento C).

Tabela 9. Experimentos para avaliação de cultivares de Cynodon (sob corte) realizados na Flórida (EUA).

\begin{tabular}{clcccc}
\hline Experimento $^{(2)}$ & \multicolumn{1}{c}{ Observações } & Cultivar & $\begin{array}{c}\text { Produção } \\
\left(\mathrm{Mg} \mathrm{ha}^{-1} \mathrm{ano}^{-1}\right)\end{array}$ & $\begin{array}{c}\text { Proteina } \\
\left(\mathrm{g} \mathrm{kg}^{-1}\right)\end{array}$ & $\begin{array}{c}\text { DIVMO } \\
\left(\mathrm{g} \mathrm{kg}^{-1}\right)\end{array}$ \\
\hline A & duração: 6 anos & Florakirk & 12,8 & & \\
& 5 cortes/ano & Tifton 78 & 7,2 & & \\
\hline & intervalo(3): 4 semanas & Tifton 44 & 6,3 & & 530 \\
\hline B & duração: 8 anos & Florakirk & 15,5 & & 460 \\
& 5 a 6 cortes/ano & Coastal & 14,1 & 550 \\
& intervalo: 4 a 5 semanas & Coastcross-1 & 11,9 & 490 \\
\hline \multirow{2}{*}{ C } & duração: 2 anos & Tifton 44 & 14,3 & & 610 \\
& 5 a 6 cortes/ano & Florakirk & 14,6 & 116 & 530 \\
& intervalo: 4 a 5 semanas & Coastal & 13,4 & 114 & 610 \\
& & Coastcross-1 & 13,0 & 120 & 560 \\
& & Tifton 44 & 10,3 & 117 & 570 \\
\hline
\end{tabular}

Adaptado de Mislevy et al. (1995).

(1) produção média anual (apenas durante a estação quente); ${ }^{(2)}$ adubações: experimento $\mathrm{A}=$ $325-162-162 \mathrm{~kg} \mathrm{ha}^{-1} \mathrm{ano}^{-1}$ de $\mathrm{N}-\mathrm{P}_{2} \mathrm{O}_{5}-\mathrm{K}_{2} \mathrm{O}$; experimento $\mathrm{B}$ e $\mathrm{C}=67-20-39 \mathrm{~kg} \mathrm{ha}^{-1}$ corte $^{-1} \mathrm{de} \mathrm{N}$ $\mathrm{P}_{2} \mathrm{O}_{5}-\mathrm{K}_{2} \mathrm{O}$ e micronutrientes; ${ }^{(3)}$ intervalo entre cortes.

Segundo Sollenberger et al. (1995), num estudo conduzido em sistema de produção de feno, em Gainesville (Flórida, EUA), as pastagens foram cortadas a cada 4 ou 6 semanas e as cultivares Florakirk, Tifton 85, Suwannee e Tifton 78 produziram 7,$95 ; 8,16 ; 7,31$ e $5,59 \mathrm{Mg} \mathrm{MS} \mathrm{ha}{ }^{-1}$, respectivamente (média dos dois tratamentos), sendo observadas as maiores produções nos cortes realizados a cada 6 semanas.

Larbi et al. (1990) avaliaram, em Ona (Flórida, EUA), o desempenho de novilhos em pastejo rotacionado de Cynodon, utilizando duas gramas estrela (Florico e Florona) e uma grama bermuda (Florakirk). Os teores de PB e DIVMO observados em Florakirk foram superior aos das demais, porém a produção de forragem e 0 
desempenho animal foram inferiores. Entretanto, esta superioridade das gramas estrela observadas em Ona não se confirmou em região mais fria, onde Williams (1991) obteve major persistência e produtividade com a cultivar Florakirk quando comparada com Florico e Florona.

Pedreira (1995), na região de Gainesville (Flórida, EUA), avaliou o ganho de peso de novilhas em pastejo contínuo e não observou diferença no ganho de peso médio diário entre as novilhas que pastejaram Tifton $85\left(0,51 \mathrm{~kg} \mathrm{dia}{ }^{-1}\right)$ e Florakirk $\left(0,54 \mathrm{~kg} \mathrm{dia}^{-1}\right)$. Entretanto, os maiores ganhos de peso por área foram obtidos com Tifton 85 devido à uma maior capacidade de suporte. Os resultados foram influenciados mais pela disponibilidade de forragem do que pelo valor nutritivo, tendo sido a concentração de PB superior na Florakirk e a DIVMO e FDN na Tifton 85. 


\section{MATERIAL E MÉTODOS}

\subsection{Localização do experimento}

O experimento foi conduzido na Fazenda Guará do Pinhal, propriedade particular situada no município de Itapetininga, Estado de São Paulo, ocupando 400 $\mathrm{m}^{2}$ de uma pastagem exclusiva da cultivar de grama bermuda Florakirk (Cynodon dactylon (L.) Pers.) implantada há um ano e destinada à produção de feno. As coordenadas geográficas do local são $23^{\circ} 42^{\prime} \mathrm{S}$ e $48^{\circ} 04^{\prime} \mathrm{W}$ e altitude de $680 \mathrm{~m}$.

\subsection{Clima}

O clima da região, conforme a classificação de Köppen, corresponde a $\mathrm{Cfa}$, ou seja, mesotérmico úmido, com verão quente e sem estação seca. As temperaturas máximas e mínimas registradas no ano são de $31,3^{\circ} \mathrm{C}$ e $8,3^{\circ} \mathrm{C}$, nos meses de janeiro e julho, respectivamente. A precipitação média anual é de $1134 \mathrm{~mm}$, sendo que nos meses de dezembro, janeiro e fevereiro ocorrem as maiores precipitações; julho é o mês mais seco (INSTITUTO AGRONÔMICO DE CAMPINAS, 1980). A precipitação pluvial do período experimental foi medida através de pluviômetro instalado na área, sendo apresentada na Tabela 10.

\subsection{Solo}

O solo onde foi conduzido o experimento é um Podzólico Vermelho Amarelo, distrófico, A moderado, textura média, com relevo plano.

Em dezembro de 1996 foi realizada uma amostragem de solo na profundidade de 0-25 cm, sendo os resultados apresentados na Tabela 11 . 
Tabela 10. Precipitação pluvial ocorrida no período experimental (20/01 a 26/03/1997). Fazenda Guará do Pinhal, Itapetininga, SP.

\begin{tabular}{|c|c|c|c|c|c|}
\hline Data & $\begin{array}{c}\text { Precipitação } \\
\text { pluvial } \\
\left(\mathrm{mm} \mathrm{dia}^{-1}\right)\end{array}$ & $\begin{array}{c}\text { Precipitação } \\
\text { acumulada } \\
(\mathrm{mm})\end{array}$ & Data & $\begin{array}{c}\text { Precipitação } \\
\text { pluvial } \\
\left(\mathrm{mm} \mathrm{dia}^{-1}\right)\end{array}$ & $\begin{array}{l}\text { Precipitação } \\
\text { acumulada } \\
(\mathrm{mm})\end{array}$ \\
\hline $21 / 01$ & 40 & 40 & $18 / 02$ & 12 & 466 \\
\hline $22 / 01$ & 117 & 157 & $19 / 02$ & 29 & 495 \\
\hline $23 / 01$ & 26 & 183 & $23 / 02$ & 10 & 505 \\
\hline $24 / 01$ & 25 & 208 & $24 / 02$ & 2 & 507 \\
\hline $25 / 01$ & 30 & 238 & $04 / 03$ & 43 & 550 \\
\hline $26 / 01$ & 36 & 275 & $06 / 03$ & 1 & 551 \\
\hline $27 / 01$ & 32 & 307 & $08 / 03$ & 10 & 561 \\
\hline $28 / 01$ & 2 & 309 & $11 / 03$ & 2 & 563 \\
\hline $02 / 02$ & 6 & 315 & $15 / 03$ & 5 & 568 \\
\hline $03 / 02$ & 12 & 327 & & & \\
\hline $04 / 02$ & 6 & 333 & $20 / 01$ a $09 / 02$ & & 337 \\
\hline $06 / 02$ & 5 & 338 & $10 / 02$ a $19 / 02$ & & 158 \\
\hline $10 / 02$ & 25 & 363 & $20 / 02$ a $01 / 03$ & & 12 \\
\hline $11 / 02$ & 13 & 376 & $02 / 03$ a $11 / 03$ & & 57 \\
\hline $12 / 02$ & 36 & 412 & $12 / 03$ a $21 / 03$ & & 5 \\
\hline $15 / 02$ & 42 & 454 & $22 / 03$ a $31 / 03$ & & 0 \\
\hline
\end{tabular}

Tabela 11. Resultados da análise química de terra da área experimental (profundidade: 0 a $25 \mathrm{~cm}$; amostragem: dezembro de 1996) ${ }^{(1)}$.

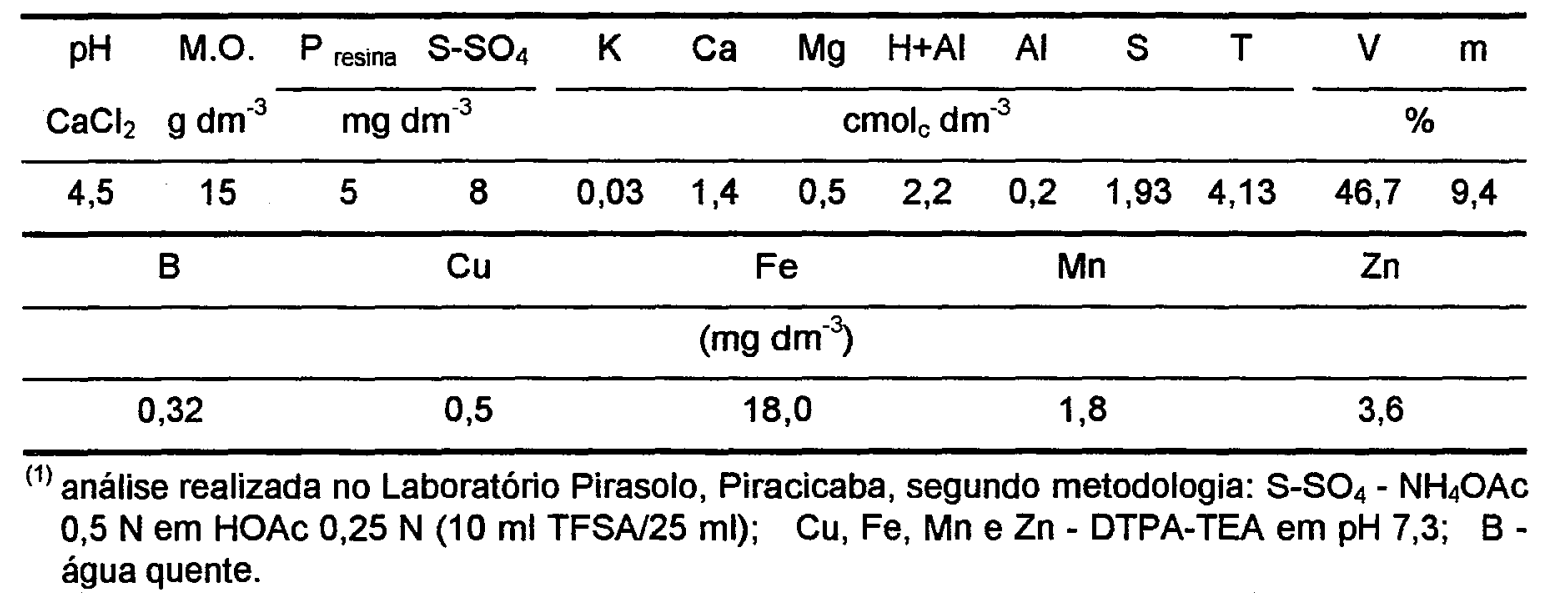




\subsection{Tratos culturais}

Dezessete dias antes do início do experimento (03/01/97) foi realizado um corte de rebaixamento da pastagem, permitindo assim a aplicação de corretivo e fertilizantes. Foram distribuídos por hectare: $5 \mathrm{Mg}$ de calcário dolomítico, $400 \mathrm{~kg}$ de sulfato de amônio ( $80 \mathrm{~kg} \mathrm{~N}$ e $96 \mathrm{~kg} \mathrm{~S} \mathrm{ha}^{-1}$ ) e $2 \mathrm{Mg}$ de Yoorin Master $\left(320 \mathrm{~kg} \mathrm{P}_{2} \mathrm{O}_{5}\right.$ solúvel em ácido cítrico a 2\%; $400 \mathrm{~kg} \mathrm{Ca;} 180 \mathrm{~kg} \mathrm{Mg} \mathrm{;} 2 \mathrm{~kg} \mathrm{~B} ; 1 \mathrm{~kg} \mathrm{Cu} ; 2,4 \mathrm{~kg} \mathrm{Mn;}$ $0,12 \mathrm{~kg} \mathrm{Mo}$ e $\left.11 \mathrm{~kg} \mathrm{Zn} \mathrm{ha}{ }^{-1}\right)$. As quantidades de corretivo e fertilizantes foram recomendadas por Haddad $^{5}$ em função dos resultados da análise de terra apresentados na Tabela 11.

Em 09/02/97 e 31/03/97 foram realizadas novas amostragens de solo na profundidade de 0 a $25 \mathrm{~cm}$, com o objetivo de acompanhar o efeito do corretivo e fertilizantes aplicados, e cujos resultados da análise estão na Tabela 12.

Tabela 12. Resultados da análise química de terra da área experimental (profundidade: 0 a $25 \mathrm{~cm}$; amostragem: fevereiro e março de 1997) ${ }^{(1)}$.

\begin{tabular}{|c|c|c|c|c|c|c|c|c|c|c|c|c|c|}
\hline \multirow[t]{2}{*}{ Data } & $\mathrm{pH}$ & M.O. & $P_{\text {resina }}$ & $\mathrm{S}-\mathrm{SO}_{4}$ & $\mathrm{~K}$ & $\mathrm{Ca}$ & $\mathrm{Mg}$ & $\mathrm{H}+\mathrm{Al}$ & Al & $\mathbf{S}$ & $\mathrm{T}$ & V & $m$ \\
\hline & \multicolumn{2}{|c|}{$\mathrm{CaCl}_{2} \mathrm{~g} \mathrm{dm}^{-3}$} & \multicolumn{2}{|c|}{$\mathrm{mg} \mathrm{dm}^{-3}$} & \multicolumn{7}{|c|}{$\mathrm{cmol}_{\mathrm{c}} \mathrm{dm}^{-3}$} & \multicolumn{2}{|c|}{$\%$} \\
\hline $09 / 02$ & 5,0 & 20 & 16 & 24,8 & 0,15 & 2,5 & 1,3 & 3,1 & 0 & 3,95 & 7,03 & 56,0 & 0 \\
\hline $31 / 03$ & 5,8 & 14 & 44 & 19,9 & 0,11 & 4,9 & 2,8 & 2,0 & 0 & 7,81 & 9,81 & 80,0 & 0 \\
\hline \multirow[t]{2}{*}{ Data } & \multicolumn{3}{|c|}{ B } & $\mathrm{Cu}$ & & \multicolumn{3}{|c|}{$\mathrm{Fe}$} & \multicolumn{2}{|c|}{$\mathrm{Mn}$} & \multicolumn{3}{|c|}{$\mathrm{Zn}$} \\
\hline & \multicolumn{13}{|c|}{$\left(\mathrm{mg} \mathrm{dm}^{-3}\right)$} \\
\hline $09 / 02$ & \multicolumn{2}{|r|}{0,18} & \multicolumn{3}{|c|}{0,48} & \multicolumn{3}{|c|}{52,0} & \multicolumn{2}{|c|}{2,1} & \multicolumn{3}{|c|}{1,9} \\
\hline $31 / 03$ & \multicolumn{2}{|r|}{0,37} & \multicolumn{3}{|c|}{0,80} & \multicolumn{3}{|c|}{60,0} & \multicolumn{2}{|c|}{5,1} & \multicolumn{3}{|c|}{3,8} \\
\hline
\end{tabular}

(1) análise realizada no Laboratório de Solos da ESALQ, segundo metodologia: $\mathrm{S}-\mathrm{SO}_{4}-\mathrm{NH}_{4} \mathrm{OAC}$ $0,5 \mathrm{~N}$ em HOAC 0,25 N (10 ml TFSA/25 ml); $\mathrm{Cu}, \mathrm{Fe}, \mathrm{Mn}$ e $\mathrm{Zn}$ - DTPA-TEA em pH 7,3; B $\mathrm{BaCl}_{2} .2 \mathrm{H}_{2} \mathrm{O} \quad 0,125 \%$ microondas (10 ml TFSA/20 ml BaCl $20,125 \%$ ).

Devido à uma modesta infestação de plantas daninhas (Brachiaria sp.), foi realizada capina manual, sendo repetida sempre que necessário.

\footnotetext{
${ }^{5}$ HADDAD, C.M. Comunicação pessoal, 1996.
} 
Observou-se a ocorrência de saúvas (Atta sp.), que foram controladas através da aplicação de iscas formicidas à base de sulfluramida (Mirex-S).

\subsection{Instalação do ensaio e amostragem}

O experimento iniciou-se em 20/01/97, quando a pastagem foi submetida a um corte de rebaixamento e uniformização, a $10 \mathrm{~cm}$ da superfície do solo, sendo removido da área o material cortado. Nesta data foram aplicados $400 \mathrm{~kg} \mathrm{ha}^{-1} \mathrm{de}$ cloreto de potássio ( $240 \mathrm{~kg} \mathrm{~K}_{2} \mathrm{O} \mathrm{ha}{ }^{-1}$ ). O experimento foi conduzido durante 70 dias, e neste período foram realizadas amostragens na pastagem a cada 10 dias, sendo a primeira 20 dias após o corte de rebaixamento, conforme Tabela 13.

Tabela 13. Datas das amostragens realizadas na pastagem de Florakirk.

Idade de corte

Data de realização do corte

(dias após o corte de rebaixamento)

\begin{tabular}{lll}
\hline 20 & $09 / 02 / 97$ \\
30 & $19 / 02 / 97$ \\
40 & $01 / 03 / 97$ \\
50 & $11 / 03 / 97$ \\
60 & $21 / 03 / 97$ \\
70 & $31 / 03 / 97$ \\
\hline
\end{tabular}

O delineamento experimental adotado foi blocos ao acaso, com 6 tratamentos (idades de corte de 20,30,40,50,60 e 70 dias após o rebaixamento) e 4 repetições, totalizando 24 amostragens, onde foram analisadas as seguintes variáveis:

- produção de matéria verde (MV);

- produção de matéria seca (MS);

- teor de matéria seca;

- teor de cinza;

- digestibilidade verdadeira in vitro da matéria seca (DVIVMS);

- digestibilidade verdadeira in vitro da matéria orgânica (DVIVMO);

- produção de matéria seca digestível (MSD); 
- produção de matéria orgânica digestível (MOD);

- teor de proteína bruta (PB);

- teor de fibra insolúvel em detergente neutro (FDN);

- teor de fibra insolúvel em detergente ácido (FDA);

- teor de hemicelulose;

- FDN digestível;

- composição mineral (macronutrientes: $\mathrm{N}, \mathrm{P}, \mathrm{K}, \mathrm{Ca}, \mathrm{Mg}$ e S; micronutrientes: $\mathrm{B}, \mathrm{Cu}$, $\mathrm{Fe}, \mathrm{Mn}$ e $\mathrm{Zn}$ );

- acúmulo de minerais;

- relação entre minerais (N:S, Ca:P, K:(Ca+Mg));

- teor de ácido cianídrico (HCN).

As amostragens foram realizadas com 0 auxílio de um quadrado de ferro de $1 \mathrm{~m}^{2}(1 \mathrm{~m} \times 1 \mathrm{~m})$, que foi arremessado aleatoriamente na área delimitada pelo bloco; o capim contido no interior do quadrado foi cortado a $10 \mathrm{~cm}$ da superfície do solo, utilizando-se tesoura de aço inoxidável. As áreas amostradas foram delimitadas com estacas e barbante para que não fossem novamente amostradas, sendo mantida uma bordadura de 0,5 $\mathrm{m}$ ao redor destas áreas.

O material colhido foi imediatamente pesado para determinação da produção de matéria verde. Cinqüenta gramas de capim verde de cada repetição foram picados e armazenados em vidro, juntamente com $60 \mathrm{ml}$ de uma solução de etanol e ácido ortofosfórico (250 ml e 6,8 $\mathrm{ml} \mathrm{litro}^{-1}$, respectivamente), e destinados à análise de $\mathrm{HCN}^{6}$. O restante do material foi acondicionado em sacos plásticos vedados para posterior determinação do teor de matéria seca. Todo material colhido foi transportado sob refrigeração (em caixas térmicas de isopor com gelo) ao Laboratório de Bromatologia do Departamento de Zootecnia da ESALQ/USP, em Piracicaba/SP.

No laboratório, o material destinado para a determinação do teor de matéria seca foi novamente pesado e submetido a lavagem com água destilada e deionizada, sendo finalmente acondicionado em sacos de papel e colocado em estufa de circulação forçada a $65^{\circ} \mathrm{C}$ durante 72 horas. Após este periodo, o material foi

\footnotetext{
${ }^{6}$ recomendação do Laboratório do Centro de Raízes Tropicais, UNESP, Botucatu.
} 
resfriado à temperatura ambiente e novamente pesado para determinação do teor de matéria seca (Association Official Analytical Chemists - AOAC, 1995). Em seguida procedeu-se a moagem do material em moinho tipo Wiley com peneira de $1 \mathrm{~mm}$. $O$ material foi homogeneizado e armazenado em sacos plásticos para posteriormente ser analisado.

O capim reservado para determinação do teor de $\mathrm{HCN}$ foi mantido sob refrigeração a $4^{\circ} \mathrm{C}$ até que fossem realizadas as análises laboratoriais.

\subsection{Análises laboratoriais}

A determinação da composição mineral do tecido vegetal (macro e micronutrientes) foi realizada no Laboratório de Nutrição Mineral de Plantas do Departamento de Química da ESALQ/USP, sendo utilizadas as seguintes metodologias de análises químicas (Malavolta et al., 1989):

- nitrogênio: método semimicro Kjeldahl;

- fósforo: colorimetria do metavanadato (fósforo total);

- potássio: fotometria de chama;

- cálcio, magnésio, cobre, ferro, manganês e zinco: espectrofotometria de absorção atômica;

- boro: colorimetria da azometina-H.

O enxofre foi determinado indiretamente em espectrofotometria de absorção atômica, com uso de sulfato de bário (Bataglia, 1976).

As análises de DVIVMS, DVIVMO, FDA e FDN foram realizadas no Laboratório de Bromatologia da ESALQ, em Piracicaba, e no Laboratório de Nutrição Animal da Universidade Federal de Goiás, em Goiânia, sendo DVIVMS e DVIVMO determinadas segundo método de Tilley \& Terry (1963) modificado por Tinnimit (1974); FDN e FDA através do método de Goering \& Van Soest (1970).

O fluído ruminal utilizado nos ensaios de digestibilidade verdadeira in vitro foi retirado de uma vaca holandesa fistulada que, num período de 7 dias anterior a coleta do fluído, recebeu a seguinte dieta: água, sal mineral, feno de capim Tifton 85 (fornecidos à vontade) e alimento concentrado $\left(1 \mathrm{~kg} \mathrm{dia}^{-1}\right)$ a base de milho, caroço de 
algodão, polpa cítrica peletizada, refinasil, tamponante e núcleo mineral. Além disso, o animal tinha acesso à um piquete de descanso formado com capim braquiária e grama estrela, cuja disponibilidade de forragem era muito reduzida.

O teor de PB foi calculado através da multiplicação do $\mathrm{N}$ total pelo fator 6,25 (AOAC, 1995).

O teor de $\mathrm{HCN}$ foi determinado por colorimetria no Laboratório do Centro de Estudos de Raízes Tropicais (CERAT) da UNESP em Botucatu/SP, segundo metodologia descrita por Wageningen (1993).

Determinou-se o teor de matéria seca das amostras em estufa a $105^{\circ} \mathrm{C}$ e todos os resultados baseados em matéria seca a $65^{\circ} \mathrm{C}$ foram corrigidos e expressos em matéria seca a $105^{\circ} \mathrm{C}$.

\subsection{Análises estatísticas}

Nas análises estatísticas foram utilizados os módulos SAS LAB e GLM do Sistema de Análises Estatísticas SAS (SAS Institute, 1988), onde foram obtidas as análises de variância, testes de comparação entre médias (teste $t$ de Student, ao nível de $5 \%$ ) e equações de regressão simples relacionando a idade de corte da pastagem e as variáveis em questão.

Em função de resultados obtidos na análises estatísticas, algumas variáveis foram transformadas e algumas observações foram excluídas para atender às hipóteses da análise de variância (SAS Institute, 1988).

O modelo estatístico utilizado está representado na Equação 1 (Mischan \& Pinho, 1996).

$$
y_{i j}=\mu+\alpha_{i}+\beta_{j}+e_{i j}
$$

onde: $y_{i j}=$ resposta correspondente ao i-ésimo tratamento no j-ésimo bloco;

$\mu=$ média geral;

$\alpha_{\mathrm{i}}=$ efeito devido ao i-ésimo nivel do fator (tratamento);

$\beta_{\mathrm{j}}=$ efeito do j-ésimo bloco;

$e_{i j}=$ erro devido à ij-ésima parcela. 


\section{RESULTADOS E DISCUSSÃO}

Entre os cortes de 30 e 40 dias de idade, foram observados sintomas de mancha foliar e mancha foliar preta, doenças causadas pelos patógenos Bipolaris spp. e Phyllachora spp. ${ }^{7}$, respectivamente. As folhas infectadas foram principalmente as basais, que apresentaram aspecto seco e manchas características das doenças, com sintomas semelhantes aos descritos por Smiley et al. (1992) e Ricci Jr. et al. (1981). A área ao redor do experimento não estava sendo submetida a corte, o que pode ter favorecido a ocorrência de doenças. Para o controle foi utilizado fungicida à base de triazol (Tilt), com aplicação de 5 litros do produto comercial por hectare.

Pedreira (1995) observou, em área de pastejo contínuo de Florakirk, uma redução no estande no fim do primeiro ano de experimento associada à ocorrência de Helminthosporium spp. (Bipolaris), embora, segundo o autor, tal fungo não seja letal e não tenha ocorrido subpastejo (condição em que, segundo Mislevy et al. (1995), há maior incidência da doença). Não foi possível determinar se a perda de estande de Florakirk foi em resposta ao manejo da pastagem, à ocorrência da doença ou à uma combinação destes fatores com outras contribuiçōes do ambiente de crescimento. Em pastejo rotacionado observou-se boa persistência da Florakirk.

O capim Florakirk mostrou-se suscetivel ao ataque de cigarrinha das pastagens (Deois spp.), e, na presença destas, as folhas apresentaram aspecto amarelado, podendo estar associado à ocorrência da cigarrinha. A infestação ocorreu principalmente no início do experimento, quando então foi aplicado inseticida biológico à base de fungo entomopatogênico Metarhizium anisopliae, conforme recomendação de Silveira Neto et al. (1994).

Entre os cortes de 40 e 50 dias de idade, ocorreu infestação de lagarta

\footnotetext{
${ }^{7}$ identificação realizada pela Clínica Fitopatológica do Departamento de Fitopatologia, ESALQ, USP.
} 
curuquerê-dos-capinzais (Mocis latipes), sendo controlada através de inseticida organofosforado (Lorsban), com aplicação de 1 litro do produto comercial por hectare. Houve desfolha do capim numa pequena área do experimento.

\subsection{Produção de forragem}

As produções de MV e MS variaram significativamente e de forma quadrática com o aumento da idade de corte $(P<0,05)$, conforme apresentado na Tabela 14 e Figura 1a. A produção máxima de MV ocorreu aos 65 dias, com $542,2 \mathrm{~g} \mathrm{~m}^{-2}$, e de MS aos 70 dias, com $214,8 \mathrm{~g} \mathrm{~m}^{-2}$, segundo as equações de regressão (Figura 1a) e considerando-se apenas o intervalo de 20 a 70 dias sujeito à análise. As produções máximas de MV e MS não ocorreram no mesmo período devido ao aumento linear do teọr de matéria seca com o aumento da idade de corte (Figura 1b).

Tabela 14. Produção de matéria verde e seca $\left(\mathrm{g} \mathrm{m}^{-2}\right)$ e teor de matéria seca $\left(\mathrm{g} \mathrm{kg}^{-1}\right) \mathrm{da}$ parte aérea de Cynodon dactylon (L.) Pers. cv. Florakirk, em função da idade de corte ${ }^{(1)}$.

\begin{tabular}{ccccccc}
\hline $\begin{array}{c}\text { Dias após o } \\
\text { rebaixamento }\end{array}$ & $\begin{array}{c}\text { Matéria verde } \\
\left(\mathrm{g} \mathrm{m}^{-2}\right)\end{array}$ & $\begin{array}{c}\text { Matéria seca } \\
\left(\mathrm{g} \mathrm{m}^{-2}\right)\end{array}$ & \multicolumn{2}{c}{$\begin{array}{c}\text { Teor de matéria seca } \\
\left(\mathrm{g} \mathrm{kg}^{-1}\right)\end{array}$} \\
\hline 20 & 157,9 & $\mathrm{~d}$ & 41,4 & $\mathrm{f}$ & 261,4 & e \\
30 & 311,3 & $\mathrm{c}$ & 89,2 & $\mathrm{e}$ & 287,0 & $\mathrm{~d}$ \\
40 & 453,7 & $\mathrm{~b}$ & 137,8 & $\mathrm{~d}$ & 303,7 & $\mathrm{c}$ \\
50 & $467,0 \mathrm{~b}$ & 162,6 & $\mathrm{c}$ & $348,8 \mathrm{~b}$ \\
60 & $546,7 \mathrm{a}$ & 193,7 & $\mathrm{~b}$ & 356,1 & $\mathrm{~b}$ \\
70 & $539,6 \mathrm{a}$ & $215,8 \mathrm{a}$ & $401,3 \mathrm{a}$ \\
\hline C.V. (\%) & 9,9 & 9,1 & 3,1
\end{tabular}

(1) médias seguidas de mesma letra, na mesma coluna, não diferem estatisticamente pelo teste t de Student $(P>0,05)$. 
(a)

$Y_{M V}=-0,1884 X^{2}+24,457 X-251,56\left(R^{2}=0,982\right)$

$Y_{M S}=-0,0354 X^{2}+6,6468 X-76,98 \quad\left(R^{2}=0,998\right)$

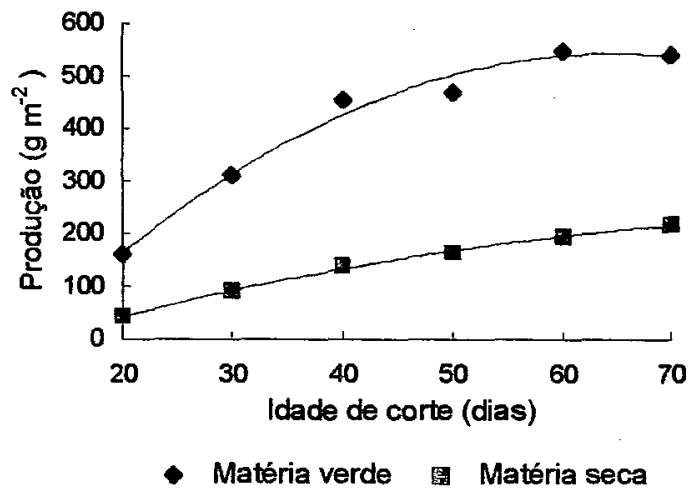

(b) $\quad Y=2,7195 X+203,99\left(R^{2}=0,974\right)$

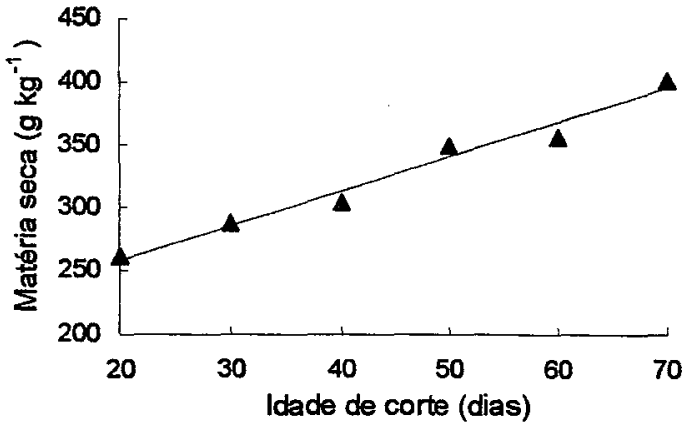

Figura 1 - Produção de matéria verde e matéria seca $\left(\mathrm{g} \mathrm{m}^{-2}\right)$ (a) e teor de matéria seca (g MS kg-1) (b) da parte aérea de Cynodon dactylon (L.) Pers. cV. Florakirk, em função da idade de corte.

Aumento no teor de MS também foi observado por Sotomayor-Rios et al. (1974) em Brachiaria, Digitaria e Cynodon (de 220,7 g para $272,3 \mathrm{~g} \mathrm{MS} \mathrm{kg}^{-1}$, dos 30 aos 60 dias de idade); porém, os teores médios observados em Florakirk (Tabela 14) foram elevados, quando comparados com os dados destes autores e de Oquendo et al. (1984), que, em 4 variedades de C. dactylon cortadas a cada 28 a 35 dias, obtiveram teor médio de 266,3 $\mathrm{g} \mathrm{MS} \mathrm{kg}^{-1}$. Castro (1997) observou em grama estrela Florico, submetida a cortes nas mesmas idades analisadas neste trabalho, teores de MS inferiores aos da Florakirk, sendo que o teor de MS observado nesta última aos 20 dias de idade $\left(261,4 \mathrm{~g} \mathrm{~kg}^{-1}\right)$ só foi atingido na Florico após 60 dias de idade. A produção de MS de Florico variou de 154 a $1099 \mathrm{~g} \mathrm{~m}^{-2}$, no período de 20 a 70 dias de idade.

A produção de MS foi inferior à observada em Gomide (1996), onde a produção de Florakirk foi $361,1 \mathrm{~g} \mathrm{e} 805,9 \mathrm{~g} \mathrm{~m}^{-2}$, aos 21 e 70 dias, respectivamente, e em Palhano \& Haddad (1992), com produção mínima em Coastcross-1 de $569,8 \mathrm{~g} \mathrm{~m}^{-2}$ (aos 20 dias) e máxima de $916,5 \mathrm{~g} \mathrm{~m}^{-2}$ (aos 60 dias). A produção obtida correspondeu apenas a $11,5 \%$ e $26,8 \%$ da produção apresentada por Gomide (1996) aos 21 e 70 dias, respectivamente. 
Mislevy et al. (1995) apresentaram como produção potencial de MS de Florakirk, submetida a corte com 28 a 35 dias de crescimento, 3,4 a 4,5 $\mathrm{Mg} \mathrm{ha}^{-1}$ (adubação de 78-34-67 kg ha-1 de $\mathrm{N}-\mathrm{P}_{2} \mathrm{O}_{5}-\mathrm{K}_{2} \mathrm{O}$ e micronutrientes). Apesar das adubações realizadas e das condições climáticas favoráveis, a produção observada neste trabalho atingiu apenas $25 \%$ deste potencial. A baixa produção de MS pode ser resultado da ocorrência de cigarrinha das pastagens no início do crescimento ou, ainda, devido à ocorrência de doenças.

Segundo critérios de Raij et al. (1996), os teores de S, K e B no solo (Tabela 12), observados no corte de 20 dias, foram considerados baixos. Os teores de $P, \mathrm{Cu} e$ Mn no solo são considerados médios, enquanto os de $\mathrm{Ca}, \mathrm{Mg}, \mathrm{Fe}$ e $\mathrm{Zn}$ são altos. $\mathrm{A}$ disponibilidade dos nutrientes do solo para as plantas pode ter sido afetada pela acidez do solo, classificada como alta para a amostragem aos 20 dias de idade, embora aos 70 dias seja considerada baixa. Comparando com as recomendações de Mislevy et al. (1995), o valor de pH do solo atingiu a faixa adequada de 5,5 a 6,5 (em água); o teor de Ca no solo no início do experimento foi próximo ao recomendado $\left(2,75\right.$ a $\left.3,25 \mathrm{cmol}_{\mathrm{c}} \mathrm{dm}^{-3}\right)$, entretanto, no final do período, esteve acima do indicado.

Observou-se um crescimento inicial do capim muito lento e de forma desuniforme. Até os 50 dias de idade, predominou um desenvolvimento de folhas eretas (folhas 'espetadas') e de coloração clara, com perfilhamento e propagação dos estolões reduzidos. No corte aos 50 dias foram observadas as primeiras inflorescências.

Aos 60 dias de idade, observou-se inflorescências em toda a área experimental e, a partir desta data, as plantas começaram a apresentar arquitetura foliar mais próxima do padrão da cultivar, coloração mais escura e aspecto mais vistoso.

\subsection{Composição bromatológica e digestibilidade verdadeira}

Os resultados da análise bromatológica e da digestibilidade verdadeira in vitro estão apresentados na Tabela 15. Todas as variáveis analisadas diferiram significativamente em função da idade de corte $(P<0,05)$ e suas respectivas equações de regressão estão apresentadas na Figura 2. 
Tabela 15. Teores de cinza, proteina bruta (PB), fibra insolúvel em detergente neutro (FDN) e ácido (FDA) e hemicelulose na matéria seca, digestibilidade verdadeira in vitro, FDN digestível e produção de matéria digestível $\left(\mathrm{g} \mathrm{m}^{-2}\right)$ da parte aérea de Cynodon dactylon (L.) Pers. cv. Florakirk, em função da idade de corte ${ }^{(1)}$.

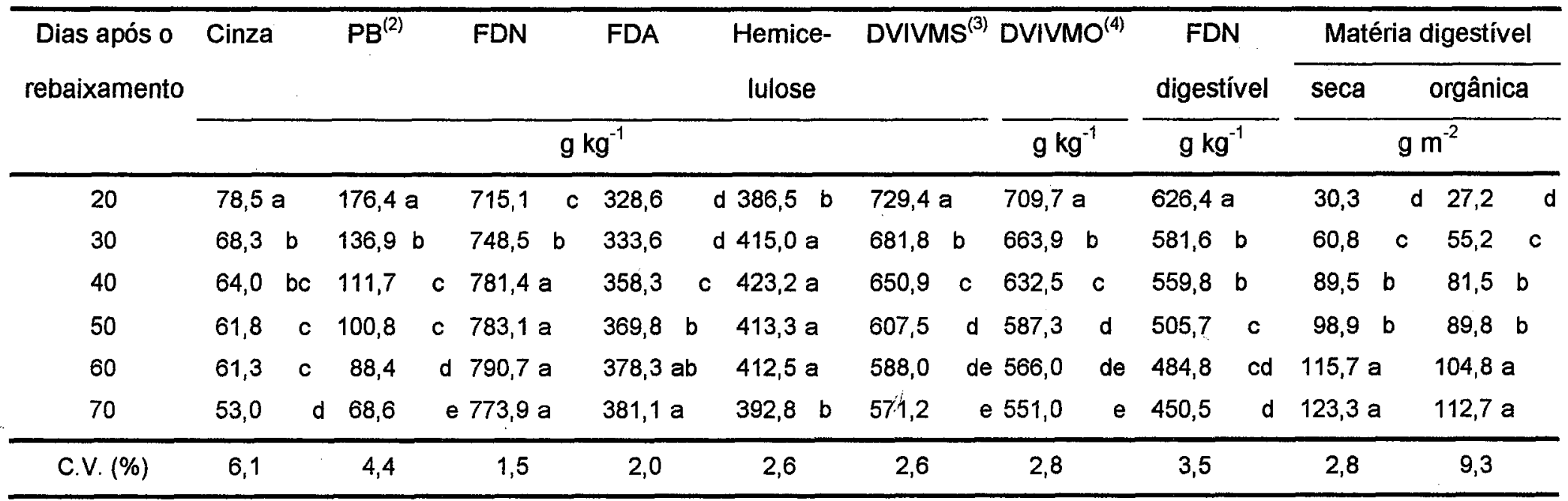

(1) médias seguidas de mesma letra, na mesma coluna, não diferem estatisticamente pelo teste t de Student $(P>0,05)$;

${ }^{(2)}$ transformação de variável: $\mathrm{PB}=1 / \sqrt{ } \mathrm{x}$;

(3) digestibilidade verdadeira in vitro da matéria seca;

${ }^{(4)}$ digestibilidade verdadeira in vitro da matéria orgânica. 

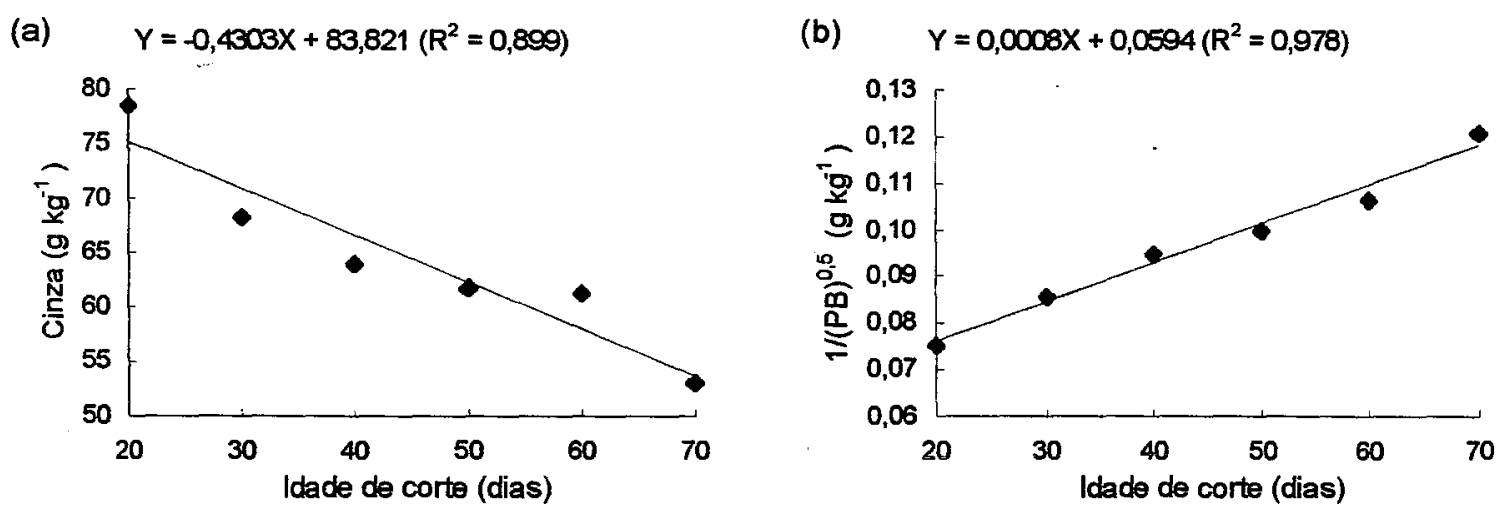

(c) $\quad Y=-0,0629 X^{2}+6,866 X+602,15\left(R^{2}=0,982\right)$

(d) $\quad Y=-0,0135 X^{2}+2,3803 X+282,39\left(R^{2}=0,962\right)$
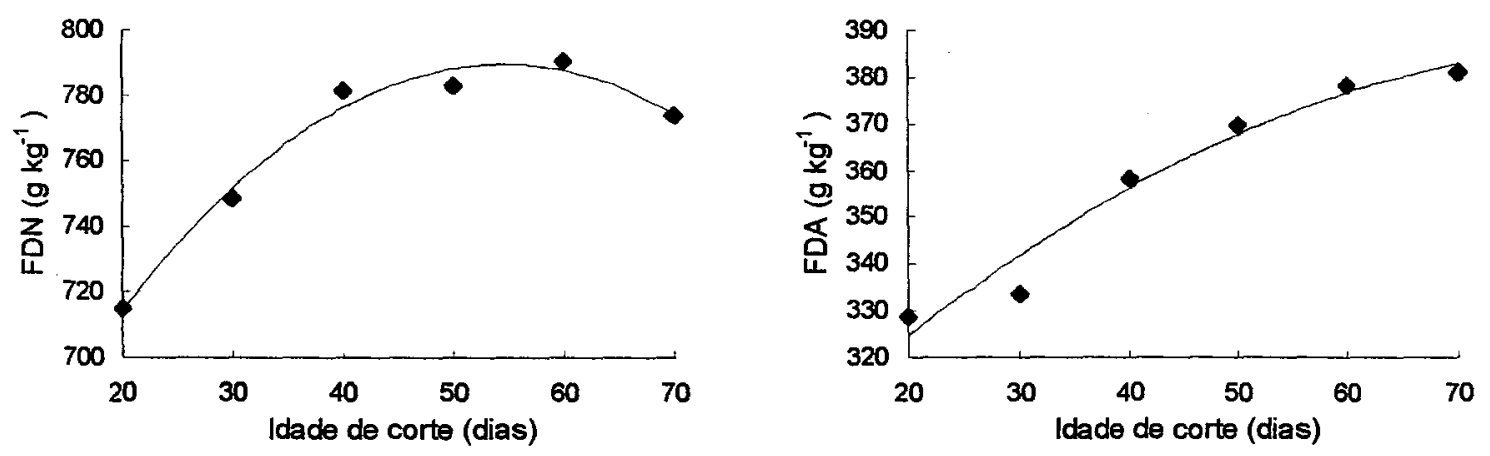

(e) $Y=-0,0494 X^{2}+4,4857 X+319,76\left(R^{2}=0,900\right)$

(f)

$$
\begin{aligned}
& Y_{M S}=0,0356 X^{2}-6,3938 X+843,32\left(R^{2}=0,996\right) \\
& Y_{M O}=0,0347 X^{2}-6,358 X+824,14\left(R^{2}=0,995\right)
\end{aligned}
$$
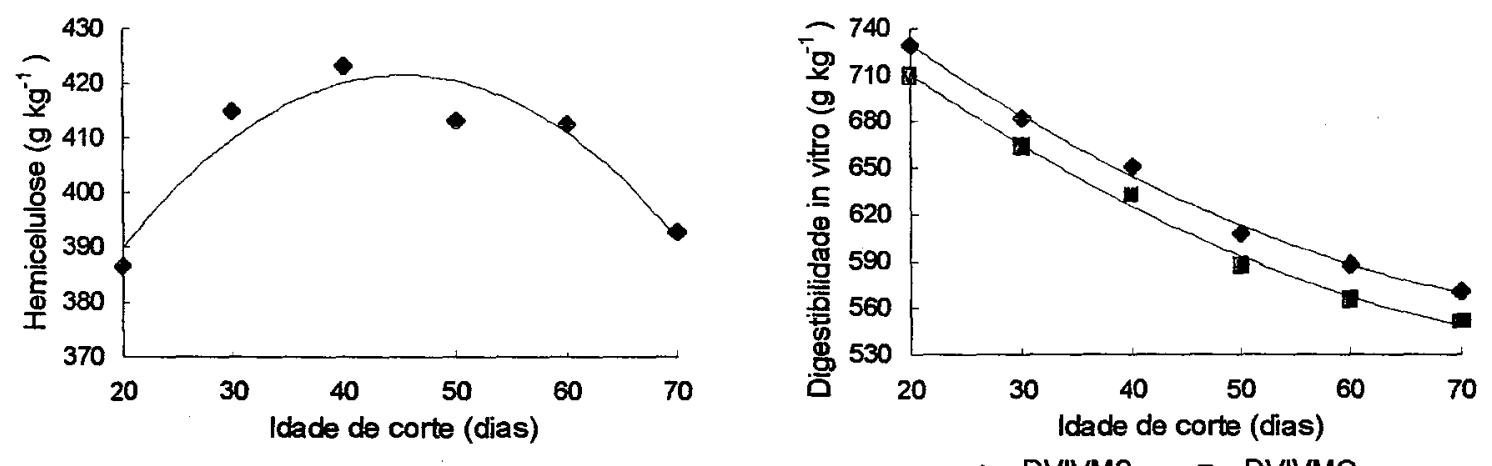

Figura 2 - Teores $\left(g \mathrm{~kg}^{-1}\right)$ de (a) cinza, (b) proteina bruta, (c) fibra em detergente neutro, (d) fibra em detergente ácido, (e) hemicelulose e (f) digestibilidade verdadeira in vitro da MS e da MO da parte aérea de Cynodon dactylon (L.) Pers. cv. Florakirk, em função da idade de corte. 
A concentração de cinza decresceu linearmente com o aumento da idade de corte, sendo seu valor máximo observado aos 20 dias $\left(75,2 \mathrm{~g} \mathrm{~kg}^{-1}\right)$ e o mínimo aos 70 dias $\left(53,7 \mathrm{~g} \mathrm{~kg}^{-1}\right)$, segundo a equação de regressão (Figura 2a). Arroyo-Aguilú \& Coward-Lord (1974) observaram efeito semelhante em forrageiras tropicais.

A concentração de PB decresceu linearmente com o aumento da idade de corte, sendo seu valor máximo observado aos 20 dias $\left(175,9 \mathrm{~g} \mathrm{~kg}^{-1}\right)$ e o minimo aos 70 dias $\left(75,1 \mathrm{~g} \mathrm{~kg}^{-1}\right)$, segundo a equação de regressão (Figura $2 \mathrm{~b}$ ). O decréscimo na concentração de PB também foi observado em diversas cultivares de grama bermuda submetidas a corte (Griffin \& Watson, 1982; Monson \& Burton, 1982; Holt \& Conrad, 1986).

Baseando-se nos dados da Tabela 15, o decréscimo diário na concentração de PB foi $2,2 \mathrm{~g} \mathrm{~kg}^{-1}$. Este valor é semelhante ao apresentado por Minson (1990) como valor médio de diversas espécies forrageiras $(2,2 \mathrm{~g})$, porém superior à média citada pelo autor para $C$. dactylon (1,7 g). Palhano \& Haddad (1992) observaram redução de $2,1 \mathrm{~g} \mathrm{~kg}^{-1} \mathrm{dia}^{-1}$ em Coastcross-1, no período de 20 a 70 dias. Gomide (1996), no período de 14 a 56 dias de crescimento em Florakirk, observou redução de $2,4 \mathrm{~g} \mathrm{~kg}^{-1}$ dia $^{-1}$, com concentração de $175 \mathrm{~g} \mathrm{~PB} \mathrm{~kg}^{-1}$ aos 14 dias.

Segundo Minson (1992), esta redução na concentração de PB é decorrente do aumento na proporção de hastes, cuja concentração protéica é inferior à das folhas, e devido à diminuição na PB das folhas e hastes. Gomide (1996) observou, em Florakirk, redução na relação folha:haste entre 21 e 70 dias de crescimento (de 1,10 para 0,29 ), sendo que a concentração de PB na folha diminuiu $33 \%$, enquanto na haste $69 \%$.

A concentração mínima de PB necessária para que não haja redução no

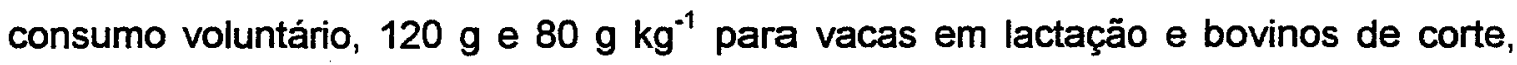
respectivamente, segundo Forbes (1995), foi atendida até os 40 e 65 dias de crescimento, respectivamente (conforme Figura $2 \mathrm{~b}$ ).

As concentraçōes de FDN e FDA aumentaram de forma quadrática com o avanço da idade de corte, sendo os valores mínimos observados aos 20 dias $(714,3 \mathrm{~g}$ e $\left.324,6 \mathrm{~g} \mathrm{~kg}^{-1}\right)$ e os valores máximos aos 55 e 70 dias de crescimento $(789,5 \mathrm{~g} \mathrm{e}$ $389,9 \mathrm{~g} \mathrm{~kg}^{-1}$ ), respectivamente, segundo as equações de regressão (Figuras $2 \mathrm{c}$ e $2 \mathrm{~d}$ ).

Houve uma elevação da concentração de hemicelulose entre 20 e 45 dias, 
com posterior decréscimo, embora não se observe diferença significativa entre os cortes de 30 a 60 dias. A concentração máxima de hemicelulose ocorreu aos 45 dias, com 421,6 g kg-1, segundo a equação de regressão (Figura 2e). Arroyo-Aguilú \& Coward-Lord (1974) não observaram correlação entre a idade de corte e a concentração de hemicelulose em forrageiras tropicais, sendo maior a correlação entre FDA e idade que entre FDN e idade, devido à participação do conteúdo de hemicelulose na fração FDN.

Segundo Griffin \& Watson (1982), a concentração de FDN e FDA variaram pouco com a idade de corte das gramas bermuda Coastal, Alicia e Callie. Brown et al. (1988) observaram, em Florakirk submetida a corte aos 42 dias de idade, teores de FDN e FDA (795 g e $412 \mathrm{~g} \mathrm{~kg}^{-1}$, respectivamente) superiores aos deste experimento $\left(779,6 \mathrm{~g} \mathrm{e} 358,5 \mathrm{~g} \mathrm{~kg}^{-1}\right.$, respectivamente). Os teores apresentados por Palhano \& Haddad (1992) também são superiores aos deste experimento, considerando as mesmas idades de corte. As concentrações máximas de FDN e FDA em Coastcross-1 ocorreram aos 70 dias de idade (806,4 g e 463,8 $\left.\mathrm{g} \mathrm{kg}^{-1}\right)$. Em Gomide (1996), as concentrações máximas de FDN e FDA em Florakirk ocorreram aos 56 e 70 dias de

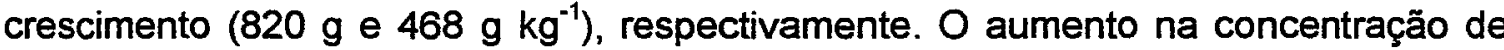
FDN e FDA ocorreu tanto na fração folha como na haste, sendo mais acentuado na primeira.

Apesar da concentração inicial de FDN (20 dias) em Florico (Castro, 1997) $\left(650 \mathrm{~g} \mathrm{~kg}^{-1}\right)$ ter sido inferior à da Florakirk, a concentração aos 70 dias foi semelhante para ambas. No caso da FDA, as concentrações iniciais foram semelhantes e aos 70 dias a concentração em Florakirk foi inferior à da Florico $\left(417 \mathrm{~g} \mathrm{~kg}^{-1}\right)$.

As DVIVMS e DVIVMO decresceram de forma quadrática com o aumento da idade de corte, sendo os valores máximos observados aos 20 dias $\left(729,7 \mathrm{~g} \mathrm{~kg}^{-1} \mathrm{e}\right.$ $710,9 \mathrm{~g} \mathrm{~kg}^{-1}$, respectivamente) e os valores minimos aos 70 dias $\left(570,3 \mathrm{~g} \mathrm{~kg}^{-1} \mathrm{MS} \mathrm{e}\right.$ $549,1 \mathrm{~g} \mathrm{~kg}^{-1}$, respectivamente), segundo as equações de regressão (Figura $2 \mathrm{f}$ ). $\mathrm{O}$ decréscimo na digestibilidade com o aumento da idade de corte também foi observado em diversas cultivares de grama bermuda submetidas a corte (Monson \& Burton, 1982; Holt \& Conrad, 1986), o mesmo sendo observado em condições de pastejo (Mislevy et al., 1988; Adjei et al., 1989; Pedreira, 1995). Este decréscimo deve-se ao acréscimo no conteúdo de parede celular (o que pode ser observado pelo 
aumento na concentração de FDN, conforme Figura $2 \mathrm{c}$ ), associado, provavelmente, a um aumento na lignificação da mesma. Buxton \& Redfearn (1997) consideram a concentração de fibra como o principal fator limitante da digestibilidade e, segundo Van Soest (1994), o efeito da fibra na digestibilidade depende da sua associação com a lignina.

Griffin \& Watson (1982) observaram aumento na concentração de lignina nas cultivares Coastal, Alicia e Callie com o aumento na idade de corte, embora a digestibilidade e a concentração de FDN e FDA tenham variado pouco com a idade. Arroyo-Aguilú \& Coward-Lord (1974) observaram, em 10 forrageiras tropicais analisadas, correlação negativa entre idade de corte e concentração de lignina.

Ambas as digestibilidades decresceram numa taxa de $3,2 \mathrm{~g} \mathrm{~kg}^{-1} \mathrm{dia}^{-1}$. A redução diária foi superior à observada por Minson (1992) (1 a $2 \mathrm{~g} \mathrm{~kg} \mathrm{k}^{-1}$, para pastagens em geral) e inferior à citada por Crowder \& Chheda (1982) (5 a $6 \mathrm{~g} \mathrm{~kg}^{-1}$, para capins tropicais). Em Pedreira (1995), a redução na DIVMO de Florakirk foi de $1,6 \mathrm{~g} \mathrm{~kg}^{-1} \mathrm{dia}^{-1}$ com o aumento do ciclo de pastejo de 21 para 35 dias.

Em Coastcross-1, Palhano \& Haddad (1992) observaram redução de $4,6 \mathrm{~g} \mathrm{~kg}^{-1}$ $\mathrm{dia}^{-1}$, no período de 20 a 70 dias de idade, sendo a digestibilidade inicial $743,6 \mathrm{~g} \mathrm{~kg}^{-1}$, superior à observada neste experimento.

Aos 70 dias, a digestibilidade da Florakirk foi próxima à da grama estrela Florico (Castro, 1997) e superior à da Coastcross-1 (Palhano \& Haddad, 1992), embora nestas duas últimas tenha sido observada uma estabilização da digestibilidade aos 40 e 50 dias, respectivamente, o que não ocorreu na Florakirk até os 70 dias.

DVIVMS abaixo de $650 \mathrm{~g} \mathrm{~kg}^{-1}$, o que segundo Moore \& Mott (1973) seria um fator limitante do consumo, foi observada a partir de 40 dias de idade. Em Palhano \& Haddad (1992), este valor foi atingido aos 33 dias de crescimento da cultivar Coastcross-1.

Devido à solubilização da sílica em detergente neutro (Van Soest, 1994), os valores de DVIVMS foram superiores aos de DVIVMO, o mesmo tendo ocorrido em Castro (1997), com a grama estrela Florico.

A digestibilidade da fração FDN decresceu linearmente com o aumento da idade de corte (Figura 3a), sendo o valor máximo observado aos 20 dias $\left(622,2 \mathrm{~g} \mathrm{~kg}^{-1}\right)$ 
e o mínimo aos 70 dias $\left(447,4 \mathrm{~g} \mathrm{~kg}^{-1}\right)$, segundo a equação de regressão.

Para Buxton \& Redfearn (1997), a redução na digestibilidade da fibra deve-se, principalmente, à lignificação da mesma. Segundo Van Soest (1994), há uma associação entre forragens com alta digestibilidade e elevada concentração de FDN digestível, o que pode ser observado nas Figuras $2 \mathrm{f}$ e $3 \mathrm{c}$, embora a digestibilidade da forragem tenha decrescido de forma quadrática e a digestibilidade da fração FDN de forma linear.

Brown et al. (1988) observaram DVIVMO de $439 \mathrm{~g} \mathrm{~kg}^{-1}$ e digestibilidade da fração FDN de $499 \mathrm{~g} \mathrm{~kg}^{-1}$ em Florakirk submetida a corte aos 42 dias de idade. Ambos os valores são inferiores aos calculados neste experimento na mesma idade de corte (618 $\mathrm{g} \mathrm{kg}^{-1}$ e $545 \mathrm{~g} \mathrm{~kg}^{-1}$, respectivamente).

A produção de MS digestível e de MO digestivel aumentou de forma quadrática com o avanço da idade de corte, sendo os valores máximos observados aos 70 dias de crescimento $\left(122,3 \mathrm{~g}\right.$ e $111,6 \mathrm{~g} \mathrm{~m}^{-2}$ ), respectivamente, segundo as equações de regressão (Figura 3b). Este aumento na produção de matéria digestível deve-se principalmente ao aumento na produção de MS e MO (Figura 1a), uma vez a DVIVMS e a DVIVMO decresceram com o avanço da idade de corte.

(a)

$$
Y=-3,4957 X+692,1\left(R^{2}=0,988\right)
$$

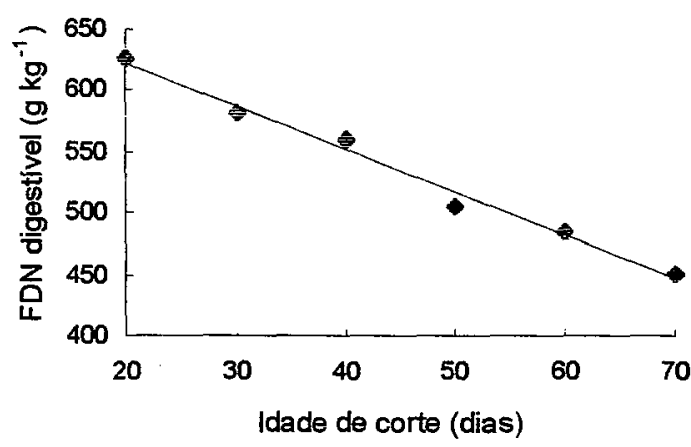

(b)

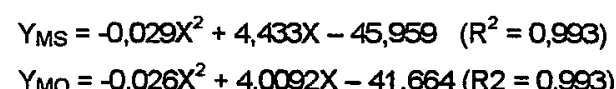

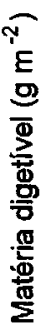

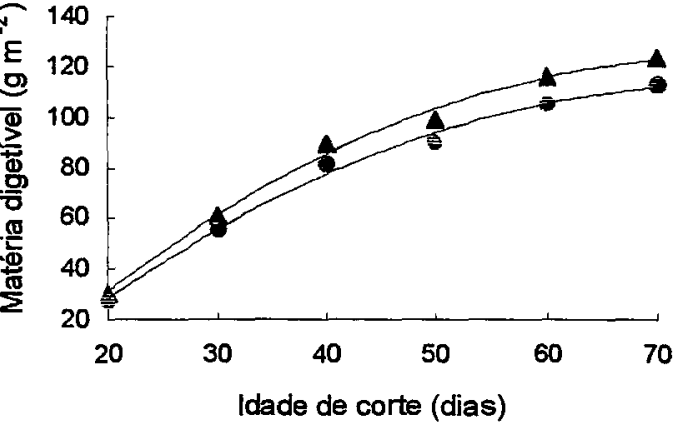

A MS digestivel

Figura 3 - Digestibilidade de FDN $\left(\mathrm{g} \mathrm{kg}^{-1}\right)$ (a) e produção de matéria seca digestível e matéria orgânica digestivel $\left(\mathrm{g} \mathrm{m}^{-2}\right)$ (b) da parte aérea de Cynodon dactylon (L.) Pers. cv. Florakirk, em função da idade de corte. 
O valor nutritivo da cultivar Florakirk obtido neste experimento foi superior ao observado por Brown et al. (1988) e por Gomide (1996), na mesma cultivar, e por Palhano \& Haddad (1992), com a cultivar Coastcross-1, quando comparados na mesma idade de corte. Porém, as produçōes de MS obtidas neste experimento foram inferiores. Esta superioridade no valor nutritivo deve-se, provavelmente, a um crescimento limitado da forrageira em função da ocorrência de doença ou de algum fator ambiental limitante ao desenvolvimento adequado da planta. Segundo Van Soest (1994), a limitação no crescimento da planta promove o atraso na sua maturação e redução no decréscimo do valor nutritivo esperado com o avanço da idade da planta.

Aos 40 dias de crescimento observou-se uma associação adequada entre produção de forragem e valor nutritivo, principalmente quanto à concentração de PB e digestibilidade, sendo essa a época mais adequada para o corte do capim Florakirk, nas condições do presente experimento. Entretanto, a manutenção de níveis aceitáveis de digestibilidade, FDN e FDA em Florakirk, com estádio de maturação avançado, permitiria a utilização desta forrageira em sistemas de produção onde o diferimento dos pastos seja adotado como técnica de reserva forrageira para o periodo crítico.

Apesar do elevado valor nutritivo da forragem cortada aos 20 e 30 dias de idade, a produção de MS nestes períodos é limitada.

Adjei et al. (1989) e Gomide (1996) obtiveram idade ideal de corte para Florakirk entre 28 e 42 dias de crescimento. O mesmo foi observado para outras cultivares de grama bermuda (Remy et al., 1979; Griffin \& Watson, 1982; Palhano \& Haddad, 1992). Para a grama estrela Florico, Castro (1997) sugeriu o corte aos 35 dias de idade.

\subsection{Composição mineral}

\subsubsection{Macronutrientes}

A concentração dos macronutrientes $\mathrm{N}, \mathrm{P}, \mathrm{K}, \mathrm{Ca}, \mathrm{Mg}$ e $\mathrm{S}$ e $\mathrm{o}$ acúmulo destes elementos na matéria seca do capim Florakirk, em função da idade de corte, estão 
apresentados nas Tabelas 16 e 17, respectivamente.

Tabela 16. Teores de macronutrientes da matéria seca $\left(\mathrm{g} \mathrm{kg}^{-1}\right)$ da parte aérea de Cynodon dactylon (L.) Pers. cv. Florakirk, em função da idade de corte ${ }^{(1)}$.

\begin{tabular}{|c|c|c|c|c|c|c|c|c|c|c|}
\hline \multirow{2}{*}{$\begin{array}{l}\text { Dias após o } \\
\text { rebaixamento }\end{array}$} & \multicolumn{2}{|l|}{$\mathrm{N}^{(2)}$} & \multicolumn{2}{|l|}{$P$} & \multicolumn{2}{|l|}{$\mathrm{K}$} & \multicolumn{2}{|c|}{$\mathrm{Ca}^{(2)}$} & \multirow[t]{2}{*}{$\mathrm{Mg}$} & \multirow[t]{2}{*}{$S$} \\
\hline & \multicolumn{8}{|c|}{$\mathrm{g} \mathrm{kg}^{-1}$} & & \\
\hline 20 & \multicolumn{2}{|c|}{$28,2 a$} & \multicolumn{2}{|c|}{$6,3 a$} & \multicolumn{2}{|c|}{$31,3 a$} & \multicolumn{2}{|c|}{$3,8 a b$} & $3,0 \mathrm{a}$ & $2,4 a$ \\
\hline 30 & 21,9 & $b$ & 4,8 & $b$ & 25,1 & b & 4,3 & & $3,0 \mathrm{a}$ & $2,5 a$ \\
\hline 40 & 17,9 & $c$ & 4,3 & $b c$ & 24,9 & $b$ & 3,4 & $b$ & $2,9 a$ & $2,3 a$ \\
\hline 50 & 16,1 & c & 4,0 & c & 20,7 & $c$ & 3,5 & $b$ & $2,5 \mathrm{bc}$ & $2,5 a$ \\
\hline 60 & 14,1 & $d$ & 3,9 & c & 15,0 & d & 2,2 & c & $2,8 a b$ & $2,3 a$ \\
\hline 70 & 11,0 & e & 3,0 & $d$ & 8,7 & e & 2,2 & c & 2,4 & $1,6 \quad b$ \\
\hline C.V. (\%) & 4,4 & & 12,1 & & 11,6 & & 9,1 & & 7,0 & 18,4 \\
\hline
\end{tabular}

(1) médias seguidas de mesma letra, na mesma coluna, não diferem estatisticamente pelo teste $t$ de Student $(P>0,05)$;

(2) transformações de variáveis: $N=1 / \sqrt{ } x ; \mathrm{Ca}=1 / x$.

Tabela 17. Acúmulo de macronutrientes na matéria seca $\left(\mathrm{g} \mathrm{m}^{-2}\right)$ da parte aérea de Cynodon dactylon (L.) Pers. Cv. Florakirk, em função da idade de corte ${ }^{(1)}$.

\begin{tabular}{|c|c|c|c|c|c|c|c|c|c|c|}
\hline \multirow{2}{*}{$\begin{array}{c}\text { Dias após o } \\
\text { rebaixamento }\end{array}$} & $\mathbf{N}$ & $\mathbf{P}$ & $\mathrm{K}$ & & $\mathrm{Ca}$ & & $\mathrm{Mg}$ & & $S$ & \\
\hline & \multicolumn{10}{|c|}{$\mathrm{g} \mathrm{m}^{-2}$} \\
\hline 20 & $1,18 \quad c$ & 0,25 & 1,28 & d & 0,15 & d & 0,12 & $d$ & 0,10 & e \\
\hline 30 & $1,99 b$ & $0,42 \quad c$ & 2,26 & $b c$ & 0,37 & c & 0,27 & c & 0,22 & d \\
\hline 40 & $2,45 a$ & $0,58 \quad b$ & $3,44 a$ & & 0,47 & $b$ & 0,40 & $b$ & 0,32 & c \\
\hline 50 & $2,64 a$ & $0,64 a b$ & $3,36 a$ & & 0,57 & & 0,41 & b & 0,41 al & \\
\hline 60 & $2,74 a$ & $0,74 a$ & $3,05 a$ & & 0,44 & $b c$ & $0,54 a$ & & $0,51 a$ & \\
\hline 70 & $2,38 a b$ & $0,65 a b$ & 1,89 & cd & 0,48 & $b$ & $0,52 a$ & & 0,34 & $b c$ \\
\hline C.V. (\%) & 13,09 & 13,11 & 18,95 & & 13,91 & & 11,53 & & 17,23 & \\
\hline
\end{tabular}

${ }^{(1)}$ médias seguidas de mesma letra, na mesma coluna, não diferem estatisticamente pelo teste $t$ de Student $(P>0,05)$.

Para todos os macronutrientes as concentrações diferiram significativamente em função da idade de corte $(P<0,05)$. Os teores de $N, P, K$ e Mg decresceram linearmente com o aumento da idade de corte, apresentando valores máximos aos 20 
dias e mínimos aos 70 dias de idade (Figura 4). A variação nos teores de Ca e $\mathrm{S}$ deuse de forma quadrática (Figura 4), com concentração máxima de Ca ocorrendo aos 22 dias $\left(3,9 \mathrm{~g} \mathrm{~kg}^{-1}\right)$ e de $\mathrm{S}$ aos 37 dias $\left(2,5 \mathrm{~g} \mathrm{~kg}^{-1}\right)$ e mínima aos 70 dias para ambos os macronutrientes $\left(2,1 \mathrm{~g}\right.$ Ca e $\left.1,7 \mathrm{~g} \mathrm{~S} \mathrm{~kg}^{-1}\right)$, segundo as equações de regressão.

\section{Nitrogênio}

Houve uma redução de $61 \%$ no teor de $\mathrm{N}$ com o aumento da maturidade da planta no periodo de 20 a 70 dias (de 28,2 para $11,0 \mathrm{~g} \mathrm{~kg}^{-1}$ ), estando de acordo com as afirmações de Gomide (1978) e Little (1982) e com os dados obtidos por Sotomayor-Rios et al. (1974) e Palhano \& Haddad (1992), sendo que neste último, as concentrações de $\mathrm{N}$ observadas em Coastcross-1 (30,5 e 14,1 $\mathrm{g} \mathrm{kg}^{-1}$, aos 20 e 70 dias, respectivamente) são muito próximas à da Florakirk.

Os teores de $\mathrm{N}$ observados estão compreendidos no intervalo de concentração considerado normal para as plantas por Gallo et al. (1974) (10 a $\left.30 \mathrm{~g} \mathrm{~kg}^{-1}\right)$.

Fósforo

O teor de $P$ variou de 5,8 a $3,0 \mathrm{~g} \mathrm{~kg}^{-1}$, segundo a equação de regressão (Figura 4b). A redução no teor de $\mathrm{P}$ com a idade da planta é citada por diversos autores (Gomide, 1978; Little, 1982; Minson, 1990 e Spears, 1994), porém os teores obtidos em todas as idades de corte (Tabela 16) foram superiores ao teor considerado normal por Follett \& Wilkinson (1995) $\left(2,5 \mathrm{~g} \mathrm{~kg}^{-1}\right)$ e do teor médio de gramíneas no Estado de São Paulo (Tabela 5) apresentado por Malavolta et al. (1986) $\left(2,1 \mathrm{~g} \mathrm{~kg}^{-1}\right)$. Segundo Gallo et al. (1974), apenas 2,4\% das amostras de gramineas tropicais do Estado de São Paulo apresentaram teores de $P$ acima de $4 \mathrm{~g} \mathrm{~kg}^{-1}$. Palhano e Haddad (1992) obtiveram concentrações de $P$ entre 1,6 e 2,7 $\mathrm{g} \mathrm{kg}^{-1}$ em Coastcross-1. 
(a) $\quad Y=0,0021 X+0,1486\left(R^{2}=0,978\right)$

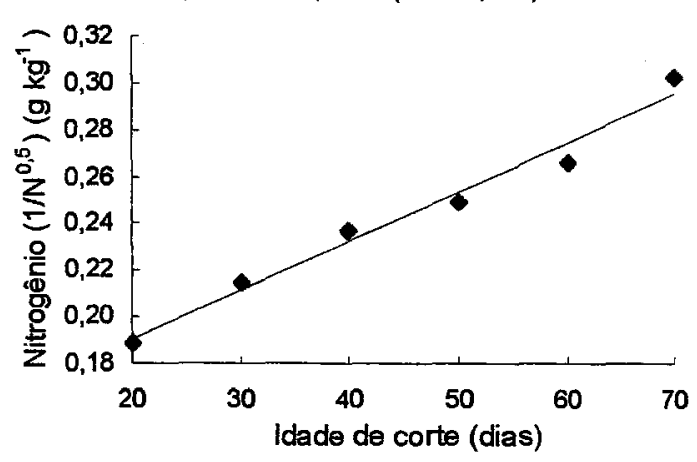

(c) $Y=-0,4209 \mathrm{X}+39,888\left(\mathrm{R}^{2}=0,955\right)$

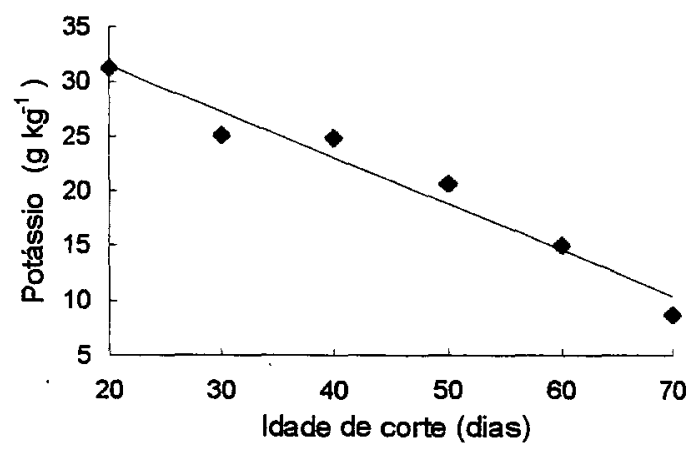

(e)

$$
Y=-0,0109 X+3,2543\left(R^{2}=0,712\right)
$$

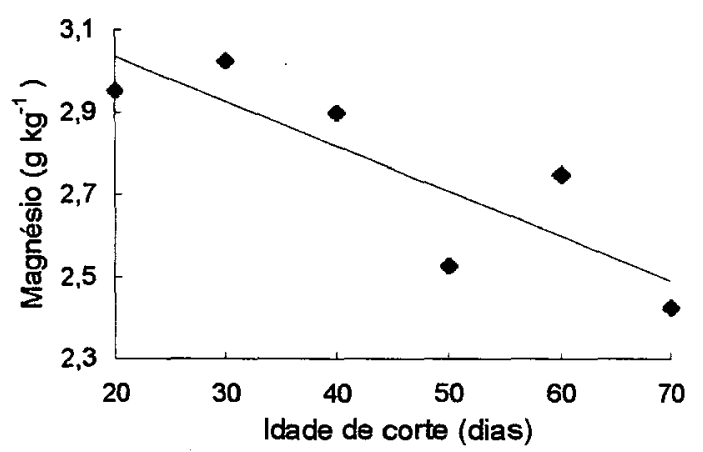

(b) $\quad Y=-0,0564 X+6,9226\left(R^{2}=0,889\right)$

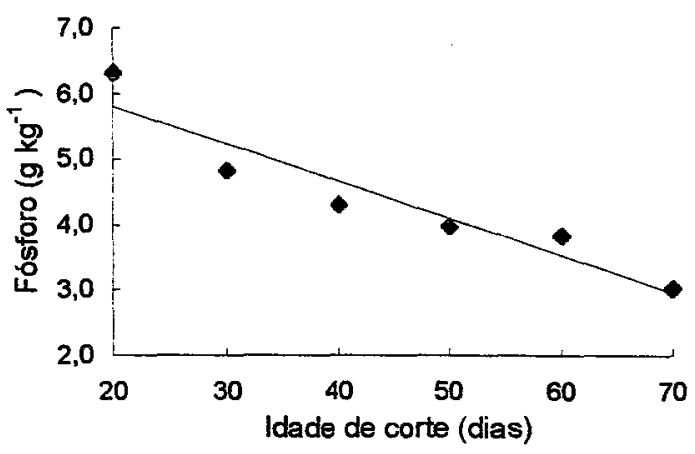

(d) $\quad Y=0,000097 X^{2}-0,0042 X+0,3003$ $\left(R^{2}=0,834\right)$

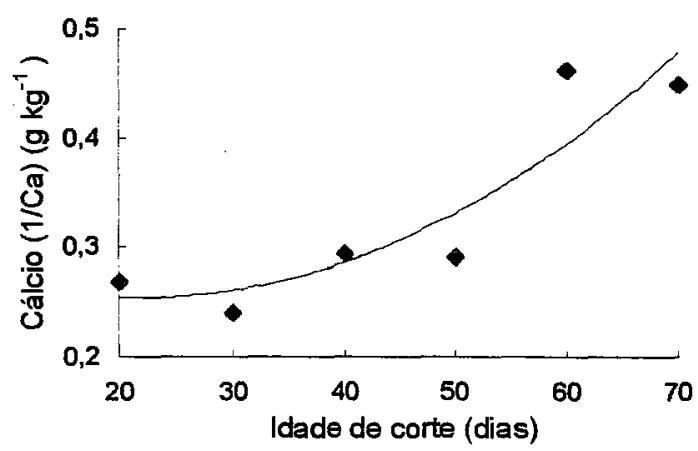

(f)

$$
Y=-0,000786 X^{2}+0,0579 X+1,475
$$

$\left(R^{2}=0,817\right)$

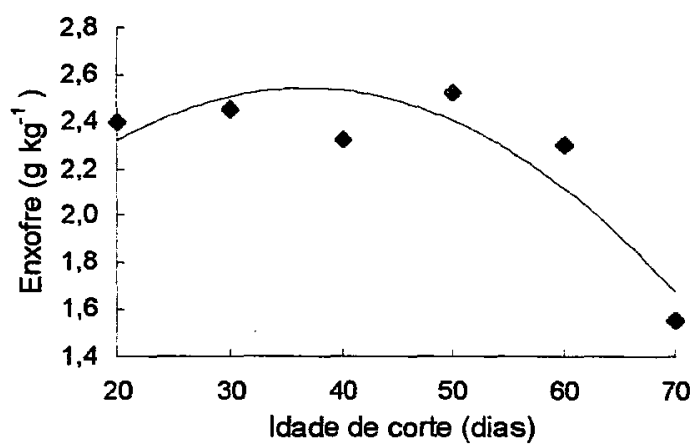

Figura 4 - Teores de macronutrientes na matéria seca $\left(\mathrm{g} \mathrm{kg}^{-1}\right)$ da parte aérea de Cynodon dactylon (L.) Pers. cv. Florakirk, em função da idade de corte. 
As concentrações críticas de $P$ em $C$. dactylon apresentadas na literatura variam de 1,92 $\mathrm{g}$ (Mesa et al., 1983) a $2,8 \mathrm{~g} \mathrm{~kg}^{-1}$ (Kelling \& Matocha ${ }^{2}$, citados por Robinson, 1996), valores inferiores aos das concentrações observadas neste trabalho, mostrando assim que houve um acúmulo de $P$ na planta em todas as idades de corte analisadas. Um excesso de $P$ na parte aérea pode ser decorrente de elevados niveis de $\mathrm{P}$ no solo, o que não foi observado neste trabalho, ou do efeito de concentração devido à presença de algum fator limitante ao crescimento da planta (luz, umidade, temperatura ou nutrientes) (Martin \& Matocha, 1973). Até os 30 dias de idade, a ocorrência de deficiência de outros macronutrientes não é provável, uma vez que os teores observados (Tabela 16) estão acima das concentrações criticas apresentadas por Kelling \& Matocha ${ }^{2}$, (citados por Robinson, 1996), para as cultivares de grama bermuda Coastal, comum e Midland. A partir dos 40 dias de idade pode ter ocorrido deficiência de $N$, pois a concentração crítica observada por estes autores variou entre 22 e $25 \mathrm{~g} \mathrm{~kg}^{-1}$.

A redução média no teor de $P$ foi $0,066 \mathrm{~g} \mathrm{~kg}^{-1}$ dia-1, superior aos $0,05 \mathrm{~g}$ observados por Minson (1990) em C. dactylon, provavelmente devido à elevada concentração do nutriente aos 20 dias de idade.

\section{Potássio}

O K foi o macronutriente cujo teor apresentou a maior redução com o avanço da idade, reduzindo $72,2 \%$ de 20 para 70 dias, ao contrário de Palhano \& Haddad (1992), onde a variação no teor de $K$ foi a menor entre os macronutrientes $(18,8 \%)$. Entretanto, segundo Underwood (1971) e Spears (1994), o declínio que ocorre na concentração de K é marcante.

Os teores observados aos 20 e 70 dias de idade não estão compreendidos no intervalo de concentração considerada normal nas plantas (12 a $29 \mathrm{~g} \mathrm{~kg}^{-1}$ ) por Gallo et al. (1974), conforme Tabela 6. Castro (1997) observou teores de K em Florico entre 28,7 e $37,9 \mathrm{~g} \mathrm{~kg}^{-1}$, que, segundo o autor, seriam decorrentes de um consumo de luxo desse elemento em função da alta disponibilidade do mineral no solo e da elevada capacidade de extração dessa forrageira. Este efeito provavelmente pode ter ocorrido com a Florakirk aos 20 dias de idade, pois a concentração observada foi superior à considerada normal. Entretanto, não é possível isolar este fato de um possível efeito 
de concentração do elemento na planta em função da baixa produção de MS observada no período.

Richardson \& Croughan (1989) observaram aumento na incidência de Helminthosporium em grama bermuda quando os niveis de $\mathrm{K}$ no tecido decresceram a partir de $25 \mathrm{~g} \mathrm{~kg}^{-1}$. Neste trabalho, este limite foi atingido a partir do 30 dias de idade, coincidindo com o período de visualização dos sintomas de doença.

\section{Cálcio}

Observa-se na Tabela 16 que houve uma tendência de elevação do teor de Ca nos primeiros 30 dias de crescimento da planta, porém estabilizando num patamar inferior aos 40 e 50 dias de crescimento, reduzindo novamente aos 60 e 70 dias. Segundo Little (1982), a concentração de Ca mantém-se relativamente constante; entretanto, Palhano \& Haddad (1992) observaram decréscimo linear no teor de Ca com o aumento da idade de corte. Segundo Minson (1990), o teor de Ca pode ou não reduzir, e este diferença observada entre este trabalho e o de Palhano \& Haddad (1992) comprovam a afirmação de Norton (1982), não havendo um padrão consistente em espécies tropicais.

Os teores de Ca observados neste trabalho $\left(2,2\right.$ a $\left.4,3 \mathrm{~g} \mathrm{~kg}^{-1}\right)$ foram próximos do intervalo de concentração considerado normal para as plantas por Gallo et al. (1974) (2 a $4 \mathrm{~g} \mathrm{~kg}^{-1}$ ), porém abaixo dos valores médios apresentados na Tabela 5 para gramíneas tropicais no Estado de São Paulo $\left(4,6\right.$ e 4,9 $\left.\mathrm{g} \mathrm{kg}^{-1}\right)$ e por Minson (1990) para $C$. dactylon $\left(5 \mathrm{~g} \mathrm{~kg}^{-1}\right.$ ), segundo o qual, a espécie é uma das que apresentam as maiores concentrações de $\mathrm{Ca}$ entre as gramineas tropicais.

O teor de Ca variou $42,1 \%$ para Florakirk, valor próximo ao observado em Coastcross-1 (40,7\%) por Palhano \& Haddad (1992) dentro do periodo experimental de 20 a 70 dias de idades.

\section{Magnésio}

A menor variação com o aumento da idade de corte foi observada nos teores de $\mathrm{Mg}$, com redução de $20 \%$ dos 20 aos 70 dias, estando de acordo com Minson (1990), segundo o qual o teor de Mg pode ou não reduzir. Os teores de Mg obtidos foram maiores ou próximos do limite superior considerado normal para as plantas por 
Gallo et al. (1974) $\left(2,6 \mathrm{~g} \mathrm{~kg}^{-1}\right)$, o que também foi observado por Malavolta et al. (1986) (Tabela 5) e Palhano \& Haddad (1992).

Em Palhano \& Haddad (1992), as concentrações de Mg em Coastcross-1 variaram entre 2,8 e $3,9 \mathrm{~g} \mathrm{~kg}^{-1}$, enquanto em Florakirk foi observada variação entre 2,4 e $3,0 \mathrm{~g} \mathrm{~kg}^{-1}$.

\section{Enxofre}

Os teores de $\mathrm{S}$ mantiveram-se estáveis de 20 a 60 dias de idade da planta, sem diferença significativa (Tabela 16), reduzindo apenas aos 70 dias. Palhano \& Haddad (1992) observaram um decréscimo mais acentuado nos teores de $S$ em Coastcross-1.

As concentrações médias de $S$ observadas neste trabalho foram próximas à concentração considerada normal $\left(2 \mathrm{~g} \mathrm{~kg}^{-1}\right)$ por Follett \& Wilkinson (1995) e acima da concentração média ( $1 \mathrm{~g} \mathrm{~kg}^{-1}$ ) observada por Malavolta et al. (1986) em gramíneas no Estado de São Paulo. Porém, Gallo et al. (1974) consideram como concentração normal de $S$ nas plantas 1 a $3 \mathrm{~g} \mathrm{~kg}^{-1}$.

Em Florico não houve diferença significativa na concentração de $S$ em função da idade de corte, sendo $2,3 \mathrm{~g} \mathrm{~kg}^{-1}$ a concentração média entre 20 e 70 dias (Castro, 1997). Quanto aos demais macronutrientes, os teores de $\mathrm{N}, \mathrm{K}, \mathrm{Ca}$ e $\mathrm{Mg}$ foram superiores em Florico, quando comparada à Florakirk nas mesmas idades de corte, o que não ocorreu com o $P$.

A causa para a diminuição observada nos teores de macronutrientes pode ser o efeito de diluição destes com o aumento da produção de matéria seca, como observado por Gomide (1978), associado à redução na relação folha:haste, conforme determinação de Gomide (1996) em capim Florakirk, ou ainda à redistribuição dos nutrientes dentro da planta (Malavolta et al., 1986).

\section{Acúmulo de macronutrientes}

$\mathrm{O}$ acúmulo dos macronutrientes analisados variou com a idade de corte de forma quadrática (Figura 5), assim como a produção de MS, embora a concentração de $\mathrm{N}, \mathrm{P}, \mathrm{K}$ e $\mathrm{Mg}$ tenham variado linearmente. O máximo acúmulo de $\mathrm{N}$ e Ca ocorreu,

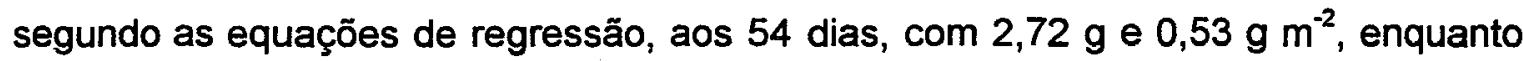


de K, S, P e Mg ocorreu aos 48, 56, 61 e 70 dias, com 3,44 g; 0,43 g; 0,69 g e 0,53 g $\mathrm{m}^{-2}$, respectivamente. Segundo Robinson (1996), a produção é, normalmente, o principal determinante da extração de nutrientes pela cultura, porém, neste caso, a extração foi determinada pela combinação dos fatores produção de matéria seca e concentração de nutrientes na planta. A extração máxima de macronutrientes não coincidiu com o periodo de máxima produção de MS e nem com o de máxima concentração do nutriente na planta, com exceção ao $\mathrm{K}$, que coincidiu com a idade de máxima produção de MS.

Palhano \& Haddad (1992) também observaram acúmulo de macronutrientes em Coastcross-1 variando de forma quadrática, porém com valores máximos aos 40 dias de crescimento, com exceção do $\mathrm{S}$, cujo acúmulo não foi influenciado pela idade da planta. Entretanto, os valores obtidos em Coastcross-1 foram superiores aos de Florakirk, devido principalmente à maior produção de MS observada com a Coastcross-1.

A redução no acúmulo de macronutrientes nos estádios de maturação mais avançados pode ser decorrente do aumento do número de folhas mortas ou senescentes e da diminuição nos teores de macronutrientes na planta. 


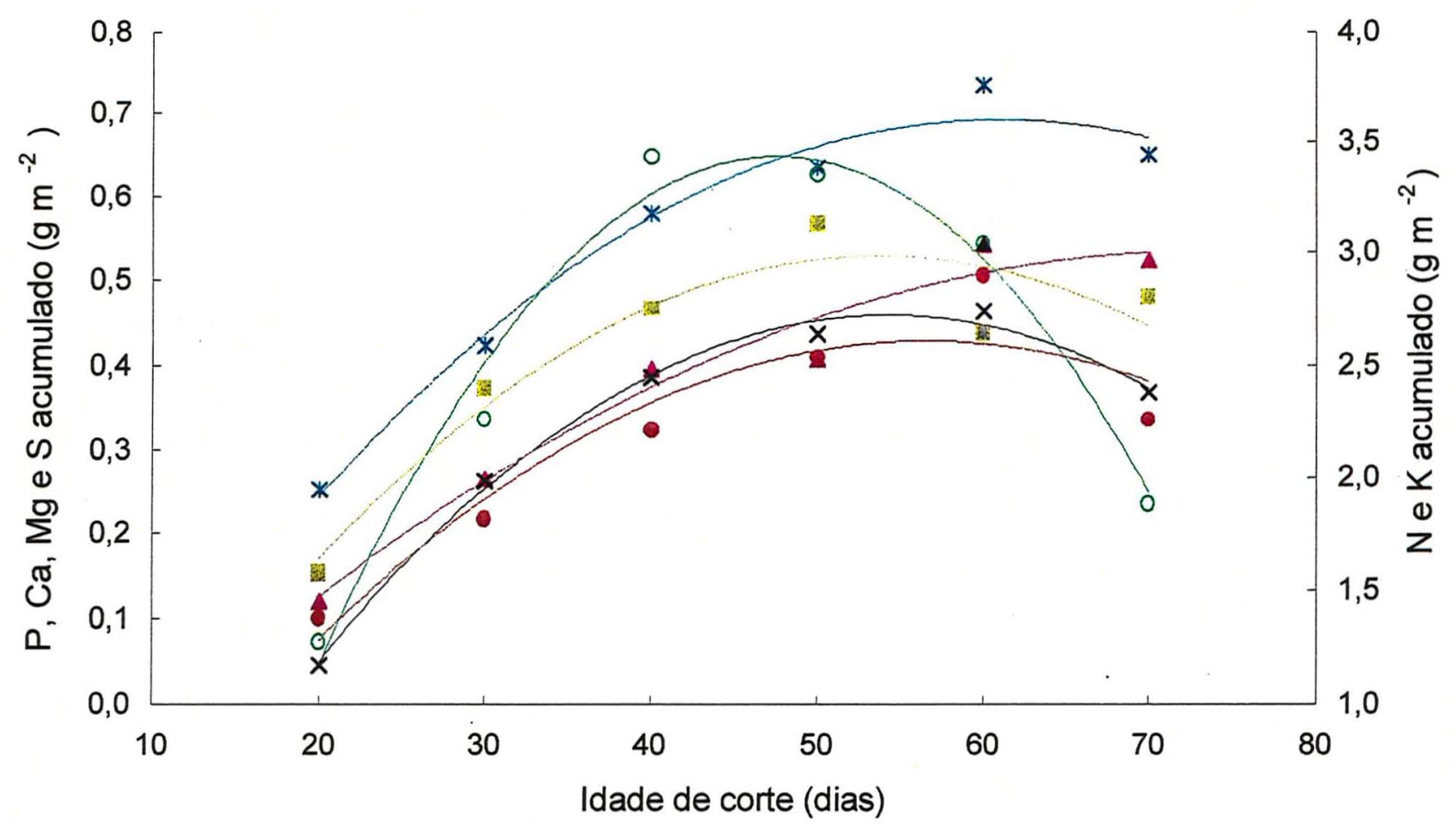

$* \mathrm{P} \triangle \mathrm{Ca} \Delta \mathrm{Mg} \bullet \mathrm{S} \circ \mathrm{K} \times \mathrm{N}$
$N: Y=-0,00131 X^{2}+0,1419 X-1,127$
$\left(R^{2}=0,994\right)$
$\mathrm{Ca}: Y=-0,000319 X^{2}+0,0343 X-0,391$
$\left(R^{2}=0,899\right)$
$P: Y=-0,000266 X^{2}+0,0325 X-0,297$
$\left(R^{2}=0,979\right)$
$M g: Y=-0,000141 X^{2}+0,0208 X-0,233$
$\left(R^{2}=0,969\right)$
$K: Y=-0,00297 X^{2}+0,2829 X-3,292$
$\left(R^{2}=0,969\right)$
$S: \quad Y=-0,000265 X^{2}+0,0299 X-0,416$
$\left(R^{2}=0,893\right)$

Figura 5 - Acúmulo de macronutrientes na matéria seca $\left(\mathrm{g} \mathrm{m}^{-2}\right)$ da parte aérea de Cynodon dactylon (L.) Pers. cv. Florakirk, em função da idade de corte. 


\section{Exigência animal}

Conforme as recomendações de NRC (1989a) (Tabela 2), os teores de macronutrientes no capim Florakirk foram adequados à nutrição de bovinos de leite até os 60 dias de idade, com exceção do Ca (insuficiente em todas as idades de corte) e de vacas em início da lactação (categoria com maiores exigências).

Para bovinos de corte e eqüinos (Tabelas 3 e 4), os teores de macronutrientes observados, com exceção do $\mathrm{Ca}$, foram suficientes para atender às exigências destes animais em todas as idades de corte analisadas. $O$ teor de $P$ aos 70 dias pode ser insuficiente apenas para animais com ritmo de crescimento muito acelerado.

Castro (1997) também observou niveis de Ca em Florico insuficientes para atender às exigências animais.

A concentração de $\mathrm{K}$ aos 20 dias de idade $\left(31,3 \mathrm{~g} \mathrm{~kg}^{-1}\right)$ foi superior à concentração máxima tolerada $\left(30 \mathrm{~g} \mathrm{~kg}^{-1}\right)$ para bovinos leiteiros e de corte (NRC, 1989a e 1996), podendo ocorrer diarréia em bovinos devido à maior concentração de K em relação a Ca e Mg (Haddad \& Platzeck, 1985).

Conforme Humphreys (1991), a concentração mínima de $N$, observada aos 70 dias $\left(11 \mathrm{~g} \mathrm{~kg}^{-1}\right)$, foi igual ao limite mínimo para que não haja limitação no consumo de forragem, sendo a exigência de $\mathrm{N}$ pelo animal atendida de forma mais adequada até os 60 dias de crescimento ( $\mathrm{N}$ acima de $13 \mathrm{~g} \mathrm{~kg}^{-1}$ ). A concentração de $S$ aos 70 dias também poderia limitar o consumo, uma vez que é inferior a $1,7 \mathrm{~g} \mathrm{~kg}^{-1}$.

A concentração de $S$ com base na MOD variou entre $3,07 \mathrm{~g} \mathrm{~kg}^{-1}$ (70 dias) e $4,45 \mathrm{~g} \mathrm{~kg}^{-1}$ (50 dias). Apenas aos 70 dias de idade, a concentração de $\mathrm{S}$ atendeu as recomendações de Durand \& Komisarczuk (1988) para um desenvolvimento adequado dos microrganismos ruminais $\left(2,5\right.$ a $\left.3,1 \mathrm{~g} \mathrm{~kg}^{-1}\right)$, sendo que nos demais cortes a concentração de $S$ foi superior à recomendada. A concentração de $\mathrm{Mg}$ variou de 4,5 a $5,3 \mathrm{~g} \mathrm{~kg}^{-1}$ (MOD), estando também acima do intervalo recomendado pelos mesmos autores $\left(1,5\right.$ a $\left.2,5 \mathrm{~g} \mathrm{~kg}^{-1}\right)$.

De modo geral, as concentrações de macronutrientes observadas em Florakirk atenderam à maioria das exigências minerais de bovinos (leite e corte) e eqüinos, com exceção do Ca. Segundo Minson (1990), as exigências de Ca são superestimadas, porém apenas aos 30 dias a concentração deste nutriente foi superior a $4 \mathrm{~g} \mathrm{~kg}^{-1}$, valor que seria suficiente para suprir a maioria das formas de produção animal. 
Mesmo que as concentrações de Mg observadas em todas as idades de crescimento atendessem às exigências dos bovinos, a sua utilização poderia ser prejudicada, segundo Fontenot et al. (1989), pelo alto nivel de K presente até os 40 dias de idade (acima de $22,5 \mathrm{~g} \mathrm{~kg}^{-1}$ ) e pelo elevado nível de $\mathrm{P}$ associado à baixa concentração de $\mathrm{Ca}$.

Embora Fick et al. (1978) tenham observado que o $\mathrm{P}$ seja o nutriente mais deficiente nas forrageiras da América Latina (deficiência em 72,8\% das amostras), em relação às exigências animais, isto não foi observado neste trabalho, uma vez que a concentração de $\mathrm{P}$ excedeu as concentrações médias citadas em literatura. Gallo et al. (1974) observaram deficiência de P em $41 \%$ das amostras de gramíneas tropicais do Estado de São Paulo analisadas.

\section{Relações entre nutrientes}

Algumas das principais relações entre nutrientes são apresentadas na Tabela 18.

Tabela 18. Relação entre nutrientes na matéria seca da parte aérea de Cynodon dactylon (L.) Pers. cv. Florakirk, em função da idade de corte ${ }^{(1)}$.

\begin{tabular}{|c|c|c|c|}
\hline \multirow{2}{*}{$\begin{array}{l}\text { Dias após o } \\
\text { rebaixamento }\end{array}$} & $N: S$ & Ca:P & \multirow{2}{*}{$\frac{\mathrm{K}:(\mathrm{Ca}+\mathrm{Mg})}{\left(\mathrm{meq} \mathrm{meq}^{-1}\right)}$} \\
\hline & \multicolumn{2}{|c|}{$\left(\mathrm{g} \mathrm{g}^{-1}\right)$} & \\
\hline 20 & 11,98 a & $0,61 a$ & 1,85 a \\
\hline 30 & $8,94 \quad b$ & $0,88 \quad b$ & $1,41 \quad b c$ \\
\hline 40 & 7,75 bc & $0,82 \quad b$ & $1,57 a b$ \\
\hline 50 & 6,39 & $0,90 \quad b$ & $1,39 \quad b c$ \\
\hline 60 & 6,67 & $0,57 a$ & 1,13 \\
\hline 70 & 7,22 bc & $0,74 \quad b$ & 0,71 \\
\hline C.V. (\%) & 18,32 & 5,92 & 13,00 \\
\hline
\end{tabular}

(1) médias seguidas de mesma letra, na mesma coluna, não diferem estatisticamente pelo teste $t$ de Student $(P>0,05)$.

A relação N:S decresceu com a idade de corte, variando de 6,39 a 11,98. Este decréscimo ocorreu devido à redução na concentração de $\mathrm{N}$ com o avanço da 
maturidade, uma vez que a concentração de $S$ manteve-se constante até os 60 dias de idade.

Observou-se em todas as idades de corte relação N:S inferior ao intervalo de 12:1 a 15:1, considerado ideal por Follett \& Wilkinson (1995) para a máxima produção vegetal, $e$ inferior a 14:1, valor no qual a relação tende a se estabilizar quando as gramineas atingem a maturidade, segundo Vitti \& Novaes (1986).

Segundo Church (1993), a relação N:S ideal é 15:1 para bovinos e 10:1 a 12:1 para ovinos e, segundo Van Soest (1994), 12:1 para os microrganismos ruminais. Assim, a relação N:S obtida neste trabalho só atenderia a exigência de ovinos aos 20 dias de idade da planta.

A baixa relação $\mathrm{N}: \mathrm{S}$ observada deve-se, em parte, a concentrações de $S$ acima das exigências animais.

A relação Ca:P observada em todas as idades de corte (de 0,57 a 0,90 ) foi inferior a 1:1, valor mínimo apresentado por Wise et al. (1963), Underwood (1981) e Vrzgula \& Bartko (1991), sendo que os primeiros observaram efeitos negativos no crescimento e na eficiência alimentar de bezerros recebendo dieta com relação Ca: $P$. inferior a 1:1. Entretanto, segundo Boin (1985), quando as exigências de $P$ são atendidas (o que ocorreria neste caso), a relação Ca:P deixa de ser importante.

Esta baixa relação Ca:P deve-se principalmente à elevada concentração de $P$ observada em todas as idades de corte, e também aos niveis de $\mathrm{Ca}$, que são insuficientes para suprir as exigências da maioria das categorias animais. Church (1993) não observou prejuizos à produção de leite em dietas com $55 \mathrm{~g} \mathrm{P} \mathrm{kg}^{-1}$, porém, em dietas com altos níveis de $\mathrm{P}$ associados à niveis relativamente baixos de $\mathrm{Ca}$, há elevada incidência de cálculos urinários em ovinos.

Apesar da elevada concentração de $K$ nos estádios iniciais de desenvolvimento do capim (Tabela 16$)$, a relação $\mathrm{K}:(\mathrm{Ca}+\mathrm{Mg})$ não foi superior a 2,2 (em miliequivalente) (Tabela 18), sendo improvável a ocorrência de tetania das pastagens (Kempt \& 't Hart, 1957; Grunes \& Welch, 1989). Até os 60 dias de idade, a concentração de $\mathrm{Mg}$ foi superior ou igual a $2,5 \mathrm{~g} \mathrm{~kg}^{-1}$, limite mínimo considerado seguro por Grunes \& Welch (1989) para evitar a tetania das pastagens em condições de altos niveis de $\mathrm{N}$ e $\mathrm{K}$. 


\subsubsection{Micronutrientes}

A concentração dos micronutrientes $\mathrm{B}, \mathrm{Cu}, \mathrm{Fe}, \mathrm{Mn}$ e $\mathrm{Zn}$ e o acúmulo destes na matéria seca do capim Florakirk, em função da idade de corte, estão apresentados nas Tabelas 19 e 20 , respectivamente.

Tabela 19. Teores de micronutrientes na matéria seca $\left(\mathrm{mg} \mathrm{kg}^{-1}\right)$ da parte aérea de Cynodon dactylon (L.) Pers. Cv. Florakirk, em função da idade de corte ${ }^{(1)}$.

\begin{tabular}{|c|c|c|c|c|c|c|c|}
\hline \multirow{2}{*}{$\begin{array}{l}\text { Dias após o } \\
\text { rebaixamento }\end{array}$} & $\mathrm{B}^{(2)}$ & $\mathrm{Cu}$ & $\mathrm{Fe}$ & & $\mathrm{Mn}$ & \multicolumn{2}{|l|}{$\mathrm{Zn}$} \\
\hline & \multicolumn{7}{|c|}{$\mathrm{mg} \mathrm{kg}^{-1}$} \\
\hline 20 & 9,7 a & 4,3 bc & 131,3 & a & $91,1 a b$ & $36,5=$ & \\
\hline 30 & $7,7 a$ & $6,3 a$ & 118,8 & $a$ & 118,1 a & 29,0 & $b$ \\
\hline 40 & $7,3 a$ & $5,9 a$ & 78,8 & b & $109,7 a b$ & 26,4 & bc \\
\hline 50 & 7,2 a & $5,4 a b$ & 65,6 & $b$ & $81,5 \quad b$ & 29,8 & b \\
\hline 60 & $6,9 a$ & $3,7 \quad c$ & 74,8 & $b$ & $86,6 a b$ & 30,4 & b \\
\hline 70 & $8,7 a$ & 4,2 bc & 89,5 & $b$ & $84,5 a b$ & 23,2 & $c$ \\
\hline C.V. (\%) & 14,6 & 17,8 & 18,9 & & 25,2 & 11,5 & \\
\hline
\end{tabular}

(1) médias seguidas de mesma letra, na mesma coluna, não diferem estatisticamente pelo teste t de Student $(P>0,05) ;{ }^{(2)}$ transformação de variável: $B=\log (x)$.

Tabela 20. Acúmulo de micronutrientes na matéria seca $\left(\mathrm{mg} \mathrm{m}^{-2}\right)$ da parte aérea de Cynodon dactylon (L.) Pers. cv. Florakirk, em função da idade de corte $e^{(1)}$.

\begin{tabular}{|c|c|c|c|c|c|c|c|c|}
\hline \multirow{2}{*}{$\begin{array}{c}\text { Dias após o } \\
\text { Rebaixamento }\end{array}$} & \multicolumn{2}{|l|}{$B$} & $\mathrm{Cu}$ & \multicolumn{2}{|l|}{$\mathrm{Fe}$} & \multirow[t]{2}{*}{ Mn } & \multicolumn{2}{|c|}{$\mathrm{Zn}$} \\
\hline & & & & $\mathrm{mg} \mathrm{m}^{-}$ & & & & \\
\hline 20 & 0,41 & $d$ & 0,18 & 5,37 & $d$ & 3,83 & 1,49 & c \\
\hline 30 & 0,70 & cd & $0,57 \quad b$ & 9,92 & $c$ & $10,98 \quad b$ & 2,55 & c \\
\hline 40 & 1,03 & $b c$ & $0,82 a$ & 10,54 & c & $15,03 a b$ & 3,63 & $b$ \\
\hline 50 & 1,17 & $b$ & $0,86 a$ & 9,15 & c & $13,10 \quad b$ & 4,81 & $a$ \\
\hline 60 & 1,15 & $b$ & 0,77 a & 13,90 & b & $14,10 a b$ & 5,63 & a \\
\hline 70 & 1,86 & a & 0,91 a & 19,11 & & $18,23 a$ & 5,03 & a \\
\hline C.V. (\%) & 13,99 & & 7,95 & 4,32 & & 24,68 & 12,38 & \\
\hline
\end{tabular}

(1) médias seguidas de mesma letra, na mesma coluna, não diferem estatisticamente pelo teste t de Student $(P>0,05)$. 
Com exceção do $\mathrm{B}$, a concentração dos demais micronutrientes diferiram significativamente em função da idade de corte $(P<0,05)$. A variação nos teores de $B$ e Fe deu-se de forma quadrática (Figura 6), com concentração máxima aos 20 dias (9,6 mg B e 138,3 $\mathrm{mg} \mathrm{Fe} \mathrm{kg}^{-1}$, respectivamente), e mínima aos 48 dias $\left(6,9 \mathrm{mg} \mathrm{B} \mathrm{kg}^{-1}\right)$ e aos 54 dias $\left(71,6 \mathrm{mg} \mathrm{Fe} \mathrm{kg}^{-1}\right)$, respectivamente, segundo as equações de regressão. Para $\mathrm{Cu}, \mathrm{Mg}$ e $\mathrm{Zn}$, a variação deu-se de forma cúbica (Figura 6). Castro (1997) não observou diferença significativa na concentração de B e Cu em Florico com o avanço da idade de corte.

A variação na concentração de micronutrientes com o aumento da idade de corte foi menor que a observada nos macronutrientes, não apresentando um comportamento típico. Segundo Underwood (1971), não há declínios consideráveis na concentração de micronutrientes com 0 avanço da maturidade e podem ocorrer mudanças não consistentes com o estádio de crescimento.

A menor variação ocorreu na concentração de B (29\%) e a maior na concentração de $\mathrm{Fe}(50 \%)$, sendo esta inferior à maior variação observada com os macronutrientes $(72,2 \%$ com o K). Segundo NRC (1996), o conteúdo de Fe das forragens é muito variável e parte desta variação é devida a contaminação pelo solo.

Conforme a concentração normal de minerais em plantas apresentadas por Follett \& Wilkinson (1995), as concentraçōes de B e Cu observadas seriam deficientes, enquanto as de $M n$ e $Z n$ seriam excessivas. Porém, Camargo et al. (1985) e Malavolta et al. (1986), observaram, no Estado de São Paulo, concentrações de Cu e $\mathrm{Zn}$ semelhantes às apresentadas na Tabela 19 e concentrações de Mn superiores às mesmas.

As concentrações de $\mathrm{Cu}$ foram muito próximas da concentração considerada, por Follett \& Wilkinson (1995), como deficiente nas plantas $\left(<5 \mathrm{mg} \mathrm{kg}^{-1}\right)$.

Palhano \& Haddad (1992) obtiveram, em Coastcross-1, concentrações médias de micronutrientes superiores às observadas neste trabalho, com exceção do $\mathrm{Zn}$. 0 excesso de $\mathrm{Zn}$ na planta pode estar associado aos altos niveis do nutriente no solo. Em Florico, os teores de $\mathrm{Fe}$ e $\mathrm{Zn}$ foram superiores aos de Florakirk, o mesmo não ocorrendo com $\mathrm{B}, \mathrm{Cu}$ e $\mathrm{Mn}$, cujos teores médios foram semelhantes em ambas as cultivares (Castro, 1997). 
(a) $\quad Y=0,000182 X^{2}-0,0175 X+1,260\left(R^{2}=0,898\right)$
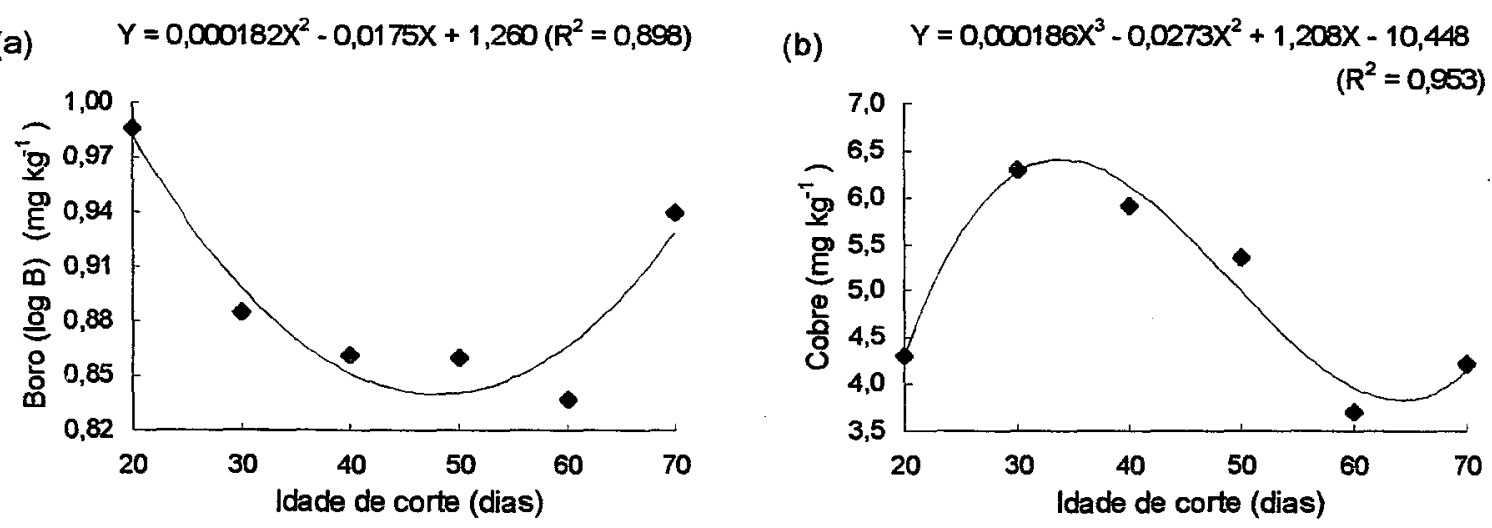

(c) $\quad Y=0,0594 X^{2}-6,3571 X+241,64\left(R^{2}=0,908\right)$

(d) $\quad Y=0,00277 X^{3}-0,391 X^{2}+16,486 X-102,89$
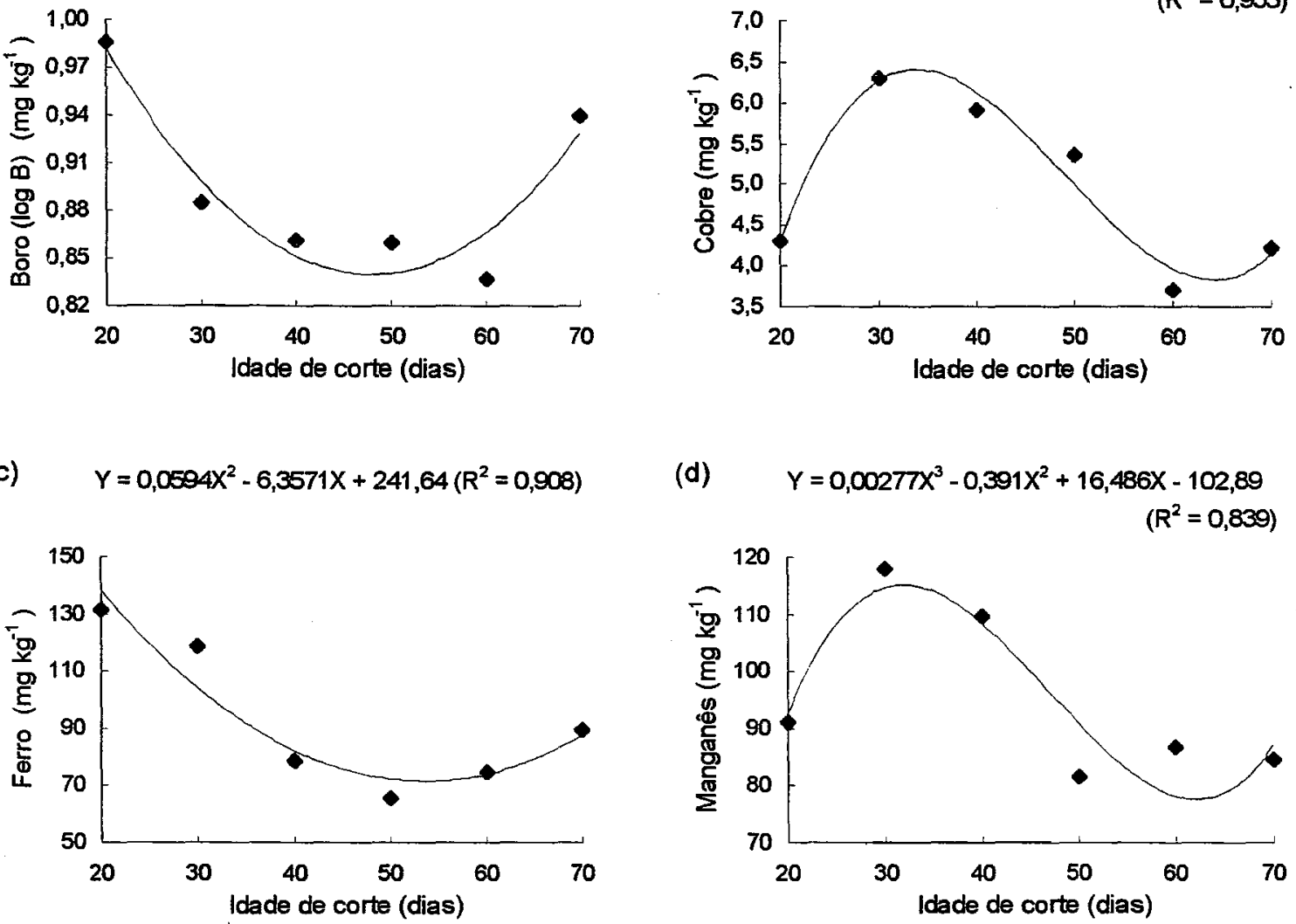

(e)

$$
\begin{array}{r}
Y=-0,000828 X^{3}+0,1145 X^{2}-5,0211 X+98,06 \\
\left(R^{2}=0,978\right)
\end{array}
$$

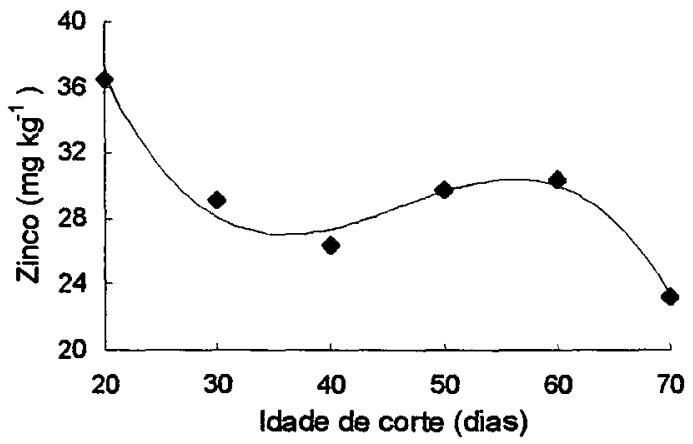

Figura 6 - Teores de micronutrientes na matéria seca $\left(\mathrm{mg} \mathrm{kg}^{-1}\right)$ da parte aérea de Cynodon dactylon (L.) Pers. cv. Florakirk, em função da idade de corte. 
Segundo Gallo et al. (1974), 80\% das amostras de gramíneas analisadas no Estado de São Paulo continham de 10 a $20 \mathrm{mg} \mathrm{B} \mathrm{kg}^{-1}$, enquanto Malavolta et al. (1986) observaram concentração média de $17 \mathrm{mg} \mathrm{B} \mathrm{kg}^{-1}$ numa condição semelhante. As concentrações de $B$ na planta obtidas neste trabalho foram inferiores e podem ser decorrentes do baixo teor do nutriente no solo.

Entre o corte de rebaixamento e o de 70 dias de idade, houve uma elevação no $\mathrm{pH}$ do solo (Tabela 12), com aumento na disponibilidade dos micronutrientes no solo, inclusive de B e Mn, cuja disponibilidade, segundo Fleming (1973) e Matos \& Colozza (1986), decresce com o aumento do pH. O aumento na disponibilidade de $\mathrm{B}$ e Mn deve-se, provavelmente, à disponibilização dos micronutrientes do fertilizante aplicado. $O$ aumento dos demais micronutrientes no solo pode ser devido ao aumento do $\mathrm{pH}$, associado à disponibilização dos micronutrientes contidos no fertilizante. Este aumento nos niveis de micronutrientes do solo não foi acompanhado por aumento na concentração dos mesmos na planta.

Apesar da elevada concentração de $\mathrm{P}$ na planta não se observou deficiência de $\mathrm{Zn}$, conforme sugerido por Marschner (1986), uma vez que esta concentração de $P$ não está associada ao excesso de $\mathrm{P}$ no solo, o que inibiria a absorção de $\mathrm{Zn}$ pela planta, e nem a um crescimento acentuado da planta, o que acarretaria na diluição do Zn na planta.

$\mathrm{O}$ acúmulo de micronutrientes na MS de Florakirk (Tabela 20) aumentou com o avanço da idade de corte, sendo de forma linear para o $\mathrm{B}$, quadrática para Zn e cúbica para $\mathrm{Cu}, \mathrm{Fe}$ e $\mathrm{Mn}$ (Figura 7). $\mathrm{O}$ acúmulo máximo de $\mathrm{B}, \mathrm{Cu}, \mathrm{Mn}$ e Fe deu-se aos 70 dias de crescimento e de $\mathrm{Zn}$ aos 68 dias. Ao contrário dos macronutrientes, o acúmulo de micronutrientes foi influenciado principalmente pela produção de MS, uma vez que a variação na concentração de micronutrientes na planta foi menor. 


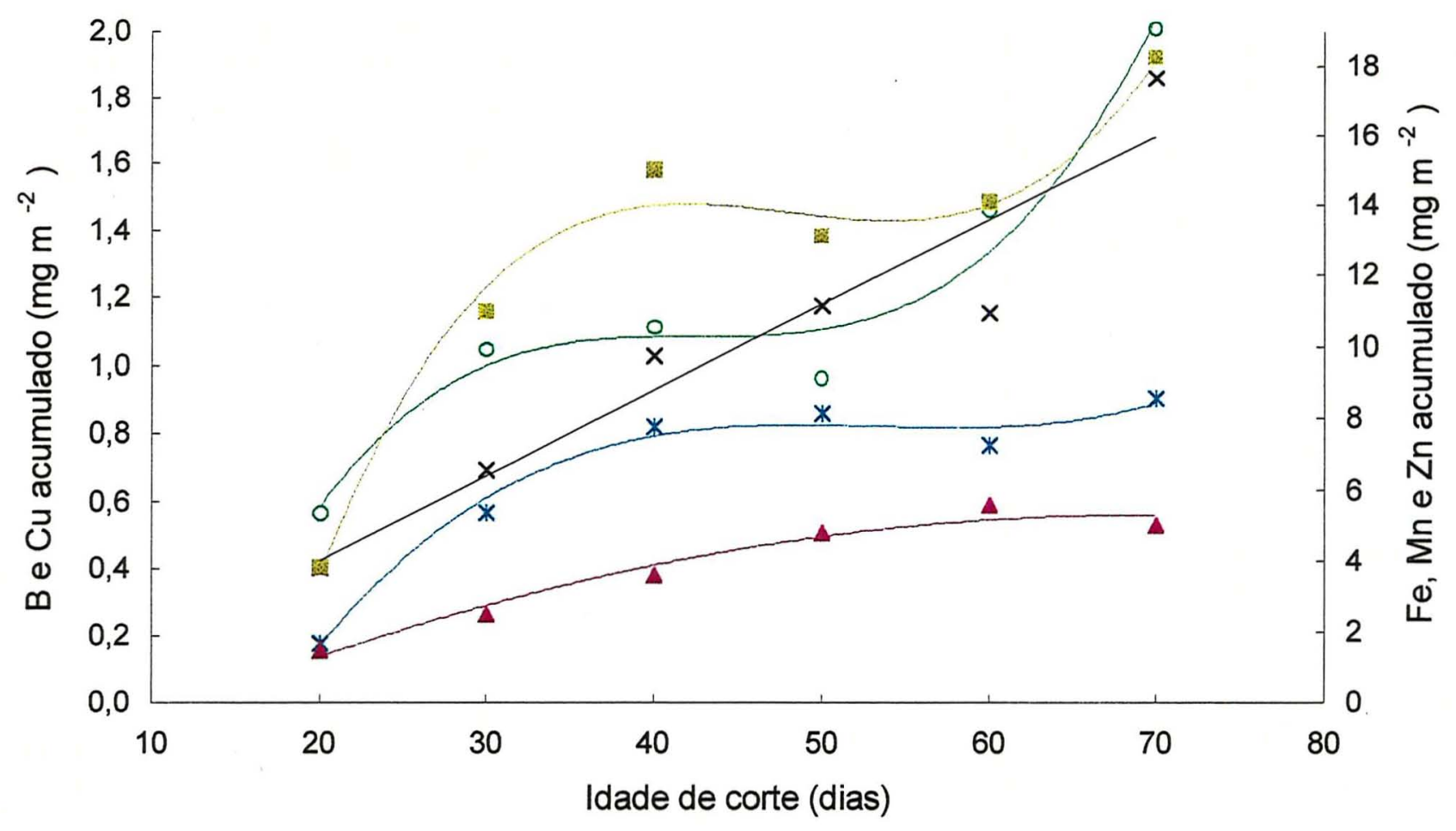

* $\mathrm{Cu} \times \mathrm{B} \circ \mathrm{Fe} \mathrm{Mn} \Delta \mathrm{Zn}$
B : $Y=0,0251 X-0,0752$
$\left(R^{2}=0,902\right)$
Wn: $Y=0,000537 X^{3}-0,0773 X^{2}+3,6522 X-42,789\left(R^{2}=0,983\right)$
$\mathrm{Cu}: Y=0,0000193 X^{3}-0,00307 X^{2}+0,1615 X-1,991 \quad\left(R^{2}=0,981\right)$
$Z n: Y=-0,0017 X^{2}+0,2304 X-2,6462$
$\left(R^{2}=0,964\right)$
Fe : $Y=0,00043 X^{3}-0,0545 X^{2}+2,3026 X-22,134 \quad\left(R^{2}=0,967\right)$

Figura 7 - Acúmulo de micronutrientes na matéria seca $\left(\mathrm{mg} \mathrm{m}^{-2}\right)$ da parte aérea de Cynodon dactylon (L.) Pers. cv.

Florakirk, em função da idade de corte. 


\section{Exigência animal}

Conforme as Tabelas 2, 3 e 4 (NRC 1989a; 1989b; 1996), os teores de Cu em todas as idades de corte foram insuficientes para suprir as exigências de bovinos e eqüinos, o mesmo ocorrendo com o $\mathrm{Zn}$, com exceção aos 20 e 60 dias de idade, cuja concentração seria suficiente para atender as exigências de bovinos de corte. As concentrações de $\mathrm{Fe}$ e $\mathrm{Mn}$ foram adequadas para todas as categorias animais apresentadas, sem problemas de toxidez, embora Church (1993) considere concentrações de 75 a 200 mg Mn kg-1 ligeiramente excessivas para os animais.

A deficiência de $Z n$ pode ser acentuada devido à elevada concentração de $P$ e ao antagonismo entre os dois nutrientes, afetando a absorção de $\mathrm{Zn}$ pelo animal (Georgievskii et al., 1982).

Segundo Spears (1994), os niveis de $\mathrm{Zn}$ recomendados pelo NRC (1989a; 1996) seriam superestimados e, segundo Minson (1990), dietas com 16 a $26 \mathrm{mg} \mathrm{Zn}$ $\mathrm{kg}^{-1}$ seriam suficientes para ruminantes; assim, apenas aos 70 dias de idade, a concentração de Zn seria deficiente em relação à exigência animal.

A ocorrência de deficiência de $\mathrm{Zn}$, em relação à exigência animal, foi observada por Gallo et al. (1974) em diversos trabalhos realizados no Estado de São Paulo e em aproximadamente $75 \%$ das amostras de forrageiras da América Latina analisadas por Fick et al. (1978).

\section{4 Ácido Cianídrico}

A concentração de $\mathrm{HCN}$ na matéria verde do capim Florakirk, em função da idade de corte, é apresentada na Tabela 21.

A variação no teor de $\mathrm{HCN}$ deu-se de forma linear (Figura 8), com concentração máxima (na matéria verde) aos 20 dias $\left(67 \mathrm{mg} \mathrm{kg}^{-1}\right.$ ) e mínima aos 70 dias $\left(20,3 \mathrm{mg} \mathrm{kg}^{-1}\right)$, segundo a equação de regressão.

Segundo a classificação proposta por Harris \& Shearer (1994), a cultivar Florakirk, nas condições deste estudo, foi adequada para pastejo em relação à concentração de HCN, pois a mesma não ultrapassou $100 \mathrm{mg} \mathrm{kg}^{-1}$ (matéria verde). 
Tabela 21. Teor de $\mathrm{HCN}$ na matéria verde $\left(\mathrm{mg} \mathrm{kg}^{-1}\right)$ da parte aérea de Cynodon dactylon (L.) Pers. cv. Florakirk, em função da idade de corte ${ }^{(1)}$.

\begin{tabular}{cc}
\hline Dias após o rebaixamento & $\mathrm{HCN}\left(\mathrm{mg} \mathrm{kg}^{-1}\right)$ \\
\hline 20 & $68,4 \mathrm{a}$ \\
30 & $60,7 \mathrm{ab}$ \\
40 & 35,3 bc \\
50 & $48,7 \mathrm{ab}$ \\
60 & 31,5 bc \\
70 & $17,8 \quad \mathrm{c}$ \\
\hline C.V. (\%) & 45,8 \\
\hline
\end{tabular}

(1) médias seguidas de mesma letra, na mesma coluna, não diferem estatisticamente pelo teste de Tukey $(P>0,05)$;

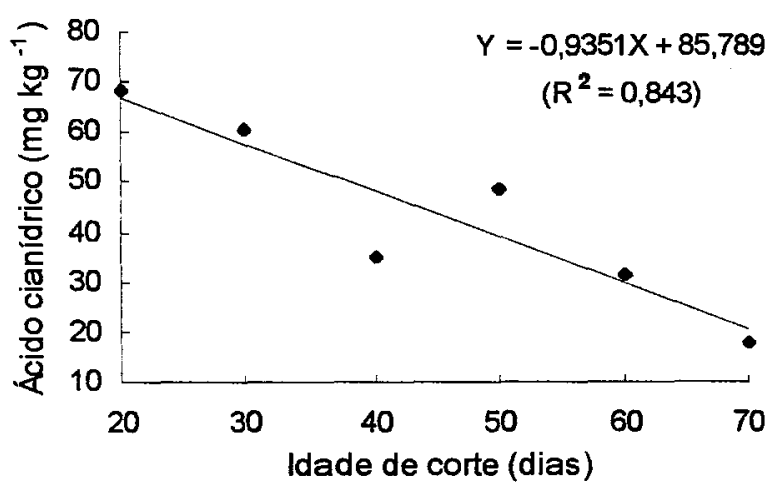

Figura 8 - Teor de $\mathrm{HCN}$ na matéria verde $\left(\mathrm{mg} \mathrm{kg}^{-1}\right)$ da parte aérea de Cynodon dactylon (L.) Pers. cv. Florakirk, em função da idade de corte.

A máxima concentração de $\mathrm{HCN}$ em relação à matéria seca ocorreu aos 20 dias (262 mg kg-1), sendo inferior a $750 \mathrm{mg} \mathrm{kg}^{-1}$, concentração a partir da qual Boyad et al. (1938) consideram perigosa para animais ruminantes.

Diversos fatores afetam o nivel de HCN na planta, dentre os quais estádio de crescimento, clima, adubação nitrogenada e o manuseio do material vegetal (Schroder, 1997; Aguilera, citado por Herrera, 1996), sendo difícil isolar o efeito de 
cada um.

Schroder (1997), Vélez-Santiago et al. (1979) e Aguilera, citado por Herrera (1996), observaram, em grama estrela e bermuda, redução na concentração de HCN associada ao aumento na maturação da planta, o mesmo ocorrendo com a Florakirk (Tabela 21). Entretanto, Castro (1997) não observou efeito da idade de corte sobre a concentração de $\mathrm{HCN}$ na grama estrela Florico, embora a concentração média $(88,7 \mathrm{~g}$ $\mathrm{kg}^{-1}$ ) tenha sido superior à observada em Florakirk.

O declínio na concentração de $\mathrm{HCN}$ pode ser devido também à redução na concentração de $\mathrm{N}$ na planta, ocorrido com o aumento da idade de corte (Tabela 16).

A concentração de $\mathrm{HCN}$ observada na cultivar Florakirk aos 20 dias após o corte de rebaixamento foi superior às concentrações apresentadas por Schroder (1977) para as cultivares Coastal, Coastcross-1, Callie e hibrido 74-68, cortadas a intervalos de 21 dias e com aplicação de $336 \mathrm{~kg} \mathrm{~N} \mathrm{ha}^{-1}$ ano-1. $^{-1}$.

Com exceção do corte aos 70 dias, onde a concentração de $S$ foi insuficiente para atender à necessidade de categorias animais mais exigentes, o $\mathrm{S}$ presente na planta seria suficiente para detoxicar o $\mathrm{HCN}$, pois, atendidas as exigências animais (Tabelas 2 e 3), o excesso de $S$ superou a relação $1,2 \mathrm{~g}$ de $\mathrm{S}$ por grama de HCN, indicada por Bird et al. (citado por Durand \& Komisarczuk, 1988) para a formação de tiocianeto (composto não tóxico).

\subsection{Considerações Gerais}

Devido à suscetibilidade da cultivar Florakirk à doenças foliares, a avaliação dos efeitos da doença no valor nutritivo e no desempenho animal permitiria determinar a necessidade ou não de controle ou práticas de manejo que minimizariam as perdas na qualidade da forragem, como por exemplo o corte antecipado da pastagem.

Atravẻs da análise de outras variáveis, como concentração de lignina, relação folha:haste e análise bromatológica das frações folha e haste, obter-se-iam outras informações que, provavelmente, auxiliariam na interpretação dos resultados apresentados. 


\section{CONCLUSÕES}

Dentro das condições experimentais observadas no presente trabalho, concluise que:

- a produção de matéria seca de Florakirk aumenta com o avanço da idade de corte, embora seja inferior à observada em outros trabalhos.

- a digestibilidade da matéria seca, da matéria orgânica e de FDN decrescem com a idade, sendo o valor de digestibilidade da matéria seca considerado como limitante para o consumo observado a partir de 40 dias de idade.

- até os $\mathbf{4 0}$ dias de idade, a concentração de proteína bruta atende às necessidades minimas das diversas categorias animais, inclusive das mais exigentes.

- o efeito da idade de corte é superior na concentração de macronutrientes quando comparado ao efeito na concentração de micronutrientes.

- as concentrações de macronutrientes em Florakirk, com exceção do cálcio em idades mais avançadas, são adequadas para a nutrição de bovinos e eqüinos. Deficiências de cobre e zinco e relação Ca:P inadequada podem ser corrigidas através de suplementação mineral.

- a presença de glucosídeos cianogênicos em Florakirk não limita a sua utilização, pois a concentração de ácido cianídrico não atinge limites considerados tóxicos e reduz com o avanço da idade.

- considerando-se a associação entre produção de forragem, valor nutritivo e exigência animal, a idade ideal para utilização da pastagem de Florakirk seria aos 40 dias de crescimento da planta, embora a manutenção de niveis aceitáveis de digestibilidade, FDN e FDA em Florakirk, com estádio de maturação avançado, 
permita o aproveitamento desta forrageira na forma de pastejo diferido.

- a suscetibilidade de Florakirk ao ataque de cigarrinha e à doenças foliares pode inviabilizar a exploração econômica desta forragem. 


\section{REFERÊNCIAS BIBLIOGRÁFICAS}

ADJEI, M.B.; MISLEVY, P.; KALMBACHER, R.S.; BUSEY, P. Production, quality, and persistence of tropical grasses as influenced by grazing frequency. Proceedings of Soil and Crop Science Society of Florida, v.48, p.1-6, 1989.

AGRIOS, G.N. Plant pathology. 3.ed. San Diego: Academic Press, Inc., 1988. 803p.

AMMERMAN, C.B.; MOORE, J.E.; HENRY, P.R. et al. Effect of age and sample preparation on mineral concentration of bermudagrass hay. Journal of Dairy Science, v.65, n.7, p.1329-33, July 1982.

ARROYO-AGUILÚ, J.A.; COWARD-LORD, J. Relationships between and within physical and chemical constituents and in vitro true digestibility in tropical forage grasses. Journal of Agriculture of University of Puerto Rico, v.58, n.4, p.43747, Oct. 1974.

ASSOCIATION OFFICIAL ANALYTICAL CHEMISTS. Offical methods of analysis. 16.ed. Washington: AOAC, 1995. 1015p. 2v.

BARBETTI, M.J.; JONES, R.A.C.; RILEY, I.T. Problems and progress in assessing direct and indirect yield losses caused by pathogens in pasture species. In: CHAKRABORTY, S.; LEATH, K.T.; SKIPP, R.A. et al. Pasture and forage crop pathology. Madison: ASA, CSSA, SSSA, 1996. p.63-118.

BARNES, F.R.; GUSTINE, D.L. Allelochemistry and forage crop. In: MATCHES, A.G.; HOWELL. R.W., ed. Anti-quality components of forage. Madison: CSSA, 1973. p.1-13. 
BATAGLIA, O.C. Determinação indireta de enxofre em plantas por espectrofotometria de absorção atômica. Ciência e Cultura, v.28, n.6, p.672-5, jun. 1976.

BOIN, C. Exigências de minerais pelas categorias do rebanho bovino e funções desses nutrientes. In: SIMPÓSIO SOBRE NUTRIÇÃO DE BOVINOS, 3. Piracicaba, 1985. Anais. Piracicaba: FEALQ, 1985. p.15-46.

BOYD, F.T.; AAMODT, O.S.; BOHSTEDT, G.; TROUG, G. Sundangrass management for control of cyanide poisoning. Journal of American Society of Agronomy, v.30, n.7, p.569-82, July 1938.

BROWN, W.F.; PITMAN, W.D.; MISLEVY, P. Intake and digestibility of, and performance by, cattle grazing Cynodon varieties. Nutrition Reports International, v.38, n.6, p.1201-9, Dec. 1988.

BURTON G.W. Registration of Coastcross-1 Bermudagrass. Crop Science, v.12, n.1, p.125, Jan./Feb. 1972.

BURTON, G.W.; MONSON, W.G. Registration of 'Tifton 44' Bermudagrass. Crop Science, v.18, n.5, p.911, Sep./Oct. 1978.

BURTON, G.W.; MONSON, W.G. Registration of 'Tifton 68' Bermudagrass. Crop Science, v.24, n.6, p.1211, Nov./Dec. 1984.

BURTON, G.W.; MONSON, W.G. Registration of 'Tifton 78' Bermudagrass. Crop Science, v.28, n.1, p.187-8, Jan./Feb. 1988.

BURTON, G.W.; GATES, R.N.; HILL, G.M. Registration of 'Tifton 85' Bermudagrass. Crop Science, v.33, n.3, p.644-5, May/June 1993.

BUXTON, D.R.; FALES, S.L. Plant environment and quality. In: FAHEY Jr., G.C. ed. Forage quality, evaluation, and utilization. Madison: ASA, CSSA, SSSA, 1994. p.155-99.

BUXTON, D.R.; MERTENS, D.R. Quality-related characteristics of forages. In: BARNES, R.F.; MILLER, D.A.; NELSON, C.J. Forages: the science of grassland agriculture. 5.ed. lowa: lowa State University Press, 1995. v.2, p.83-96. 
BUXTON, D.R.; REDFEARN, D.D. Plant Limitations to fiber digestion and utilization. Journal of Nutrition, v.127, p.814S-8S, 1997. Supplement, 5 S.

CAMARGO, W.V. de A.; SANTIAGO, A.M.H.; PRUCOLI, J.O. et al. Teores minerais em gramíneas no Estado de São Paulo. Revista Brasileira de Medicina Veterinária, v.7, n.1, p.3-7, fev. 1985.

CASTRO, F.G.F. Efeito da idade de corte sobre a produção, composição químicabromatológica, digestibilidade in vitro da matéria seca e da matéria orgânica e conteúdo de ácido cianidrico de C. nlemfuensis Vanderyst var. nlemfuensis cv. Florico. Piracicaba, 1997. 128p. Dissertação (Mestrado) - Escola Superior de Agricultura "Luiz de Queiroz", USP.

CHURCH, D.C. EI ruminante: fisiologia digestiva y nutricion. Zaragoza: Editorial ACRIBIA, 1993. 641p.

CORSI, M.; Produção e qualidade de forragens tropicais. In: SOCIEDADE BRASILEIRA DE ZOOTECNIA. Novas tecnologias de produção animal. Piracicaba: FEALQ, 1990. p.177-93.

CORSI, M.; SILVA, R.T. de L. Fatores que afetam a composição mineral de plantas forrageiras. In: SIMPÓSIO SOBRE NUTRIÇÃO DE BOVINOS, 3., Piracicaba, 1985. Anais. Piracicaba: FEALQ, 1985. p.1-14.

CROWDER, L.V.; CHHEDA, H.R. Tropical grassland husbandry. New York: Longman, 1982. 561p. (Tropical agriculture series).

DE WET, J.M.J.; HARLAN, J.R. Biosystematics of Cynodon L. C. Rich. (Gramineae). Taxon, v.19, p.565-9, Aug. 1970.

DURAND, M.; KOMISARCZUK, S. Influence of major minerals on rumen microbiota. Journal of Nutrition, v.118, n.2, p.249-60, Feb. 1988.

ELLIS, R.P. A review of comparative leaf blade anatomy in the systematics of the Poaceae: the past twenty-five years. In: SODERSTROM, T.R.; HILU, K.W.; CAMPBELL, C.S.; BARKWORTH, M.E. Grass: systematics and evolution. 
Washington: Smithsonian Institution Press, 1986. p.3-10.

ESPINOSA, W.; GARCIA, F.; ALMAGUER, N. Edades al corte y dias de henificacion sobre el rendimiento de MS y caracteristicas del heno de Bermuda Cruzada 1 (Cynodon dactylon $x$ Cynodon nlemfuensis). Ciencia y Tecnica en la Agricultura, Pastos y Forrajes, v.8, n.1, p.49-59, abr. 1985.

FICK, K.R.; MCDOWELL, L.R.; HOUSER, R.H. Current status of mineral research in Latin America. In: LATIN AMERICAN SYMPOSIUM ON MINERAL NUTRITION RESEARCH WITH GRAZING RUMINANTS, Belo Horizonte, 1976. Proceedings. Gainesville: University of Florida, 1978. p.149-62.

FLEMING, G.A. Mineral composition of herbage. In: BUTLER, G.W.; BAILEY, R.W. Chemistry and biochemistry of herbage. New York: Academic Press, 1973. v.1, p.529-66.

FOLLETT, R.F.; WILKINSON, S.R. Nutrient management of forages. In: BARNES, R.F.; MILLER, D.A.; NELSON, C.J. Forages: the science of grassland agriculture. 5.ed. lowa: lowa State University Press, 1995. v.2, p.55-82.

FONTENOT, J.P.; ALLEN, V.G.; BUNCE, G.E. et al. Factors influencing magnesium absorption and metabolism in ruminants. Journal of Animal Science, v.67, n.12, p.3445-55, Dec. 1989.

FORBES, J.M. Voluntary food intake and diet selection in farm animals. Wallingford: $C A B$ International, 1995. 532p.

GALLO, J.R.; HIROCE, R.; BATAGLIA, O.C. et al. Composição quimica inorgânica de forrageiras do Estado de São Paulo. Boletim da Indústria Animal, v.31, n.1, p.115-37, jan.jun. 1974.

GEORGIEVSKII, V.I.; ANNENKOV, B.N.; SAMOKHIN, V.T. Mineral nutrition of animals. London: Butterworths, 1982. 475p.

GOERING, H.K.; VAN SOEST, P.J. Forage fiber analysis: apparatus, reagents, procedures and some applications. Washington: USDA, 1970. 20p. (USDA. 
Agriculture Handbook, 379).

GOMIDE, C.C.C. Algumas características fisiológicas e químicas de cinco cultivares de Cynodon. Jaboticabal, 1996. 77p. Dissertação (Mestrado) - Faculdade de Ciências Agrárias e Veterinárias, UNESP.

GOMIDE, J.A. Mineral composition of grasses and tropical leguminous forages. In: LATIN AMERICAN SYMPOSIUM ON MINERAL NUTRITION RESEARCH WITH GRAZING RUMINANTS, Belo Horizonte, 1976. Proceedings. Gainesville: University of Florida, 1978. p.32-40.

GOMIDE, J.A; NOLLER, C.H.; MOTT, G.O. et al. Effect of plant age and nitrogen fertilization on the chemical composition and in vitro cellulose digestibility of tropical grasses. Agronomy Journal, v.61, n.1, p.116-20, Jan./Feb. 1969a.

GOMIDE, J.A; NOLLER, C.H.; MOTT, G.O. et al. Mineral composition of six tropical grasses as influenced by plant age and nitrogen fertilization. Agronomy Journal, v.61, n.1, p.120-3, Jan./Feb. 1969b.

GONZALEZ, Y.; OILDA, T. Niveles críticos de K en Guinea Común SIH-127, Buffel cv. Biloela y Bermuda Cruzada-1 cv. Coast-cross no⒈ Pastos y Forrajes, v.5, n.1, p.49-57, 1982

GRIFFIN, J.L.; WATSON, V.H. Production and quality of four bermudagrasses as influenced by rainfall patterns. Agronomy Journal, v.74, n.6, p.1044-7, Nov./Dec. 1982.

GROSS, C.F.; JUNG, G.A. Magnesium, $\mathrm{Ca}$, and $\mathrm{K}$ concentration in temperate-origin forage species as affected by temperature and $\mathrm{Mg}$ fertilization. Agronomy Journal, v.70, n.3, p.397-403, May/June 1978.

GROSS, C.F.; JUNG, G.A. Season, temperature, soil $\mathrm{pH}$, and Mg fertilizer effects on herbage $\mathrm{Ca}$ and $\mathrm{P}$ levels and ratios of grasses and legumes. Agronomy Journal, v.73, n.4, p.629-34, July/Aug. 1981.

GRUNES, D.L.; WELCH, R.M. Plant contents of magnesium, calcium and potassium 
in relation to ruminant nutrition. Journal of Animal Science, v.67, n.12, p.3485-94, Dec. 1989.

GUTIERREZ-ORNELAS, E.; KLOPFENSTEIN, T.J. Changes in availabity and nutritive value of different corn residue parts as affected by early and late grazing seasons. Journal of Animal Science, v.69, n.4, p.1741-50, Apr. 1991.

HAAG, H.P. ed. Nutrição mineral de forrageiras no Brasil. Campinas: Fundação Cargill, 1984. 152p.

HADDAD, C.M.; PLATZECK, C.O. Administração e consumo de um suplemento mineral. In: SIMPÓSIO SOBRE NUTRIÇÃO DE BOVINOS, 3., Piracicaba, 1985. Anais. Piracicaba: FEALQ, 1985. p.67-86.

HAMILTON, R.I.; LAMBOURNE, L.J.; ROE, R.; MINSON, D.J. Quality of tropical grasses for milk production. In: INTERNATIONAL GRASSLAND CONGRESS, 11., Surfers Paradise, 1970. Proceedingd. Surfers Paradise: s.ed., 1970. p.860-4.

HARLAN, J.R. Cynodon species and their value for grazing and hay. Herbage Abstracts, v.40, n.3, p.233-8, Sep. 1970.

HARLAN, J.R.; de WET, J.M.J. Sources of variation in Cynodon dactylon (L.) Pers. Crop Science, v.9, n.6, p.774-8, Nov./Dec. 1969.

HARLAN, J.R.; de WET, J.M.J.; RAWAL, K.M. Geographic distribution of the species of Cynodon L. C. Rich (Gramineae). East African Agricultural and Forestry Journal, v.36, p.220-6, Oct. 1970.

HARRIS, B.; SHEARER, K.J. Nitrate, prussic acid (HCN) and grass tetany problems in cattle feeding. Florida: Florida Cooperative Extension Service, IFAS, University of Florida, 1994. 3p. (Dairy Science, DS6).

HARRIS, J.R.; MERSON, G.H.J.; HARDY, M.J.; CURTIS, D.J. Determination of cyanide in animal feeding stuffs. Analyst, v.105, p.974-80, Oct. 1980.

HEGARTY, M.P. Deleterious factors in forages affecting animal production. In: HACKER, J.B., ed. Nutritional limits to animal production from pastures. U.K.: 
Commonwealth Agricultual Bureaux, Farnham Royal, 1982. p.133-50.

HERRERA, R. S. El genero Cynodon para la produccion de forraje en Cuba. In: WORKSHOP SOBRE O POTENCIAL FORRAGEIRO DO GÊNERO Cynodon, 1., Juiz de Fora, 1996. Anais. Juiz de Fora: EMBRAPA-CNPGL, 1996. p.153-66.

HOLT, E.C.; CONRAD, B.E. Influence of harvest frequency and season on bermudagrass cultivar yield and forage quality. Agronomy Journal, v.78, n.3, p.433-6, May/June 1986.

HUBER, D.M.; ARNY, D.C. Interactions of potassium with plant diseases. In: MUNSON, R.D., ed. Potassium in agriculture. Madison: ASA, CSSA, SSSA, 1985. p.467-88.

HUMPHREYS, L.R. Tropical pasture utilisation. Cambridge: Cambridge University Press, 1991. 206p.

INSTITUTO AGRONÓMICO DE CAMPINAS. Boletim de dados climáticos. Campinas: Instituto Agronômico de Campinas, 1980. 50p

KEMP, A.; 't HART, M.L. Grass tetany in grazing milking cows. Netherlands Journal of Agricultural Science, v.5., n.1, p.4-17, Feb. 1957.

LARBI, A.; MISLEVY, P.; ADJEI, M.B.; BROWN, W.F. Seasonal herbage and animal production from three Cynodon species. Tropical Grasslands, v.24, n.4 p.305-10, Dec. 1990.

LEATH, K.T.; WELTY, R.E.; PRATT, R.G.; SONODA, R.M. Pasture/forage crops and diseases in the United States. In: CHAKRABORTY, S.; LEATH, K.T.; SKIPP, R.A. et al. Pasture and forage crop pathology. Madison: ASA, CSSA, SSSA, 1996. p.33-58.

LITTLE, D.A Utilization of minerals. In: HACKER, J.B., ed. Nutritional limits to animal production from pastures. U.K.: Commonwealth Agricultual Bureaux, Farnham Royal, 1982. p.259-83.

LUCCI, C. Bovinos leiteiros jovens. São Paulo: Nobel, 1989. 371p. 
MALAVOLTA, E.; LIEM, T.H; PRIMAVESI, A.C.P.A. Exigências nutricionais das plantas forrageiras. In: MATTOS, H.B. ed. Calagem e adubação de pastagens. Piracicaba: Associação Brasileira para Pesquisa da Potassa e do Fosfato, 1986. p.31-91p.

MALAVOLTA, E.; VITTI, G.C.; OLIVIERA, S.A. de. Avaliação do estado nutricional das plantas: princípios e aplicações. Piracicaba: Associação Brasileira para Pesquisa da Potassa e do Fosfato, 1989. 201p.

MARSCHNER, $H$. Mineral nutrition of higher plants. New York: Academic Press, 1986. $674 p$.

MARTIN, W.E.; MATOCHA, J.E. Plant analysis as an aid in the fertilization of forage crops. In: WALSH, L.M.; BEATON, J.D. ed. Soil testing and plant analysis. Madison: SSSA, 1973. p.393-426.

MARTZ, F.A.; GERRISH, J.R. Nutrition of grazing ruminants. In: SIMPÓSIO INTERNACIONAL SOBRE EXIGÊNCIAS NUTRICIONAIS DE RUMINANTES, Viçosa, 1995. Anais. Viçosa: JARD, 1995. p.103-19.

MATHEWS, B.W.; SOLLENBERGER, L.E.; STAPLES ,C.R. In vitro digestibility and nutrient concentration of bermudagrass under rotational stocking, continuous stocking, and clipping. Communications in Soil Science and Plant Analysis, v.25, n.3/4, p.301-17, 1994.

MATOCHA, J.E.; SMITH, L. Influence of potassium on Helminthosporium cynodontis and dry matter yields of 'Coastal' bermudagrass. Agronomy Journal, v.72, n.3, p.565-7, May/June 1980.

MATTOS, H.B.; COLOZZA, M.T. Micronutrientes em pastagens. In: MATTOS, H.B. ed. Calagem e adubação de pastagens. Piracicaba: Associação Brasileira para Pesquisa da Potassa e do Fosfato, 1986. p.233-56p.

MAYLAND, H.F.; WILKINSON, S.R. Soil factors affecting magnesium availability in plant-animal systems: a review. Journal of Animal Science, v.67, n.12, p.343744, Dec. 1989. 
MESA, A.R.; HERNANDEZ, C.; DE LA CRUZ, R. Niveles críticos de P em cvs. de Cynodon dactylon (L.) Pers. Pastos y Forrajes, v.6, p.89-100, 1983.

MINSON, D.J. Effects of chemical and physical composition of herbage eaten upon intake In: HACKER, J.B., ed. Nutritional limits to animal production from pastures. U.K.: Commonwealth Agricultual Bureaux, Farnham Royal, 1982. p.167-82.

MINSON, D.J. Forage in ruminant nutrition. San Diego: Academic Press, 1990. p.483.

MINSON, D.J. Composición química y valor nutritivo de las gramíneas tropicales. In: SKERMAN, P.J.; RIVEROS, F. Gramíneas tropicales. Roma: FAO, 1992. p.181-99. (Colección FAO: Producción Vegetal, 23).

MINSON, D.J.; WILSON, J.R. Prediction of intake as an element of forage quality. In: FAHEY Jr., G.C. ed. Forage quality, evaluation, and utilization. Madison: ASA, CSSA, SSSA, 1994. p.533-63.

MISCHAN, M.M; PINHO, S.Z. Experimentação agronômica: dados nãobalanceados. Botucatu: FUNDIBIO, 1996. 456p.

MISLEVY, P.; PATE, F.M. Establishment, management, and utilization of Cynodon grasses in Florida. In: WORKSHOP SOBRE O POTENCIAL FORRAGEIRO DO GÊNERO Cynodon, 1., Juiz de Fora, 1996. Anais. Juiz de Fora: EMBRAPACNPGL, 1996. p.127-38.

MISLEVY, P.; MOTT, G.O.; MARTIN, F.G. Effect of grazing frequency on forage quality and stolon characteristics of tropical perennial grasses. Proceedings of Soil and Crop Science Society of Florida, v.41, p.77-83, 1982.

MISLEVY, P.; RUELKE, O.C.; MARTIN, F.G. Grazing evaluation of Cynodon species. Proceedings of Soil and Crop Science Society of Florida, v.47, p.207-12, 1988. MISLEVY, P.; BROWN, W.F.; DUNAVIN, L.S. et al. 'Florakirk' bermudagrass. Florida: Florida Agricultural Experiment Station, 1995. 9p. (Circular S 395). 
MISLEVY, P.; BROWN, W.F.; CARO-COSTAS, R. et al. Registration of 'Florico' Stargrass. Crop Science, v.33, n.2, p.358-9, Mar./Apr. 1993a.

MISLEVY, P.; BROWN, W.F.; DUNAVIN, L.S., R. et al. Registration of 'Florona' Stargrass. Crop Science, v.33, n.2, p.359-60, Mar./Apr. 1993b.

MOE, A.J.; CARR, S.B. Laboratory assays and near-infrared reflectance spectroscopy for estimates of feeding value of corn silage. Journal of Dairy Science, v.68, n.8, p.2220-6, Aug. 1985.

MONSON, W.G.; BURTON, G.W. Harvest frequency and fertilizer effects on yield, quality, and persistence of eight bermudagrasses. Agronomy Journal, v.74, n.2, p.371-4, Mar.IApr. 1982.

MOORE, J.E.; MOTT, G.O. Structural inhibitors of quality in tropical grasses. In: MATCHES, A.G. Anti-quality components of forages. Madison: CSSA, 1973. p.53-98. (Special Publication, 4).

MOTT, G.O. Evaluating forage production. In: HEATH, M.E.; METCALFE, D.S.; BARNES, R.F. Forages: the science of grassland agriculture. 3.ed. lowa: The lowa State University Press, 1975. p.126-35.

NATIONAL RESEARCH COUNCIL. Nutrient requirements of beef cattle. 7.ed. Washington: National Academy of Science, 1996. 242p. (Nutrient Requeriments of Domestic Animals, 4).

NATIONAL RESEARCH COUNCIL. Nutrient requirements of dairy cattle. 6.ed. Washington: National Academy of Science, 1989a. 157p. (Nutrient Requeriments of Domestic Animals, 3).

NATIONAL RESEARCH COUNCIL. Nutrient requirements of horses. 5.ed. Washington: National Academy of Science, 1989b. 100p. (Nutrient Requeriments of Domestic Animals, 6).

NELSON, C.J.; MOSER, L.E. Plant factors affecting forage quality. In: FAHEY Jr., G.C. ed. Forage quality, evaluation, and utilization. Madison: ASA, CSSA, 
SSSA, 1994. p.115-54.

NOLTE, M.E.; CLINE, J.H.; DEHORITY, B.A. et al. Treatment of wheat straw with alkaline solutions prepared form wood ashes to improve fiber utilization by ruminants. Journal of Animal Science, v.64, n.3, p.669-77, Mar. 1987.

NORTON, B.W. Differences between species in forage quality. In: HACKER, J.B., ed. Nutritional limits to animal production from pastures. U.K.: Commonwealth Agricultual Bureaux, Farnham Royal, 1982. p.89-110.

OQUENDO, G.; GERARDO, J.; MANTECON, F. Comportamiento de 20 variedades de pastos tropicales en suelos pardos de la empresa pecuaria 'Rectangulo' de Guaimaro. Ciencia y Tecnica en la Agricultura, Pastos y Forrajes, v.7, n.2, p.41-56, dic. 1984 .

PALHANO, A.L.; HADDAD, C.M. Exigências nutricionais e valor nutritivo de Cynodon dactylon (L.) Pers. cv. Coast-cross nำ1. Pesquisa Agropecuária Brasileira, v.27, n. 10, p.1429-38, out. 1992.

PEDREIRA, C.G.S. Plant and animal responses on grazed pastures of Florakirk and Tifton 85 bermudagrasses. Florida, 1995. 152p. Dissertation (Doctor of Philosophy) - University of Florida.

RAIJ, B. van; CANTARELLA, H.; QUAGGIO, J.A. et al. Recomendações de adubação e calagem para o Estado de São Paulo. Campinas: Instituto Agronômico/Fundação IAC, 1996. 285p. (Boletim 100).

RAYMOND, W.F. The nutritive value of forage crops. Advances in Agronomy, v.21, p.1-108, 1969.

REID, R.L.; JUNG, G.A. Effects of elements other than nitrogen on the nutritive value of forage. In: MAYS, D.A., ed. Forage fertilization. Madison: ASA, CSSA, SSSA, 1974. p.395-433.

REMY, V.A.; CACERES, O.; GARCIA-TRUJILLO, R. et al. Hierba bermuda (Cynodon dactylon L. Pers.). Pastos y Forrajes, v.2, n.1, p.1-46, abr. 1979. 
RICCI Jr., A; GERALDI, M.A.P.; ITO, M.F. Ocorrência de Bipolaris cynodontis (Marig.) Shoemaker - (Helminthosporium cynodontis Marignoni) em grama seda (Cynodon dactylon (L.) Pers). Summa Phytopathologica, v.7, n.1/2, p.44-48, jan./abr. 1981.

RICHARDSON, M.D.; CROUGHAN, S.S. Potassium influence on susceptibility of bermudagrass to Helminthsporium cynodontis toxin. Crop Science, v.29, n.5, p.1280-2, Sep./Oct. 1989.

ROBINSON, D.L. Fertilization and nutrient utilization in harvested forage systems Southern forage crops. In: NUTRIENT CYCLING IN FORAGE SYSTEMS SYNPOSIUM, Columbia, 1996. Proceedings. Kansas: Potash and Phosphate Institute, Foundation for Agronomic research, 1996. p.65-92.

ROBINSON, D.L.; KAPPEL, L.C.; BOLING, J.A. Management practices to overcome the incidence of grass tetany. Journal of Animal Science, v.67, n.12, p.3470-84, Dec. 1989.

SANTOS, A.M.P.V.; BOECHAT, S.C. Cynodon (Poaceae, Chloridoideae) no Rio Grande do Sul, Brasil. Iheringia, Série Botânica, n.44, p.85-102, jun. 1994.

SAS INSTITUTE. User's guide: statistics. release 6.03. Cary: SAS Institute, 1988. $1028 \mathrm{p}$.

SCHRODER, V.N. Hydrogen cyanide from forage plantas. Proceedings of Soil and Crop Science Society of Florida, v.36, p.195-7, 1977.

SILVEIRA NETO, S.; MARCHINI, L.C.; ALVES, S.B. Pragas das pastagens. In: PEIXOTO, A.M.; MOURA, J.C. de; FARIA, V. P. de. Pastagens: fundamentos da exploração racional. 2.ed. Piracicaba: FEALQ, 1994. p.819-35. (FEALQ. Série atualização em zootecnia, 10).

SKERMAN, P.J.; RIVEROS, F. Gramíneas tropicales. Roma: FAO, 1992. 849p. (Colección FAO: Producción y protección vegetal, 23).

SMILEY, R.W.; DERNOEDEN, P.H.; CLARKE, B.B. Compendium of turfgrass diseases. 2.ed. Minnesota: The American Phytopathological Society, 1992. 98p. 
SMITH, J.D.; JACKSON, N.; WOOLHOUSE, A.R. Fungal diseases of amenity turfgrasses. 3.ed. Suffolk: E \& F. N. Spon, 1989. 401p.

SOLLENBERGER, L.E.; CHERNEY, D.J.R. Evaluating forage production and quality. In: BARNES, R.F.; MILLER, D.A.; NELSON, C.J. Forages: the science of grassland agriculture. 5.ed. lowa: lowa State University Press, 1995. v.2, p.97110.

SOLLENBERGER, L.; PEDREIRA, C.G.S.; MISLEVY, P.; ANDRADE, I.F. New Cynodon forages for the subtropics and tropics. In: INTERNATIONAL CONFERENCE ON LIVESTOCK IN THE TROPICS, 1., Gainesville, 1995 Proceedings. Gainesville: University of Florida, 1995. p.22-6.

SOTOMAYOR-RÍOS, A.; JULIÁ, F.J.; ARROYO-AGUILÚ, J.A. Effects of harvest intervals on the yield and composition of 10 forage grasses. Journal of Agriculture of University of Puerto Rico, v.58, n.4, p.448-55, Oct. 1974.

SPEARS, J.W. Minerals in forages. In: FAHEY Jr., G.C. ed. Forage quality, evaluation, and utilization. Madison: ASA, CSSA, SSSA, 1994. p.281-317.

TAPPER, B.A.; REAY, P.F. Cyanogenic glycosides and glucosinolates. In: BUTLER, G.W.; BAILEY, R.W. Chemistry and biochemistry of herbage. New York: Academic Press, 1973. v.1, p.447-76.

TILLEY, J.M.A.; TERRY, R.A. A two stage technique for the in vitro digestion of forage crops. Journal of the British Grassland Society, v.18, p.104-11, 1963.

TINNIMIT, P. Forage evaluation using various laboratory techniques. East Lansing, 1974. Thesis (Ph.D.) - Michigan State University.

TOKARNIA, C.H.; DÖBEREINER, J. Diseases caused by mineral deficiencies in cattle raised under range conditions in Brazil. In: LATIN AMERICAN SYMPOSIUM ON MINERAL NUTRITION RESEARCH WITH GRAZING RUMINANTS, Belo Horizonte, 1976. Proceedings. Gainesville: University of Florida, 1978. p.163-9.

UNDERWOOD, E.J. Trace elements in human and animal nutrition. 3.ed. New 
York: Academic Press, 1971. 543p.

UNDERWOOD, E.J. The mineral nutrition of livestock. 2.ed. Aberdeen: Commonwealth Agricultural Bureaux, 1981. 180p.

VAN SOEST, P.J. Nutritional ecology of the ruminant. 2.ed. New York: Cornell University Press, 1994. 476p.

VAN SOEST, P.J.; MERTENS, D.R.; DEINUM, B. Preharvest factors influencing quality of conserved forage. Journal of Animal Science, v.47, n.3, p.712-20, Mar. 1978.

VÉLEZ-SANTIAGO, J.; SOTOMAYOR-RIOS, A.; TORRES-RIVERA, S. Effects of three harvest intervals and two fertilizer rates on the yield and HCN content of ten Cynodon cultivars. Journal of Agriculture of University of Puerto Rico, v.61, n.1 p.35-44, Jan. 1979.

VIEIRA, L.M.; GOMIDE, J.A. Estimativa da digestibilidade e do consumo de matéria seca de gramíneas forrageiras tropicais, pela técnica do rúmen artificial. Experientiae, v.10, n.4, p.71-91, abr. 1970.

VITTI, G.C.; NOVAES, N.J. Adubação com enxofre. In: MATTOS, H.B. ed. Calagem e adubação de pastagens. Piracicaba: Associação Brasileira para Pesquisa da Potassa e do Fosfato, 1986. p.191-231p.

VRZGULA, L.; BARTKO, P. Disorders in mineral metabolism. In: VRZGULA, L. Metabolic disorders and their prevention in farm animals. New York: Elsevier, 1991. p.84-140 (Developments in animal and veterinary sciences, 24).

WAGENINGEN AGRICULTURAL UNIVERSITY. Manual assay for the cyanogen content in cassava products. Wageningen: Wageningen Agricultural University, 1993. 1v.

WERNER, J.C. Adubação potássica. In: MATTOS, H.B. ed. Calagem e adubação de pastagens. Piracicaba: Associação Brasileira para Pesquisa da Potassa e do Fosfato, 1986. p.175-90p. 
WILLIAMS, M.J. Productivity and nutritive value of Cynodon spp. in Northcentral Florida. Proceedings of Soil and Crop Science Society of Florida, v.50, p.55-8, 1991.

WISE, M.B.; ORDOREZA, A.L.; BARRICK, E.R. Influence of variations in dietary calcium:phosphorus ratio on performance and blood constituents of calves. Journal of Nutrition, v.79, n.1, p.79-85, Jan. 1963. 